\title{
CARACTERIZAÇÃO GENÉTICA DE POPULAÇÕES DE JACARÉ-DE-PAPO-AMARELO (Caiman latirostris), UTILIZANDO MARCADORES MICROSSATÉLITES
}

\author{
PRISCILLA MARQUI SCHMIDT VILLELA
}

Dissertação apresentada à Escola Superior de Agricultura "Luiz de Queiroz", Universidade de São Paulo, para obtenção do título em Mestre em Ecologia de Agroecossistemas.

P I R A C I C A B A

Estado de São Paulo - Brasil

Abril - 2004 


\title{
CARACTERIZAÇÃO GENÉTICA DE POPULAÇÕES DE JACARÉ-DE-PAPO-AMARELO (Caiman latirostris), UTILIZANDO MARCADORES MICROSSATÉLITES
}

PRISCILLA MARQUi SCHMIDT VILLELA

Bacharel em Ciências Biológicas

\author{
Orientador: Prof. Dr. LUIZ LEHMANN COUTINHO \\ Co-Orientador: Prof. Dr. LUCIANO MARTINS VERDADE
}

Dissertação apresentada à Escola Superior de Agricultura “Luiz de Queiroz”, Universidade dr São Paulo, para obtenção do título em Mestre en Ecologia de Agroecossistemas.

P I R A C I C A B A

Estado de São Paulo - Brasil

Abril - 2004 
Dados Internacionais de Catalogação na Publicação (CIP) DIVISÃO DE BIBLIOTECA E DOCUMENTAÇÃO - ESALQ/USP

Villela, Priscilla Marqui Schmidt

Caracterização genética de populações de jacaré-de-papo-amarelo (Caiman

latirostris), utilizando marcadores microssatélites / Priscilla Marqui Schmidt Villela. - Piracicaba, 2004.

114 p. : il.

Dissertação (mestrado) - - Escola Superior de Agricultura Luiz de Queiroz, 2004. Bibliografia.

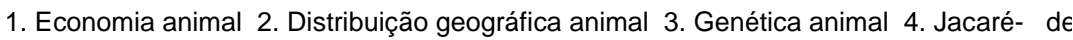
papo-amarelo 5. Marcador molecular 6. Populações animais 7. Proteção animal 8. Reprodução animal 9. Variação genética I. Título

CDD 639.394

"Permitida a cópia total ou parcial deste documento, desde que citada a fonte - O autor" 
A meus pais, Claudemir e Ivone,

pelo amor e incentivo. 


\section{AGRADECIMENTOS}

Agradeço a todos que colaboraram direta ou indiretamente para a realização desse trabalho. Em especial :

Ao Prof. Dr. Luiz Lehmann Coutinho, pela orientação, apoio e compreensão.

Ao Prof. Dr. Luciano Martins Verdade, pelas valiosas contribuições e pelo seu entusiasmo.

À Dra. Maria Imaculada Zucchi, pela amizade, atenção e valiosas sugestões.

Ao Prof. Dr. Roland Vencovsky e Prof. Dr. Alexandre Guedes Coelho pelas sugestões e direcionamento das análises estatísticas.

À FAPESP, pela concessão da bolsa de estudo e pelo apoio financeiro à pesquisa.

À equipe National geographic, ao Zoológico Arruda Câmara de João Pessoa e ao Aquario de Natal pela ajuda na coleta de material.

Aos meus irmãos, Patrícia e José Antonio pelo incentivo durante toda a minha vida.

Ao Daniel pelo amor, carinho e paciência durante a realização deste trabalho, sempre me animando e me apoiando nos momentos mais difíceis. 
Aos colegas do laboratório de Ecologia Animal, em especial ao André, Cantarelli, Pedro, Claudia, Graziela, Raquel pela troca de idéias e amizade.

Aos colegas do laboratório de Biotecnologia Animal, em especial aos técnicos Jorge e Nirlei pela amizade e pelo suporte oferecido, ao Rodrigo pela ajuda na coleta de dados, a Mirian, Érika Jorge, Érika Baron, Karen e Matheus, pela convivência e troca de experiência durantes estes anos.

Aos meus amigos, Ana Paula (Flipper), Anderson, Bel, Dri, Carla, Clarissa, Marina, Dani, Telmo, Rogério, Urha, Folha, Mim, Barizon, pelo apoio, grande amizade e momentos de descontração.

A todos os demais colegas, que de alguma forma contribuíram para realização deste trabalho, o meu muito obrigado. 


\section{SUMÁRIO}

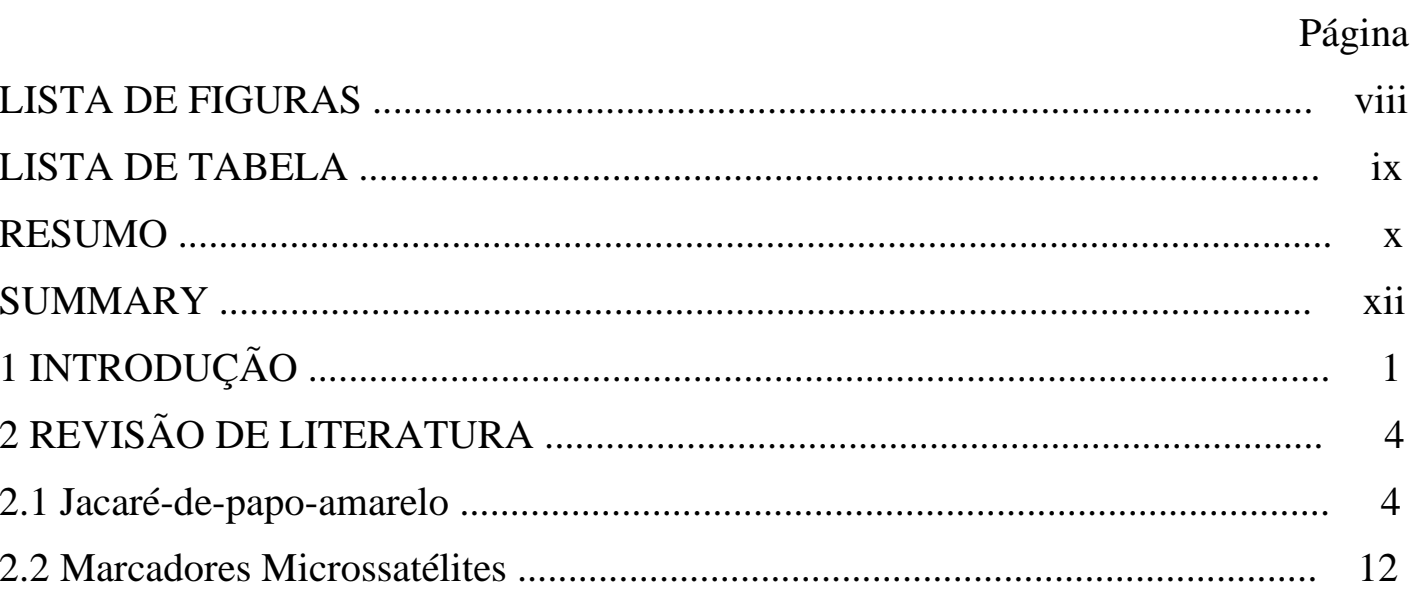

2.3 Utilização de marcadores microssatélites: estudos com animais ...................... 15

2.4 Parâmetros populacionais, Estrutura populacional e Parentesco ...................... 19

3 MATERIAL E MÉTODOS ............................................................................ 24

3.1 Captura e imobilização de jacarés e conservação de sangue ............................. 24

3.2 Sítios de coleta e amostragem ........................................................................ 24

3.3 Extração do DNA ….................................................................................... 27

3.4 Otimização da Amplificação ........................................................................ 27

3.5 Primers utilizados ................................................................................. 28

3.6 Precipitação dos produtos da PCR ............................................................... 29

3.7 Eletroforese em sequenciador automático e genotipagem dos animais ........... 30

3.8 Análise dos dados ......................................................................................... 31

4 RESULTADOS E DISCUSSÃO .................................................................. 34

4.1 Variação Genética ...................................................................................... 34

4.2 Diferenciação gênica e genotípica .................................................................... 36 
4.3 Heterozigosidade observada $\left(\mathrm{H}_{\mathrm{o}}\right)$, diversidade gênica $\left(\mathrm{H}_{\mathrm{e}}\right)$ e teste exato para equilíbrio de Hardy-Weinberg 36

4.4 Estrutura Genética 38

4.5 Correlação entre distância geográfica e variação genética 45

5 CONCLUSÕES 60

6 CONSIDERAÇÕES FINAIS 62

ANEXOS 64

REFERÊNCIAS BIBLIOGRÁFICAS . 78

APÊNDICES 


\section{LISTA DE FIGURAS}

Página

1 Foto Caiman latirostris ................................................................................ 4

2 Distribuição geográfica de Caiman latirostris ...................................................... 6

3 Mapa do Brasil indicando os sítios de coleta das populações de Caiman latiostris ................................................................................... 26

4 Número de alelos exclusivos, identificados por microssatélites, em nove populações de Caiman latirostris ......................................................... $\quad 35$

5 Padrão de diferenciação genética obtido pela estatística Rho entre as populações de Caiman latirostris definidos pelo critério de agrupamento UPGMA

6 Gráfico de correlação entre as matrizes de distância geográfica e diferenciação.genética (Rho)

7 Parentesco entre as populações de Caiman latirostris de João Pessoa (PB) e Natal (RN)

8 Parentesco dentro da População de C. latirostris da Ilha do Cardoso (IC) .......... 51

9 Parentesco dentro da População de C. latirostris de João Pessoa (PB) ................ 52

10 Parentesco dentro da População de C. latirostris do Banhado do Taim (RS) ..... 53

11 Parentesco dentro da População de Caiman latirostris de Natal (RN) ................ 54

12 Parentesco dentro da População de C. latirostris da Lagoa Vermelha (AL) ....... 55

13 Parentesco dentro da População de Caiman latirostris de Pantanal (Pt) .............. 56

14 Parentesco dentro da População de C. latirostris de duraflora (DuF) .................. 56

15 Parentesco dentro da População de C. latirostris de Charqueada (CH) .............. 57

16 Parentesco dentro da População de C. latirostris de Porto de Areia (PoA) ......... 57

17 Parentesco entre os indivíduos da colônia em cativeiro da ESALQ .................... 58 


\section{LISTA DE TABELAS}

Página

1 Populações de Caiman latirostris analisadas e suas coodenardas ..................... 25

2 Primers e condição de amplificação ................................................................. 29

3 Alelos exclusivos encontrados nas nove populações de Caiman latirostris ..... 34

4 Estimativa da diversidade gênica (h), heterozigosidade observada $\left(\mathrm{H}_{\mathrm{o}}\right)$ e Índice de fixação (f) ..................................................................................... 37

$5 \quad$ Estatísticas Rho para as populações estudadas ............................................... 39

6 Resultados das estatísticas Rho sobre os componentes de variação .................. 40

$7 \quad$ Valores de Rho e $\delta^{2} \mu$ comparando as populações de Caiman latirostris .......... 41

8 Resultados das estatísticas Rho calculados sobre os componentes de variação para as populações de Caiman latirostris estudadas ........................... 43

9 Médias dos parentescos encontrado nas nove populações de Caiman latrostris estudadas ........................................................................................ 48

10 Dados de campo dos indivíduos da população da Ilha do Cardoso (IC) .......... 51

11 Dados de campo dos indivíduos da população de João Pessoa ......................... 52 


\section{CARACTERIZAÇÃO GENÉTICA DE POPULAÇÕES DE JACARÉ-DE-PAPO- AMARELO (Caiman latirostris), UTILIZANDO MARCADORES MICROSSATÉLITES}

Autora: PRISCILLA MARQUI SCHMIDT VILLELA

Orientador: Prof. Dr. LUIZ LEHMANN COUTINHO

Co-Orientador: Prof. Dr. LUCIANO MARTINS VERDADE

\section{RESUMO}

Um componente considerado crítico para o manejo bem sucedido de populações silvestres é a manutenção da variação genética. No intuito de avaliar a magnitude e a distribuição da variabilidade genética existente em populações de Caiman latirostris, nove populações distribuídas ao longo do eixo latitudinal da distribuição da espécie no Brasil e uma população em cativeiro foram estudadas com auxílio de onze locos microssatélites. A diversidade gênica média $\left(\mathrm{H}_{\mathrm{e}}=\mathrm{h}\right)$ e a heterozigosidade média observada $\left(\mathrm{H}_{0}\right)$ apresentaram valores elevados, 0,628 e 0,567, respectivamente, denotando existência de elevada variabilidade genética para esta espécie nas regiões de estudo. A população paulista mesmo estando na zona intermediária de distribuição geográfica no Brasil não possui a maior variabilidade genética. $\mathrm{O}$ valor $\mathrm{F}_{\mathrm{ST}}$ estimado foi 0,270 e o $\mathrm{R}_{\mathrm{ST}}$ foi 0,342 . Ambas as medidas de diferenciação entre as populações foram significativas $(\mathrm{P}<0,05)$. As altas estimativas de $\mathrm{F}_{\mathrm{ST}}$ e $\mathrm{R}_{\mathrm{ST}}$ sugerem a ausência 
ou fluxo gênico restrito entre essas populações, exceção feita entre as populações de Natal (RN) e João Pessoa (PB), onde não houve diferenciação significativa entre as populações, sugerindo assim que há fluxo gênico entre elas, fato confirmado pelo coeficiente de parentesco.

Pôde-se concluir neste trabalho que a distância genética entre a população do litoral é afetada pela existência da Serra do Mar como barreira geográfica pelo fato desta população apresentar as maiores diferenciações genéticas e não se agrupar a nenhuma população pelo método de agrupamento UPGMA, mesmo estando próxima das populações paulista.

A distância genética entre as populações parece não acompanhar a distância geográfica, em termos de gradiente latitudinal $(\mathrm{r}=0,206)$. Entretanto quando retiramos a população da Ilha do Cardoso esta correlação aumenta significativamente (r=0,540), indicando haver um certo padrão espacial da variabilidade genética entre as populações. O coeficiente médio de parentesco foi baixo entre e dentro das populações estudadas. Com estes resultados podemos começar a entender a dinâmica e estrutura social de populações de Caiman latirostris, e quanto mais se compreende sobre a biologia destes animais mais precisa serão decisões visando condições que permitam a existência continua da espécie . 


\title{
GENETIC CHARACTERIZATION OF BROAD-SNOUTED CAIMAN (Caiman latirostris) POPULATIONS BY MICROSATELLITES MARKERS
}

\author{
Author: PRISCILLA MARQUI SCHMIDT VILLELA \\ Adviser: Prof. Dr. LUIZ LEHMANN COUTINHO \\ Co-Adiviser: Prof. Dr. LUCIANO MARTINS VERDADE
}

\section{SUMMARY}

A component considered critical for the managment well succeed of wild populations it is the maintenance of genetic variation. In the intention of evaluating the extend and the distribution of the existent genetic variability in populations of Caiman latirostris, nine populations distributed along the latitudinal axis of the distribution of the species in Brazil and a population in captivity they were studied with aid of eleven locos microsatellite. The genic mean diversity $(\mathrm{He}=\mathrm{h})$ and the observed mean heterozygosity (Ho) across all loci for all populations ranged from 0,628 and 0,567, respectively, denoting existence high genetic variability. The population from São Paulo being in the intermediate zone of geographical distribution in Brazil doesn't possess the largest genetic variability. The value dear $\mathrm{F}_{\mathrm{ST}}$ was 0,270 and $\mathrm{R}_{\mathrm{ST}}$ it was 0,342 . Both 
differentiation measures among the populations were significant $(\mathrm{P}<0,05)$. The higher estimates of $\mathrm{F}_{\mathrm{ST}}$ and $\mathrm{R}_{\mathrm{ST}}$ suggested a absence or low gene flow among those populations, exception done between the populations of Natal (RN) and João Pessoa (PB), where there was not significant differentiation among the populations, suggesting a gene flow pattern among them, fact confirmed by the related coefficient.

It could be concluded in this work that the genetic distance among the population of the coast is affected by the existence of the Mountain of the Sea as geographical barrier for the fact of this population to present the largest genetic differentiations and not to group the any population for the grouping method UPGMA, same being close of the populations from São Paulo.

The genetic distance among the populations seems not to accompany the geographical distance, in terms of latitudinal gradient $(r=0,206)$. However when we removed the population of Cardoso's Island this correlation it increases significantly $(r=0,540)$, indicating there to be a certain space pattern of the genetic variability among the populations. The medium coefficient of related was low among and inside of the studied populations. With these results we can begin to understand the dynamics and it structures social of populations of Caiman latirostris. 


\section{INTRODUÇÃO}

A exploração desordenada do território brasileiro é uma das principais causas de extinção de espécies. O desmatamento e degradação dos ambientes naturais, o avanço da fronteira agrícola, a caça de subsistência e a caça predatória, a venda de produtos e animais procedentes da caça, capturas ilegais (tráfico) na natureza e a introdução de espécies exóticas em território nacional são fatores que participam de forma efetiva do processo de extinção.

A proteção e o manejo ordenado da fauna silvestre na busca de sua conservação podem e devem ser feitos pelo Governo e a Sociedade de forma integrada no sentido de defender o que é de todos: o patrimônio natural, bem de uso comum de todos e garantia para as futuras gerações.

Existem vários fatores que contribuem para viabilidade das populações ou espécies, entre eles fatores estocásticos, demográficos, ambientais e genéticos. Planos de conservação devem levar em conta todos os fatores, inclusive a manutenção de níveis adequados de diversidade genética.

O estudo das estruturas populacionais por meio de técnicas moleculares talvez seja a parte mais importante da genética da conservação e tem sido útil tanto no estudo de populações exploradas comercialmente (ou seja, abundante, mas com riscos populacionais devido a superexploração), como nas espécies já ameaçadas de extinção. O entendimento dos níveis de diferenciação populacional, por meio de estimativas de heterozigosidade e freqüência gênica, pode levar a medidas mais acuradas sobre esforços na recuperação de certas espécies.

Marcadores genéticos apropriados devem ser desenvolvidos para que haja perspicácia no acesso da estrutura genética da população de interesse para o seu 
manejo, com meta de manter a diversidade genética. Os dados fornecidos por estes marcadores podem ainda fornecer importantes pistas sobre a historia evolutiva da espécie, padrões de fluxo gênico e parentesco entre subpopulações.

Uma vez elucidada a estrutura populacional e a dinâmica reprodutiva de populações, estas informações podem ser usados em conjunto com o que se sabe sobre ecologia e biologia da espécie. Desta maneira decisões mais adequadas de manejo podem ser tomadas.

O jacaré-de-papo-amarelo (Caiman latirostris) é um dos animais que vem sendo fortemente prejudicado em sua permanência na natureza e esteve por muito tempo na lista oficial do IBAMA como ameaçado de extinção. Atualmente, conforme a lista publicada pelo IBAMA em 2003 a espécie não se encontra ameaçada, mas ainda sofre devido a declínio populacional em determinados locais e fragmentação de sua área de distribuição. O foco de conservação do jacaré-de-papo-amarelo tem sido sua criação em cativeiro. No entanto, este esforço pode ser comprometido se não for acompanhado por estudos da espécie na natureza (Verdade, 1998).

O Programa de conservação do Jacaré-de-papo-Amarelo do laboratório de Ecologia Animal inclui a manutenção e reprodução de animais em cativeiro na ESALQ/USP (Piracicaba/SP) e o estudo da bacia do Rio Tietê, na região do Estado de São Paulo.

O Laboratório de Ecologia Animal e o Laboratório de Biotecnologia Animal, ambos da Escola Superior de Agricultura “Luiz de Queiroz" - ESALQ/USP (Piracicaba, Estado de São Paulo, Brasil), vêm de forma interdisciplinar coordenando esforços para o estudo da biologia, manejo e conservação do jacaré-de-papo-amarelo (Caiman latirostris). Esta cooperação resultou em estudos de genética de populações selvagens da região de Piracicaba e teste de maternidade em uma população em cativeiro da espécie (Zucoloto, 1998), pela utilização de marcadores microssatélites desenvolvidos para Alligator mississipiensis (Glenn et. al., 1998) e testados para Caiman latirostris. Mais recentemente, marcadores microssatélites específicos para Caiman latirostris (Zucoloto, 2002) foram desenvolvidos para ampliar a capacidade da metodologia de teste de maternidade, estudo da diversidade de populações 
selvagens de jacaré-de-papo-amarelo na região Piracicaba/SP e para a determinação do coeficiente de parentesco entre indivíduos. (Zucoloto, 2003).

A conservação e o manejo de populações naturais de Caiman latirostris será mais eficiente através do conhecimento da genética de suas populações remanescentes. Com base nesse propósito principal os marcadores desenvolvidos para Caiman latirostris (Zucoloto et al., 2002) e marcadores desenvolvidos para Alligator mississipiensis (Glenn et. al., 1998) foram utilizados no atual trabalho para realizar a caracterização genética de nove populações de Caiman latirostris distribuída ao longo do eixo latitudinal da distribuição da espécie no Brasil. Para tanto, procedeu-se a avaliação da estrutura, magnitude e distribuição da variabilidade existente entre e dentro das populações, bem como foi estimado o coeficiente de parentesco entre os indivíduos.

O uso sustentável é visto como um importante aspecto para programas de conservação de vários crocodilianos (Ross, 1998) e a avaliação da magnitude da variabilidade genética, fluxo gênico e parentesco entre populações contribui para programas mais eficazes. Sendo assim o objetivo deste trabalho é estender a avaliação da diversidade genética da espécie ao longo de sua distribuição no Brasil e quantificar a variabilidade genética e o parentesco, descrevendo como se apresentam entre e dentro de populações 


\section{REVISÃO DE LITERATURA}

\subsection{Jacaré-de-papo-amarelo}

O Caiman latirostris (jacaré-de-papo-amarelo), é um crocodiliano sul americano de porte médio. O comprimento total máximo alcançado é de 3,5 m, mas na natureza são raros os animais maiores que 2,0 m (Verdade, 1998). O focinho é mais largo que em outros crocodilianos. O corpo é de cor verde escura, com manchas mais escuras na cabeça e pescoço.

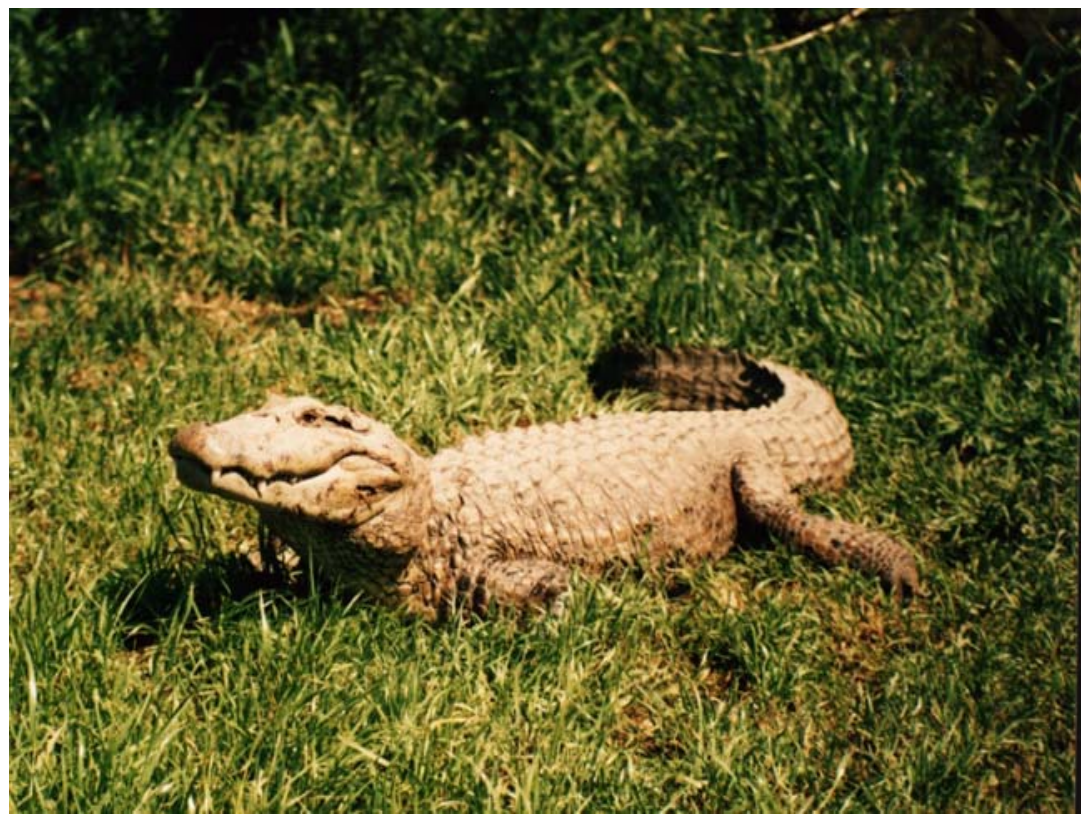

Figura 1 - Foto Caiman latirostris 
O Caiman latirostris é uma espécie altamente aquática e habita as várzeas associadas a rios. Sua distribuição geográfica (Figura 2) é restrita à América do Sul e inclui: norte da Argentina (províncias de Corrientes, Chaco, Entre Ríos, Formosa, Jujuy, Misiones, Salta, e Santa Fe), Brasil (Estados de Rio Grande do Sul, Santa Catarina, Paraná, São Paulo, Rio de Janeiro, Minas Gerais, Espírito Santo, Mato Grosso do Sul, Goiás, Bahia, Sergipe, Alagoas, Pernambuco, Paraíba, e Rio Grande do Norte, inclui as bacias hidrográficas dos Rios Paraná e São Francisco), nordeste do Uruguai (departamentos de Artigas, Salto, Paysandú, Rocha, Tacuarembó, Cerro Largo e Lavalleja), sudeste da Bolívia (rio de Pilcomayo e departamento de Beni) e sul do Paraguai (Chaco).

A espécie apresenta uma extensa distribuição latitudinal, de $5^{\circ} \mathrm{S}$ para $34^{\circ} \mathrm{S}$ e abrange um grande número de pequenas bacias costeiras a partir de Natal, no nordeste do Brasil, até o nordeste do Uruguai (Verdade, 1998).

O jacaré-de-papo-amarelo (Caiman latirostris) é um dos animais que vem sendo fortemente prejudicado em sua permanência na natureza e seu nome esteve por muito tempo na lista oficial do IBAMA como um dos animais ameaçados de extinção. A espécie foi considerada como ameaçada de extinção tanto a nível internacional (Groombridge, 1982 e Verdade, 1998), como nacional (Vanzolini, 1972 e Bernardes et al., 1990).

Atualmente o táxon não se enquadra na categoria ameaçada de extinção biológica pelo IBAMA. Entretanto está listado no Apêndice I do CITES (exceção feita a população Argentina que mudou para Apêndice II em 1997). A densidade populacional é altamente variáveis ao longo da distribuição, de quase extinto em algumas áreas antrópicas do Brasil para populações atualmente conservadas em Santa Fé, Argentina (Verdade e Piña, no prelo).

Por estar presente junto a áreas marginais de rios, lagoas, várzeas e pântanos, a espécie sofre grande pressão frente ao constante crescimento da população humana, que muitas vezes desprezam os crocodilianos e todo resto da fauna e flora locais. 


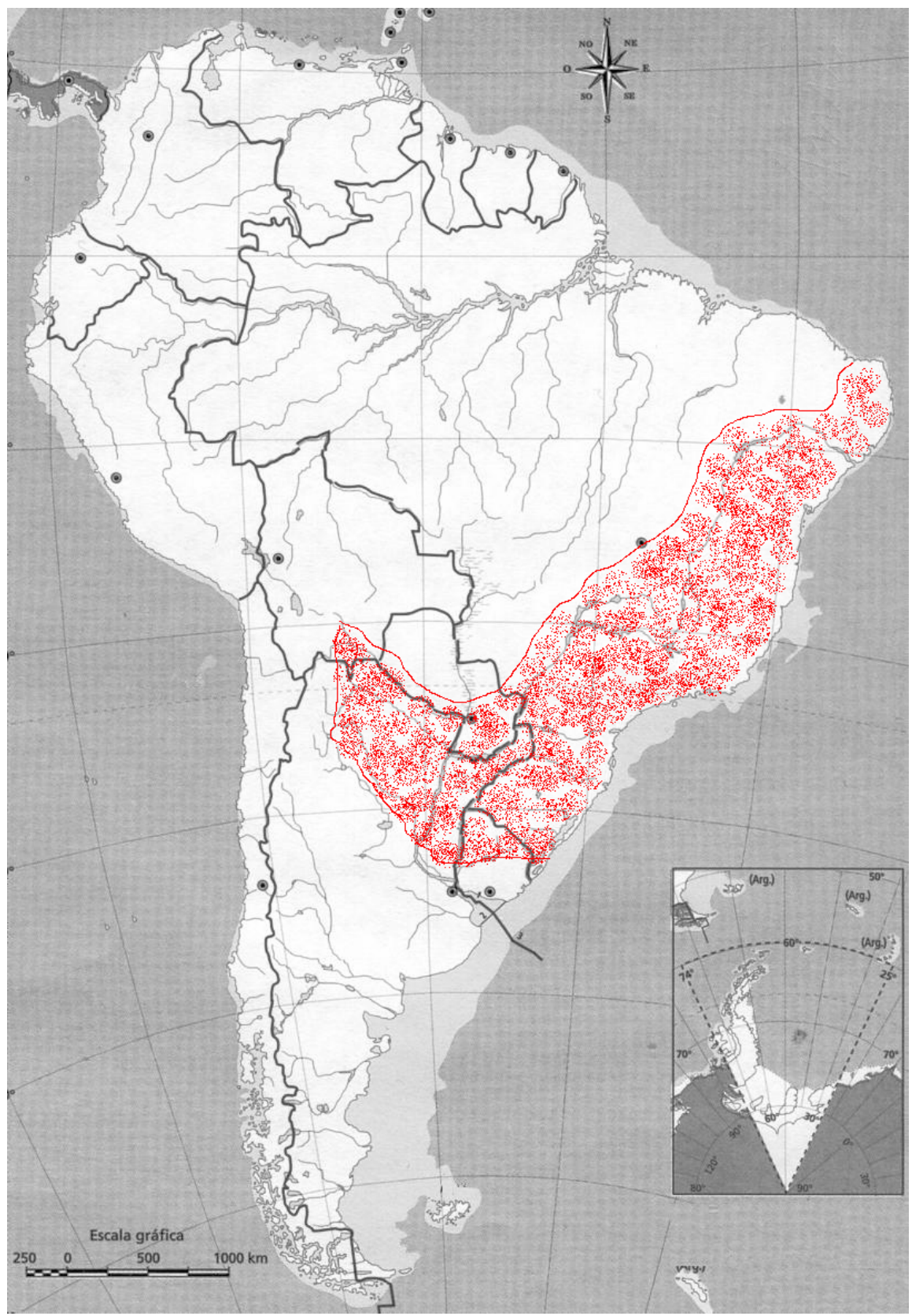

Figura 2 - Distribuição geográfica de Caiman latirostris (Verdade e Piña, no prelo) 
As principais causas do declínio de suas populações são a destruição sistemática de seu habitat e a caça ilegal. A pele do Caiman latirostris é, entre as do gênero Caiman, a mais valorizada, por apresentar produtos manufaturados de melhor qualidade (King \& Brazaitis, 1971 e Brazaitis, 1987), apesar de não ser considerada como pele clássica (Verdade, 1997b).

As várzeas e lagoas marginais de rios, o habitat da espécie, tem sofrido uma grande redução de área pela ocupação para agricultura (Verdade, 1997a). O jacaréde-papo-amarelo possivelmente apresenta a situação mais complexa, para a conservação, entre os crocodilianos brasileiros, pois suas populações encontram-se fragmentadas em grande parte de sua área de distribuição original. O estado de São Paulo encontra-se na zona central da distribuição geográfica da espécie, e mantém atualmente apenas 5 \% de sua cobertura vegetal original (Victor, 1975). Devido a este acentuado distúrbio, a ocupação de ambientes antrópicos por parte do $C$. latirostris poderá ser a alternativa para sua conservação (Verdade \& Lavorenti, 1990 e Verdade, 1997a), pois a espécie aparentemente apresenta alta capacidade para colonizar ambientes antrópicos (i.e., açudes), que podem ser relevantes para sua colonização (Verdade e Pina, no prelo).

Programas de auto-repovoamento, baseados na coleta de ovos em ambiente natural (ranching) e posterior soltura dos filhotes, como é feito na Argentina (Larriera, 1993 e Pina et al., 2002) são considerados de difícil realização para as populações brasileiras da espécie, pela falta de informações sobre distribuição atual e sobre sítios significativos de nidificação (Verdade, 1997a). Verdade (2001) evidencia que a condição para a criação em sistema ranching é a ocorrência de grandes agregados populacionais, o que não ocorre na maior parte da distribuição geográfica da espécie, pois não há áreas úmidas tão extensas quanto no Pantanal do Mato Grosso. A propagação em cativeiro tem sido defendida como uma importante forma de conservação para a espécie (Verdade, 1997a).

A criação em cativeiro, desde as etapas de reprodução farming, sistema onde ocorre o ciclo completo de vida do animal, incluindo a reprodução em cativeiro 
(Ashley, 1996), tem sido preconizado como o melhor sistema para a conservação e manejo do jacaré-de-papo-amarelo, no Brasil. A falta de sítios consideráveis de nidificação e a falta de populações grandes o suficiente para suportar a pressão de coleta de ovos e filhotes na natureza, faz com que o sistema ranching seja inviável, sobretudo no estado de São Paulo, onde há uma considerável fragmentação dos habitats originais da espécie.

O modelo de manejo do tipo farming tem sido utilizado na colônia em cativeiro da Escola Superior de Agricultura "Luiz de Queiroz" (ESALQ/USP). De acordo com Verdade (1997b), a criação em cativeiro poderia gerar recursos para a conservação da espécie na natureza e para as pesquisas necessárias sobre sua biologia e manejo.

A criação em cativeiro de espécies nativas também pode diminuir o interesse pela criação de espécies exóticas, como é o caso do Crocodylus niloticus trazido para o Rio Grande do Sul, atividade considerada como potencialmente danosa à conservação de espécies endêmicas (Verdade, 1997a). Mas não deve ser considerada como substituta do manejo de populações selvagens (Magnusson, 1984).

O programa experimental de criação em cativeiro da espécie da ESALQ foi implantado em 1988 e o crescimento de sua colônia em cativeiro vem sendo monitorado através do Studbook regional da especie, sendo o seu manejo genético organizado pelo sistema SPARKS - Single Population Animal Record Keeping System (ISIS, 1989) maximizado para manter o nível de consangüinidade o mais baixo possível (Verdade, 2001). O programa monitora populações remanescentes do jacaré-de-papo-amarelo do Estado de São Paulo (Verdade, 2001), do ponto de vista de sua ecologia e do ponto de vista genético (Zucoloto, 1998).

Na colônia em cativeiro da ESALQ foi observada a idade de aproximadamente cinco anos para o início da reprodução entre jacarés-de-papoamarelo (Verdade, 2003). Esta observação é um importante aspecto da dinâmica populacional, pois quanto maior o tempo para os indivíduos de uma população entrarem em reprodução, maior o tempo de geração e menor a taxa de incremento 
populacional (Caughley, 1977). Este número relaciona-se ao número de indivíduos migrantes por geração como demonstrado em Verdade et al. (2002).

Diferente do que ocorre com aves e mamíferos, cuja determinação do sexo é genética, em crocodilianos o sexo dos embriões é determinado pela temperatura de incubação dos ovos (Wibbels et al., 1998), não apresentando, cromossomos sexuais heteromórficos (Bull, 1980).

A diferenciação das gônadas deve ser controlada pela temperatura direta ou indiretamente, havendo um período crítico na embriogênese relacionando a temperatura com a determinação do sexo nos aligátores. Entretanto os mecanismos moleculares e fisiológicos essências neste processo são desconhecidos (Smith \& Joss, 1993). O período sensível à temperatura para a determinação do sexo em aligátores ocorre entre o sétimo e vigésimo primeiro dia de incubação dos ovos (Ferguson \& Joanen, 1982). Webb et al. (1987) verificaram que o nascimento de fêmeas ocorria em temperaturas baixas $\left(28-31^{\circ} \mathrm{C}\right)$ e mais altas $\left(33-34{ }^{\circ} \mathrm{C}\right)$, enquanto que em temperaturas intermediárias $\left(31-33^{\circ} \mathrm{C}\right)$ ocorria nascimento de machos

Piña (2003), determinou que para Caiman latirostris os ovos incubados à $29^{\circ} \mathrm{C}(\mathrm{N}=52)$ e $31^{\circ} \mathrm{C}(\mathrm{N}=54)$ produziram $100 \%$ fêmeas. Incubações à $33^{\circ} \mathrm{C}(\mathrm{N}=$ 58) produziram $100 \%$ machos. Tratamentos com alta temperatura $\left(34,5^{\circ} \mathrm{C}\right)$ produziram ambos os sexos, em uma taxa de 6 machos para 4 fêmeas $(\mathrm{N}=10)$, observando assim um padrão diferente do fêmea-macho-femea constatado por Lang \& Andrews (1994) para aligátor americano e por Ewert (1994) para tartarugas.

O período de incubação é de 65 a 87 dias; o sucesso na eclosão dos ovos, obtido na colônia em cativeiro da ESALQ/USP, varia de 40 a 86 \%, com média de $67 \%$; a mortalidade após o nascimento é baixa, sendo este índice de 0,75\% (Verdade \& Sarkis, 1998). O período de eclosão dos filhotes vai de meados de fevereiro a meados de abril (Verdade et al., 1993). Os primeiros sinais de eclosão são as rachaduras na casca, que na incubação natural é facilitada pela ação dos ácidos fracos liberados pelo material vegetal constituinte do ninho. 
O jacaré-de-papo-amarelo é conhecido por ter o rostro mais largo em relação ao comprimento entre todos os crocodilianos e seu hábito alimentar generalista possivelmente está relacionado a esta característica.

A maior parte da sua dieta é constituída de caracóis ampularídeos (Diefenbach, 1979). Melo (2002) analisou a dieta de Caiman latirostris na Estação Ecológica do Taim (EET), Rio Grande do Sul, Brasil. A autora separou os animais em duas categorias de tamanhos: jovens (seis machos e oito fêmeas, comprimento total $<120 \mathrm{~cm}$ ) e adultos (22 machos e oito fêmeas, comprimento total $\geq 120 \mathrm{~cm}$ ) em três diferentes habitats: várzea, uma pequena lagoa e um grande lago. Os invertebrados foram comuns na dieta dos jacarés dos três ambientes, sendo o caracol Ampullaria caniculata o mais consumido, estando de acordo com Diefenbach (1979).

Segundo Melo (2002) jacarés com tamanho inferior a $100 \mathrm{~cm}$ de comprimento total consumiram principalmente insetos, sendo Belostoma sp. o inseto mais consumido com 1,6 indivíduos por estômago. Tartarugas e anfíbios foram encontrados em apenas dois estômagos. Peixes e serpentes foram consumidos principalmente no grande lago, entretanto a autora ressalta que isso poderia estar relacionado à época em que foram feitas as coletas, pois com a diminuição do nível da água houve uma concentração de aves aquáticas na pequena lagoa, facilitando talvez sua captura pelos jacarés. Somente os machos capturaram mamíferos, sendo o ratão-do-banhado (Myocastor coypus), uma espécie abundante na área estudada, o mamífero mais consumido. À medida que os jacarés crescem passam a selecionar presas maiores e não a consumir mais presas, um padrão que esta de acordo com o observado para outras espécies de crocodilianos (Taylor et al., 1978; Webb et al., 1982). A presença de vertebrados na dieta foi diretamente proporcional ao tamanho dos jacarés, o consumo de peixes foi considerado baixo (29\%). Pássaros foram os únicos vertebrados consumidos nos períodos de nível de água mais baixo, entretanto aves não foram muito consumidas fora deste período. Melo (2002) conclui que seus resultados não sustentam a queixa dos pescadores locais de que o C. latirostris estaria reduzindo o estoque de peixes disponível. 
O conhecimento científico sobre a espécie vem aumentando desde a implantação do programa de propagação em cativeiro e conservação da espécie na natureza implementada pela ESALQ. Zucoloto (2003) evidencia que o estabelecimento de parceria com criadores particulares credenciados pelo programa colabora com a preservação da espécie visando viabilizar a produção de matrizes, para a formação de novas fazendas de criação e comercialização. Até o momento, foram credenciados criadores nos Estados de São Paulo (5), Minas Gerais (1), Goiás (1), Alagoas (1), Santa Catarina (1) e Rio Grande do Sul (1) e desde a implantação destas criações estima-se que foram produzidos no total 1190 ovos, resultando em 950 filhotes (Verdade, 2001).

Estes criatórios estão contribuindo indiretamente no combate da retirada clandestina de animais na natureza. Com o aumento no número de animais nascidos em cativeiro, que serão futuros reprodutores e matrizes de novos criatórios, poderá ocorrer um aumento do número de peles e carnes legais disponíveis para o mercado consumidor, advindas do abate de animais criados para este fim, proporcionando inclusive qualidade superior. Isto poderá causar enfraquecimento do comércio ilegal, com uma conseqüente queda na procura por estas peles e carnes clandestinas.

Marcadores microssatélites foram desenvolvidos por Zucoloto (2002), podendo atender a necessidade da certificação das matrizes e organização do manejo reprodutivo da espécie em cativeiro, possibilitando assim a formações de casais não aparentados para o fornecimento aos criadores.

Estes marcadores podem acessar com eficácia a estrutura genética da população de interesse para o seu manejo com meta em manter a diversidade genética. As informações fornecidas por estes marcadores podem ainda fornecer importantes pistas sobre a historia evolutiva da espécie, padrões de fluxo gênico e parentesco entre subpopulações. 


\subsection{Marcadores Microssatélites}

Marcadores moleculares codominantes têm sido usados nos estudos genéticos de populações naturais. Entre as classes de marcadores moleculares existentes, os marcadores microssatélite são os que mais se aproximam do marcador ideal para estudos de genética de populações (Rafalski et al., 1996). Isto se deve ao fato de tais marcadores possuírem as características extremamente favoráveis para este fim, dentre elas destacam-se: são abundantes e uniformemente distribuídos por todo genoma; são tipicamente codominantes; são altamente multialélicos, apresentando o maior conteúdo informativo por loco entre todas as classes de marcadores moleculares.

Microssatélite ou STR (Short Tandem repeat), são seqüência repetitiva em tandem (em “fila”) de sequencias curtas de DNA, geralmente com 1-6 pares de bases, que se repetem até algumas dezenas de vezes (Tautz \& Renz, 1984). Estes marcadores podem ser classificados em quatro classes, os microssatélites perfeitos, em que há apenas um tipo de unidade de repetição; os microssatélites compostos, onde existem dois tipos de unidades de repetição; os microssatélite complexos, onde existem mais de dois tipos de unidade de repetições; e os imperfeitos (interrompidos), em que existem uma ou mais unidades simples não repetidas dentro do arranjo do microssatélite (Weber, 1990).

O polimorfismo de um determinado loco microssatélite depende do número de motivos repetidos. Os diferentes alelos de um loco de microssatélite distinguemse uns dos outros pelo número de unidades de repetições que apresentam. Tomemos como exemplo os locos em que o dinucleotídio “CA” é a unidade de repetição. O polimorfismo irá resultar da presença de números variáveis dessas unidades de repetição. Um alelo é definido pela ocorrência de, por exemplo, 17 unidades de repetição “CA” enfileiradas, ao passo que outro alelo desse loco consiste de apenas 16 repetições.

O que define a identidade de um loco, uma vez que o polimorfismo é apenas de extensão, é a seqüência que flanqueia o trecho repetitivo. As sondas usadas nessas 
análises são dirigidas a essas seqüências flanqueadoras e permitem detectar quantas unidades de repetições estão presentes na seqüência repetitiva.

Para ser considerado um microssatélite Chambers e MacAvoy (2000) sugerem que no mínimo oito nucleotídeos repetidos em tandem são necessários para iniciar o processo de origem de um microssatélite. Assim um dinucleotídeo precisa estar repetido pelo menos 4 vezes, um trinucleotídeo precisa se repetir 3 vezes e um tetranucleotídeo 2 vezes. Conhecendo as regiões que flanqueiam as seqüências de microssatélites pode-se desenhar oligonucleótidos iniciadores específicos para um determinado loco, possibilitando sua amplificação por meio de reação de polimerase em cadeia ("PCR - Polymerase Chain Reaction"). Esta estratégia combina o alto valor informativo dos microssatélites com a facilidade da PCR.

O “desaparecimento" de um alelo ou loco de um microssatélite segundo Chambers e MacAvoy (2000) pode ocorrer devido a uma única ou várias mutações que ocorrem nas regiões flanqueadoras, impedindo a ligação dos oligonucleotídeo nas reações de amplificação por PCR. As taxas de mutações da maioria dos locos microssatélite são muito mais altas que as de locos de outros marcadores dentro do mesmo genoma. Embora muitos tipos de mutações ocorram no microssatélite, as taxas elevadas de mutações são causadas primariamente por alterações no comprimento das unidades de repetição. Os diferentes alelos de um loco de microssatélite são caracterizados pelos seus tamanhos, determinados pelo número de repetições (Estoup e Cornuet, 1999).

As altas taxas de mutações nos microssatélites são explicadas por dois modelos principais:

a. Crossing-over desigual entre moléculas de DNA (Jeffreys et al., 1994), resultado da combinação entre cromossomos homólogos que não estão alinhados corretamente, podendo ocorrer em taxas elevadas nos microssatélites, pois a presença das repetições aumenta a probabilidade de perda de alinhamento entre cromossomos homólogos . 
b. Mecanismo de replicação slipagge (Levinson e Gutman, 1987) que ocorre em regiões do DNA que contém seqüências repetidas curtas em tandem. Durante a replicação este mecanismo pode ocorrer devido à perda de pareamento entre seqüências vizinhas repetidas, com isto há formação de loop, dependendo da direção que ocorre pode resultar tanto em deleção como duplicação de um segmento de DNA durante a replicação (Li e Graur, 1991).

O mecanismo de replicação slippage é o mais aceito atualmente. Contudo, alguns dos erros no DNA slippage são corrigidos por enzimas exonucleases que fazem a leitura da fita de DNA recém sintetizada à procura de erros da polimerase. Se erros são encontrados, as exonucleases degradam a fita recém sintetizada e a DNA polimerase copia novamente.

Outra forma de reparo do DNA slippage é chamado reparo mismatch (reparo da perda de alinhamento na fita de DNA). Os loops formados na fita de DNA devido ao mecanismo slippage são reconhecidos e as bases nitrogenadas presentes nestes loops da fita molde são incorporadas na fita sintetizada. Desta maneira, a instabilidade dos microssatélites pode ser considerada um balanço entre a geração de erros de replicação ocasionados pelo DNA slippage e a correção de alguns dos erros por exonucleases ou pelo reparo mismatch (Eisen, 1999).

A alta taxa de mutação nos marcadores microssatétite, entretanto, constitui uma limitação, pois há grande chance de ocorrência de convergências (resultando em homoplasias), quando comparações são realizadas entre populações de parentesco mais remoto, ou entre espécies.

Os segmentos de microssatélites são uniformemente distribuídos pelo genoma dos eucariotos, com exceção dos telômeros, e são mais raros nas regiões codificadora. Devido a esta distribuição preferencial nas regiões não codificadora, os microssatélites podem não sofrer ação da seleção natural, sendo um marcador seletivamente neutro muito útil para estudos da genética das populações naturais. Os alelos de um loco microssatélite diferem de tamanho em função do número de 
repetições das seqüências básicas. Quando estas seqüências básicas se repetem mais que dez vezes, os microssatélites usualmente são muito polimórficos. Estudos caracterizando mutações em coleções de pedigree humano sugerem que as mutações em locos microssatélites envolvem mais ganhos do que perda de repetições (Weber e Wong, 1993). Do ponto de vista prático, seqüências de microssatélite representam importantes ferramentas da biologia molecular. O estudo dessas seqüências tem revolucionado algumas áreas da genética, como a identificação de indivíduos, confirmação de paternidade e estudos de populações (Farah, 1997).

Dois modelos para o processo mutacional dos locus microssatélite tem sido aplicado: o modelo de alelo infinito (IAM-Infinite Allele Model, Kimura e Crow, 1964), e o modelo Stepwise (SMM, Stepwise Mutation Model, Kimura e Ohta, 1978). O modelo IAM considera que mutações nas sequências de microssatélite resulta em perda ou ganho de uma ou mais unidade de repetição, sempre gerando um estado alélico não encontrado anteriormente na população. O modelo SMM é o mais aceito para microssatélite e admite que a mutação em alelos resulta na perda ou ganho de uma única unidade de repetição, e os alelos poderiam variar através de estados alélicos anteriormente presente na população

\subsection{Utilização de marcadores microssatélites: estudos com animais}

A técnica de DNA microssatélite vêm sendo aplicada com sucesso em vários animais e tem sido usada para teste de paternidade em programas de melhoramento de gado (Arranz et. al., 1996; Regitano, 1996; Ron et. al., 1996 e Rosa, 1997) e para identificação de paternidade de rotina em cães (Fredholm \& Wintero, 1996 e Pihkanen et. al., 1996) e eqüinos (Binns et. al., 1995, Bowling et. al., 1997).

Microssatélites têm sido usados ainda para medir sucesso reprodutivo, como no estudo do invertebrado Limulus polyphemus (Brockmann et. al., 1994) e de famílias de urso pardo, Ursus arctus (Craighead et. al., 1995); para testar os efeitos do sistema de acasalamento e da deriva genética sobre a estrutura de populações, 
como foi estudado com o caracol hermafrodita Bulinus truncatus (Viard et. al., 1996); para entender mecanismos do comportamento sexual em pássaros (Lifjeld et. al., 1997 e Saino et. al., 1997); para organizar programas de conservação como o do lobo mexicano Canis lupus baileyi (Garcia-Moreno et. al., 1996) e dos coalas (Houlden et. al., 1996) e para estudar a estrutura genética de populações selvagens, como em Drosophila melanogaster (England, 1996; Michalakis \& Veuille, 1996 e Schötterer, 1997), cetáceos (Buchanan et al., 1996), cavalos (Ellegren et al., 1992), lobos (Roy et al.,1994), cervídeos (Broders et al, 1999) e cobras (Prosser et al., 1999).

No dragão de Komodo (Varanus komodoensis), com análise de 10 locos de microssátelites foi possível observar baixas taxas de fluxo gênico entre populações de illhas isoladas (Ciofi e Bruford,1999).

Em ursos marrons (Ursus arctos), foi identificada estrutura populacional em algumas populações de ilhas mais isoladas e foi verificado que nessas populações insulares, a dispersão pode ser reduzida ou eliminada por barreiras aquáticas de 2 a 7 Km (Paetkau et al., 1998).

Marcadores microssatélites vêm proporcionando grandes avanços ao estudo da genética de crocodilianos. Glenn (1998), Davis et al. (2001a), Davis et al. (2001b) realizaram caracterização de marcadores microssatélites e diversidade genética de Alligator mississipiensis; FitzSimmons et al. (2001) realizaram estudos genéticos em Crocodylus pororus e Crocodylus jonhstoni; Zucoloto (1998), Zucoloto et al. (2002) e Verdade et al. (2002) desenvolveram marcadores microssatélites e estudaram diversidade genética em Caiman latirostris.

Os locos aos quais Glenn et al. (1996) se referem foram renomeados em Glenn et al. (1998). Estes marcadores foram otimizados e caracterizados para a espécie utilizando 19 amostras de alligátores do Rockfeller Wild Refuge (RWR) no Estado da Louisiania e 14 amostras de alligátore do Everglades National Park no Estado da Florida. Os autores observaram que os microssatélites desenvolvidos foram a classe mais polimórfica de marcadores utilizada para caracterizar a variação em alligátores americanos. Estudos de parentesco usando microssatélites foram 
considerados promissores por Queller et al. (1993). Aliado ao progresso na biometria de marcadores genéticos como os obtidos recentemente (Ritland, 1996; Lynch \& Ritland, 1999; Lynch, 1999; Ayres, 2000; Carlini- Gracia et al., 2001; Coelho, 2001 e 2002) estes estudos tanto em nível de cativeiro como na natureza estão obtendo um notável sucesso (Zucoloto, 1998; Zucoloto, 2003; Smith et al., 2001; Bentzen et al., 2001; DeWoody et al., 2000; Olsen et al., 2001; Davis et al., 2001a e Verdade et al., 2002).

Glenn et al (1998), caracterizou 11 locos microssatélite para alligátores americano e análises preliminares de amostras de alligátores do sul de Louisiana (SWL) e do "Everglades National Park” (ENP) revelaram 4-12 alelos por locos para 43 indivíduos, a média de heterozigosidade foi 0,47 e houve diferenciação genética entre as populações de SWL e ENP para todos os locos examinados.

Davis (2001), utilizou cinco marcadores microssatélite desenvolvidos por Glenn et. al.(1998) para examinar a estrutura genética em seis populações de Alligator mississipiensis ao longo de sua distribuição geográfica. Um total de 128 indivíduos foram analisados a heterozigosidade variou de 0,52 - 0,76 e foi encontrada diferenciação genética entre todas as populações estudadas, sugerindo subdivisão e baixo fluxo gênico. A autora também encontrou uma correlação positiva entre a distância genética e distância geográfica.

Zucoloto (1998), utilizando 14 dos microssatélites desenvolvidos por Glenn et al. (1998) nas mesmas condições de amplificação descritas para Alligator mississipiesis encontrou polimorfismo com os marcadores Ami 8 , Ami·11, Ami·13 e Ami-20. Com estes marcadores pode ser estabelecido o teste de maternidade para a colônia em cativeiro do jacaré-de-papo-amarelo da ESALQ, onde a probabilidade de exclusão combinada calculada segundo Weir (1996) foi 86 \%.

Neste estudo concluiu-se que através de regressão linear utilizando uma população com genealogia conhecida, a colônia em cativeiro da ESALQ, foi possível correlacionar o coeficiente de parentesco de Van Vleck et al. (1987) com o índice de similaridade genética de Ciampolini et al. (1995) com $\mathrm{r}^{2}=0,629$ e p $\leq$ 0,001 e pela utilização do modelo desenvolvido $(r=0,297+0,772 \mathrm{P}$, onde $\mathrm{r}$ é o 
coeficiente de parentesco e $\mathrm{P}$ a similaridade genética), foi possível calcular o coeficiente de parentesco entre animais selvagens.

A similaridade genética de Ciampolini et al. (1995) foi utilizada ainda para comparar e agrupar indivíduos através do método UPGMA. Foi observado que os indivíduos de três grupos próximos geograficamente na natureza, apresentaram-se mesclados, indicando que este método poderia ser usado em conjunto com as estatísticas $F$, para entender a estrutura de populações selvagens do jacaré-de-papoamarelo e seus mecanismos de dispersão usando marcadores microssatélites.

A estrutura genética de populações naturais de jacaré-de-papo-amarelo, Caiman latirostris remanescentes do Estado de São Paulo começou a ser estudada por Zucoloto (1998) e sua interpretação abordada em Verdade et al. (2002) com base na teoria de metapopulações e considerando a escala microgeográfica da amostragem realizada.

Neste trabalho os autores observaram que há uma variação genética entre cinco populações estudas onde a distância média entre quatro delas é $15 \mathrm{~km}$ e que a mobilidade da espécie pode alcançar $150 \mathrm{~km}$. O número médio de indivíduos migrantes por geração, uma medida do fluxo de indivíduos observado entre as cinco populações estudas, estimado em 1,09 indivíduos por geração foi considerado baixo em função da maturidade sexual ser atingida na espécie ao redor dos 10 anos (Verdade \& Sarkis, 1998).

A variação encontrada foi estimada para cada par de populações através das estatísticas Rho usando o programa RSTcalc, e foi concluído que a variação observada entre as populações é provavelmente causada por auto nível de parentesco dentro de cada grupo, o que foi demonstrado pela determinação do coeficiente de parentesco par a par entre os indivíduos dessas populações pelo método desenvolvido por Coelho (2001). 


\subsection{Parâmetros populacionais, Estrutura populacional e Parentesco}

Do ponto de vista genético, uma população pode ser definida como um conjunto de indivíduos que compartilham seus genes através de reprodução (Falconer, 1989). As freqüências alélicas e as freqüências genotípicas são parâmetros descritivos de uma população. Estas se referem, respectivamente, à quantidade observada de um determinado alelo, frente ao total de alelos da população e à quantidade observada de indivíduos com um determinado genótipo, frente ao total de indivíduos da população. A heterozigosidade esperada e observada e a diversidade genética são medidas da variabilidade genética da população (Weir, 1996). Saber quantos indivíduos heterozigotos existem em uma população é interessante, pois esses indivíduos são portadores de diferentes alelos, entretanto, em populações onde não estejam presentes indivíduos heterozigotos, a diversidade genética também é uma medida de interesse, pois refere-se à quantidade de homozigotos diferentes na população (Weir, 1996). Do ponto de vista da conservação, o estudo da heterozigosidade e da variabilidade genética são mais relevantes que a comparação entre a diversidade genética entre diferentes populações (Caughley e Sinclair, 1994).

Quando a reprodução em uma população se dá ao acaso, os gametas produzidos pela população são combinados aleatoriamente (Crow \& Kimura, 1970). Nesta situação existe uma relação simples e constante ao longo das gerações entre as freqüências alélicas e genotípicas, chamada de lei de Hardy-Weinberg. Entretanto, esse princípio aplica-se apenas a grandes populações com cruzamentos ao acaso e pressupõe ausência de seleção, mutação e migração.

Em um dado momento finito no tempo, em que uma população tenha sido amostrada, é possível saber se as proporções das freqüências alélicas, genotípicas, ou particularmente a heterozigosidade correspondem às esperadas para o equilíbrio de Hardy-Weinberg, através de um teste de aderência (goodness of fit). Isso não quer dizer que essa população esteja em equilíbrio de Hardy-Weinberg e sim que suas proporções de alelos ou genótipos, correspondem ao esperado por esse modelo naquele momento. Para saber se o equilíbrio de Hardy-Weinberg se mantém nessa 
população é necessário avaliar várias gerações pelo teste de aderência (Falconer, 1989). Populações que não atendem às restrições do princípio de Hardy-Weinberg podem ter suas proporções de alelos e genótipos alteradas ao longo das gerações. Em populações pequenas, pode ocorrer uma alteração do equilíbrio de Hardy-Weinberg chamada de endogamia, resultante de um maior número de acasalamentos entre indivíduos aparentados do que aconteceria em populações grandes, onde a probabilidade de acasalamentos entre indivíduos aparentados é menor.

Em uma população em situação de endogamia, a probabilidade de que dois indivíduos dessa população tenham alelos idênticos por descendência aumenta, pois a possibilidade de que esses dois indivíduos tenham um ancestral em comum também é maior. Quando dois indivíduos, que têm um alelo idêntico por descendência, se cruzarem, alguns dos seus filhotes poderão ser homozigotos para o alelo originário do ancestral comum, estes indivíduos são chamados de autozigotos. Uma conseqüência da endogamia é que o número de indivíduos com alelos idênticos por descendência entre eles aumenta a cada geração, aumentando assim a ocorrência de indivíduos autozigotos. Isso acarreta um aumento progressivo de genótipos homozigotos ao final de cada geração (Falconer, 1989).

A variação populacional resulta de um balanço de forças produzindo homogeneidade genética e forças tendendo a produzir diferenciação genética local. Fluxo gênico ou migração provocando a homogenização e no oposto estariam mutação, deriva genética e seleção natural favorecendo adaptações às condições ambientais locais que podem levar à diferenciação genética de populações (Futuyma, 1998). A estrutura populacional parece ser influenciada por vários fatores intrínsecos à história de vida de um organismo particular, como sistema de cruzamento e regime de fluxo gênico, mas também são influenciados pela história biogeográfica e fatores demográficos (Encalada et al., 1996). Organismos altamente dispersivos, apresentam níveis significativamente menores de estruturação populacional do que animais sedentários. A eficiência do fluxo gênico é determinada pela habilidade espécieespecífica bem como por barreira geográfica e distância isolando populações (Kvist et al., 1998). 
O grau de diferenciação populacional pode ser medido de varias maneiras: pelas distâncias genéticas; e pelas estatísticas F de Wright ou estatísticas $\theta$ s de Cockerham: índice de fixação total $(F)$, índice de fixação intrapopulacional $(f)$, diversidade entre populações $(\theta \mathrm{p})$ e mais recentemente as estatísticas $R_{S T}$ um análogo do $\theta \mathrm{p}$ de Cockerham.

Pelo que é conhecido sobre o modo de evolução de microssatélite, o emprego das distâncias genéticas como de Nei e Renolds não são as mais adequadas. Alelos desses marcadores surgem por processos bastante peculiares: os alelos são produzidos por sucessivas adições e perdas de unidades básicas (por exemplo, de dinucleotídio "CA”) e imagina-se que os alelos se originem segundo o modelo “Stepwise mutation model” (Strand et al., 1993). Conseqüentemente, a informação sobre as diferenças entre tamanho de alelos pode ter valor para inferência, além da informação sobre as freqüências de alelos. Por exemplo, seqüências contendo 14, 16 ou 30 unidades de repetição definem alelos distintos. Porém, o conhecimento sobre como esses alelos surgem, é razoável supor que os de 14 e 16 resultariam de mudanças ocorridas mais recentemente, ou seja, a análise de locos de microssatélite deve também utilizar informações sobre as características dos alelos.

A estatística $R_{S T}$ é especialmente utilizada para marcadores microssatélites por comportarem em seu cálculo o stepwise model proposto por Slatkin (1995), onde a mutação para um novo alelo de um determinado marcador microssatélite ocorre em passos, assim alelos com tamanhos mais próximos são considerados mais similares do que alelos com tamanhos mais distantes. Na prática a estatísticas $R_{S T}$ é calculada pela formula:

$$
R_{S T}=\frac{\bar{S}-S_{W}}{\bar{S}}
$$

onde $S_{w}$ é duas vezes a média da variância estimada do tamanho do alelo encontrado dentro de cada população e $\bar{S}$ é duas vezes a variância estimada do 
tamanho do alelo encontrado em todas populações. A distância baseada na estatística Rho é calculada por :

$$
\delta^{2} \mu=\left(m_{x}-m_{y}\right)
$$

onde $\mathrm{m}_{\mathrm{x}}$ e $\mathrm{m}_{\mathrm{y}}$ são as médias dos tamanhos dos alelos nas populações x e y.

Locos que apresentam freqüências semelhantes em diferentes populações apresentam baixos valores de $R_{S T}$, enquanto que aqueles com freqüências gênicas muito distintas entre populações apresentam valores altos (se aproximando de 1 à medida que a população se aproxima da fixação de alelos distintos para um loco).

O coeficiente de parentesco entre dois indivíduos é facilmente estimado quando a genealogia entre eles é conhecida. Contudo, quando esta é desconhecida, a única maneira de se estimar o coeficiente de parentesco é através de marcadores moleculares (Lynch \& Ritland, 1999; Ritland, 1989; Ritland, 2000).

O grande avanço proporcionado pelos marcadores moleculares neste contexto, foi a possibilidade de se estimar o parentesco entre indivíduos, sem a necessidade de experimentos com progênies para que um modelo particular possa ser estabelecido durante as estimativas (Ritland, 1996b; Gaiotto,2001).

Diferentes métodos podem ser utilizados para obtenção de estimativas de coeficiente de parentesco com auxílio de marcadores moleculares. Lynch (1999) descreve alguns estimadores como o de Lynch (1988) para uso com DNA fingerprinting, e os de Ritland (1996) e Lynch \& Ritland (1999) para uso com microssatélites. Este autor destaca que o uso de métodos de reamostragem (bootstrap) sobre indivíduos parece solucionar a construção de intervalo de confiança para a obtenção do coeficiente de parentesco para populações naturais.

Outro método para obtenção do coeficiente de parentesco é o método da Informação (Coelho, 2001), que define os pesos para as estimativas dos parentescos médios com base na contribuição de cada alelo para o conteúdo de informação total (sensu Shannon) e possui características semelhantes ao método de Ritland (1996). 
O método bootstrap foi utilizado por Coelho (2001) no desenvolvimento do programa de computador Sancho: Sistema de análise para o cálculo do coeficiente de herdabilidade e outros parâmetros, com o qual é possível calcular simultaneamente os coeficientes de parentesco de Ritland (1996), de Lynch \& Ritland (1999) e o coeficiente desenvolvido pelo autor baseado no método da informação.

Este método apresenta vantagens sobre os demais quando ocorre endogamia nas populações em estudo (Coelho, comunicação pessoal). A expressão do estimador de parentesco por este método é dada por:

$$
\hat{r}_{x y_{(\mathrm{inf})}}=\sum_{l} w_{l} \sum_{i} w_{i l} \hat{r}_{x y_{(\mathrm{inf})_{i l}}}
$$

Onde :

$$
w_{1}=\frac{-\sum_{i} \hat{p}_{i l} \log \hat{p}_{i l}}{-\sum_{i, l} \hat{p}_{i l} \log \hat{p}_{i l}} \quad w_{i l}=\frac{-\hat{p}_{i l} \log \hat{p}_{i l}}{-\sum_{i} \hat{p}_{i l} \log \hat{p}_{i l}}
$$




\section{MATERIAL E MÉTODOS}

\subsection{Captura e imobilização de jacarés e conservação de sangue}

A captura desses animais provenientes da natureza foi feita à noite, manualmente ou com o auxilio de laço de cabo de aço, após visualização com facho de luz intensa do tipo sealed beam e aproximação em barco, conforme descrito por Hutton et. al. (1987) e Walsh (1987). A imobilização foi mecânica, dispensando-se o uso de anestésicos ou relaxantes musculares, conforme realizado por Verdade (1997b). A marcação é realizada por anilhamento, entre os dois primeiros dedos do membro posterior direito, na membrana interdigital. O sangue foi coletado através de punção do ramo dorsal da veia cava superior, que corre no interior da coluna vertebral, conforme descrito por Olson (1975), para grandes répteis. Após a coleta, o sangue foi conservado em tampão de lise (Hoelzel, 1992), cuja composição é: 100 mM Tris-HCl, pH 8,0; 100 mM EDTA, pH 8,0; 10 mM NaCl; 0,5 \% SDS (p/v).

\subsection{Sítios de coleta e amostragem}

Os locais de coleta de animais foram: Banhado do Taim no Rio Grande do Sul trata-se reconhecidamente do extremo meridional de distribuição da espécie (Medem, 1983); Rio Pereque, Ilha do Cardoso, Litoral Sul de São Paulo, trata-se de uma população insular, podemos considerá-la como limite oriental de distribuição da 
espécie, limitada pelo oceano Atlântico; Natal no Rio Grande do norte, os indivíduos foram coletados no Aquário de Natal e foram encontrados a um raio de $5 \mathrm{Km}$ do local, João Pessoa na Paraíba, os indivíduos foram coletados no Zoológico de João Pessoa e foram encontrados em raio de aproximadamente $20 \mathrm{Km}$ do local; Lagoa Vermelha em Alagoas. Na região de Piracicaba/SP os indivíduos foram coletados em pequenas várzeas e açudes associados ao Rio Piracicaba e seus tributários na região centro-leste do Estado de São Paulo. Os sítios de campo, previamente estudados por Verdade (1997b) e Zucoloto (2003) foram utilizados: Porto de Areia, lagoa de aproximadamente 200 ha associada ao Rio Piracicaba; Pantanal, lagoa de aproximadamente 10 ha associada ao Riacho Aracua; Charqueada, açude artificial de aproximadamente 2 ha associado ao Riacho Aracua; e Duraflora açude artificial de aproximadamente 5 ha associado ao Riacho Pederneiras.

O número de laboratório de cada indivíduo, o número de anilhamento e o sexo dos animais estão descritos no APÊNDICE1.

Tabela 1. Populações de Caiman latirostris analisadas e suas coodenardas

\begin{tabular}{lccc}
\hline \multicolumn{1}{c}{ Localidade } & População & Indivíduos & Coordenadas \\
\hline Lagoa vermelha - AL & AL & 25 & $10^{\circ} 04^{\prime} \mathrm{S}, 36^{\circ} 21^{\prime} \mathrm{W}$ \\
Banhado do Taim-RS & RS & 17 & $32^{\circ} 32^{\prime} \mathrm{S}, 52^{\circ} 23^{\prime} \mathrm{W}$ \\
Ilha do Cardoso-SP & IC & 9 & $25^{\circ} 04^{\prime} \mathrm{S}, 47^{\circ} 55^{\prime} \mathrm{W}$ \\
João Pessoa-PB & PB & 12 & $25^{\circ} 04^{\prime} \mathrm{S}, 47^{\circ} 55^{\prime} \mathrm{W}$ \\
Natal-RN & RN & 5 & $5^{\circ} 43^{\prime} \mathrm{S}, 35^{\circ} 12^{\prime} \mathrm{W}$ \\
Porto de Areia-SP & PoA & 9 & $22^{\circ} 39^{\prime} \mathrm{S}, 47^{\circ} 58 \mathrm{~W}$ \\
Pantanal-SP & PT & 20 & $22^{\circ} 35 \mathrm{~S}, 47^{\circ} 51 \mathrm{~W}$ \\
CharqueadaSP & $\mathrm{CH}$ & 12 & $22^{\circ} 30^{\prime} \mathrm{S}, 47^{\circ} 48^{\prime} \mathrm{W}$ \\
Duraflora-SP & DuF & 23 & $22^{\circ} 26^{\prime} \mathrm{S}, 48^{\circ} 52^{\prime} \mathrm{W}$ \\
\hline
\end{tabular}




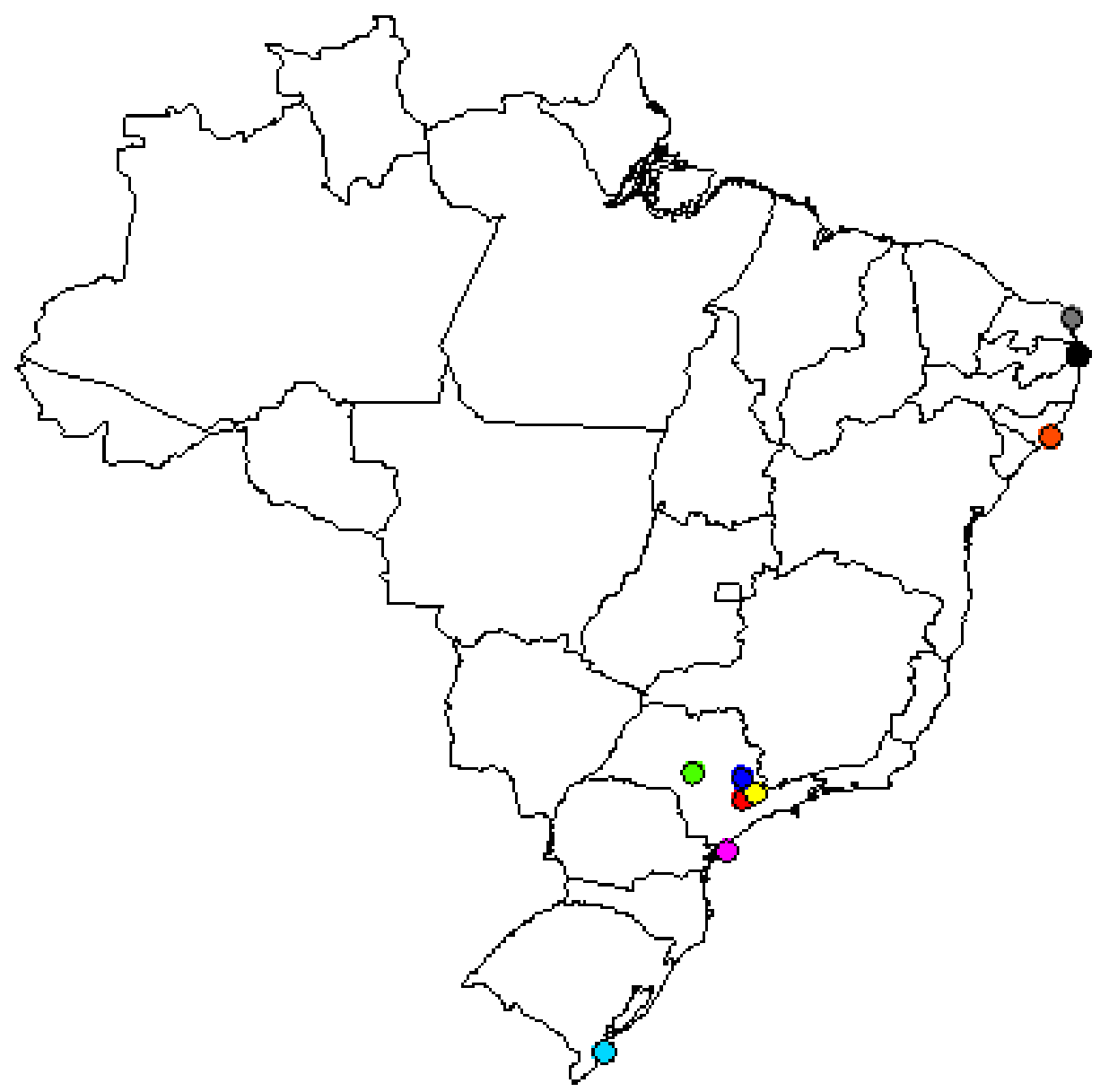

Natal (RN)

- João Pessoa (PB)

Lagoa Vermelha (AL)

Dura Flora (DuF)

Porto de Areia (PoA)

- Charqueada (CH)

Pantanal (Pt)

Illa do Cardoso (IC)

Banhado do Taim (RS)

Figura 3 - Mapa do Brasil indicando os sítios de coleta das populações de Caiman latiostris 


\subsection{Extração do DNA}

As amostras de sangue coletadas, tiveram seu DNA extraído segundo o método $\mathrm{CTAB}$, que consiste em adicionar $50 \mu \mathrm{l}$ de $\mathrm{NaCl} 5 \mathrm{M}$ e $40 \mu \mathrm{l}$ do produto CTAB $10 \%$ em $200 \mu \mathrm{l}$ da mistura (2ml de sangue em $8 \mathrm{ml}$ de solução tampão). Aquecimento da solução por 10 min. à $65^{\circ} \mathrm{C}$ para que as proteínas sejam precipitadas enquanto o DNA fica adsorvido ao CTAB. Adiciona-se $300 \mu \mathrm{l}$ de clorofórmio e centrifuga-se à 12000 rpm por 10 min., o sobrenadante é retirado para um tubo eppendorf limpo sem tocar na fase orgânica. O DNA é precipitado dessa solução com $300 \mu \mathrm{l}$ isopropanol absoluto, centrifugando-se à 12000 rpm por 10 min., descartando o sobrenadante. Faz-se duas lavagens com $250 \mu \mathrm{l}$ Etanol 70\%, com centrifugações de 5 min. à 12000 rpm em cada lavagem. O pellet é seco em estufa a $37^{\circ} \mathrm{C}$ por 30 min. e suspenso em $50 \mu \mathrm{lde} \mathrm{H}_{2} \mathrm{O}$ MilliQ e guardado em freezer à $-20^{\circ} \mathrm{C}$. Após a extração as amostras foram lidas em espectrofotômetro para sabermos a quantidade de DNA extraída e assim proceder as devidas diluições para proceder em seguida o PCR. O espectrofotômetro (HITACHI U2000) foi utilizado segundo instruções do aparelho. As amostras extraídas para a genotipagem, com o protocolo de CTAB obtiveram uma média de $100 \mathrm{ng} / \mu \mathrm{L}$, sendo então padronizado para a diluição de $20 \mathrm{ng} / \mu \mathrm{L}$, sendo utilizados em seguida a quantidade de $5 \mu \mathrm{L}$ em cada reação de PCR.

\subsection{Otimização da Amplificação}

Devido a falta de especificidade encontradas em algumas amplificação foi utilizado o PCR optimizer Kit (Invitrogen). O kit é constituído por tampões com concentrações de magnésio e pH diferentes, sendo que todos os tampões têm em comum $300 \mathrm{mM}$ de Tris-HCl e $75 \mathrm{mM}$ de Sulfato de amônio. Todos os marcadores foram testados com os tampões A, B, C, D, F, J e N, referentes ao estágio um do Kit. As condições da PCR por reação de $25 \mu$ foram padronizadas para todos os marcadores 
como sendo: $1 \mathrm{X}$ o tampão específico ; 0,1 mM de dNTP mix; 0,4 $\mu \mathrm{M}$ de cada primer; $1 \mathrm{U}$ de Taq DNA polimerase; $100 \mathrm{ng}$ de DNA e 12,77 $\mu$ de $\mathrm{H}_{2} \mathrm{O}$ deionizada. O termociclador foi programado segundo os passos: (1) $94^{\circ} \mathrm{C}$ por 3 min.; (2) $94^{\circ} \mathrm{C}$ por 1 min.; (3) Temperatura de anelamento do par de primers por 1 min. (Tabela 2); (4) $72^{\circ} \mathrm{C}$ por 1 min.; (5) Repetir 30 a 35 ciclos conforme o primer utilizado, contendo os passos 2, 3 e 4, segundo a Tabela 1 ; (6) $72^{\circ} \mathrm{C}$ por 7 min. e (7) $4^{\circ} \mathrm{C}$ indefinidamente.

Os primers da fita sense de cada microssatélite foram marcados com as fluorescências indicadas na Tabela 2. Os marcadores foram analisados no sistema do seqüenciador de DNA MegaBace 1000.

\subsection{Primers utilizados}

Foram utilizados onze pares de primers, sendo que quatro foram desenvolvidos por Glenn et al.(1998), a saber, Ami $\mu 8$, Аmi $\mu 11, A m i \mu 13$ e Аmi $\mu 20$, e sete marcadores foram desenvolvidos para Caiman latirostris (Zucoloto, 2003), Cla $\mu 2$, 5, 6, 7, 8, 9 e 10, que foram selecionados por apresentarem amplificações com fácil identificação dos genótipos e segregação coerente com as leis de Mendel.

A condição de amplificação para cada par de primer esta descrita na Tabela 2. O Tampão A (1,5 mM MgCl2, pH 8.5) foi padronizado para os marcadores Ami $\mu$, Ami $\mu 11$, Ami $\mu 13$, Cla $\mu 2$, Cla $\mu 9$ e Cla $\mu 10$; o tampão C (2,5 mM MgCl2, pH 8.5) para o marcador Cla 33 ; O tampão F (2,0 mM MgCl2, pH 9.0) para os marcadores Ami $\mu 20$, Cla 45 , Cla $\mu 7$ e Cla $\mu 8$ e o Tampão J (2,0 mM MgCl2, pH 9.5) para o marcador Cla $\mu 6$. 
Tabela 2. Primers e condição de amplificação

\begin{tabular}{|c|c|c|c|}
\hline Primers & Sequencia 5'-3' & ${ }^{\circ} \mathrm{C}$ & Ciclos \\
\hline Ami $\mu 8 \mathrm{a}$ & CCTGGCCTAGATGTAACCTTC & 55 & 30 \\
\hline Аmi $\mu 8 \mathrm{~b}$ & AGGAGGAGTGTGTTATTTCTG & & \\
\hline Ami $\mu 11 \mathrm{a}$ & AAGAGATGTGGGTGCTGCTG & 64 & 35 \\
\hline Ami $\mu 11 \mathrm{~b}$ & TCTCTGGGTCCTGGTAAAGTGT & & \\
\hline Аmi $\mu 13 a$ & CСАТССССАССАТGССАAАGTC & 64 & 35 \\
\hline Ami $\mu 13 \mathrm{~b}$ & GTCCTGCTGCTGCCTGTCACT & & \\
\hline Атін20а & ТTTТTСТTСТTТСТССАТТСТА & 58 & 30 \\
\hline Аті $\mu 20 \mathrm{~b}$ & GATCCAGGAAGCTTAAATACAT & & \\
\hline Clau2a & CCTTCAGGACCCACTTTCTT & 58 & 30 \\
\hline Clau2b & CGAATCССТСТTСССАААСТ & & \\
\hline Clau5a & GCGTAGACAGATGCATGGAA & 55 & 30 \\
\hline Clau5b & CAGTCTGAAGCTAGGGCAAA & & \\
\hline Clau6a & GAAATATGGGACAGGGAGGA & 58 & 30 \\
\hline Clau6b & GGTTGGCTGCATGTGTATGT & & \\
\hline Clau7a & CGGGGTCTTGGTGTTGACTA & 58 & 30 \\
\hline Clau7b & CGGGACCAGGAGCTGTATAA & & \\
\hline Clau8a & CAGCCACTGAAGGAATTGAC & 55 & 30 \\
\hline Clau8b & CACATACCTGACCCAGCTTATC & & \\
\hline Clau9a & ACAGGGGAAAAGAAGAGCTG & 60 & 35 \\
\hline Clau9b & ААААТСССССАСТСТТАССС & & \\
\hline Clau10a & TGGTCTTCTCTTCGTGTCCT & 60 & 35 \\
\hline Clau10b & ATGAGCCCСTCTATGTTCCT & & \\
\hline
\end{tabular}

\subsection{Precipitação dos produtos da PCR}

Após a amplificação, foi feita a precipitação dos produtos de PCR, que consiste de uma limpeza dos fragmentos de PCR para obtenção de melhores resultados na eletroinjeção no sequenciador MegaBace. A utilização de marcadores microssatélites marcados com fluorescências diferentes e o uso de tamanhos diferentes quando a fluorescência era a mesma, possibilitou que cada capilar do aparelho coletasse os dados da mesma amostra com três marcadores microssatélites 
diferentes em cada eletroforese. O sequenciador MegaBace possui 96 capilares, possibilitando que 288 genótipos sejam coletados em cada eletroforese. A purificação dos produtos de PCR foi feita segundo o protocolo a seguir: pipetar 2,5 $\mu \mathrm{L}$ do produto de PCR de cada amostra (podendo misturar até três marcadores por amostra, totalizando 7,5 $\mu \mathrm{L}$ ); adicionar 1/10 do volume de produto de PCR de acetato de amônio 7,5 M; em seguida adicionar 2,5 volumes de etanol absoluto; misturar bem e deixar descansando por $30 \mathrm{~min}$. no escuro; centrifugar por $30 \mathrm{~min}$. a 3100 g; remover o sobrenadante por inversão; adicionar $150 \mu \mathrm{L}$ de etanol 70\%; centrifugar por 10 min. a 3100 g; remover novamente o sobrenadante por inversão; secar o precipitado por 30 min. à temperatura ambiente; ressuspender o precipitado em 4,75 $\mu \mathrm{L}$ de tampão "loading solution” e 0,25 $\mu \mathrm{L}$ de marcador de peso molecular ET-ROX, segundo instruções do aparelho, e homogeneizar por um minuto para permitir a ressuspensão completa.

As placas são armazenadas em freezer $-20^{\circ} \mathrm{C}$, vedadas por adesivo plástico e embrulhadas em papel alumínio até o momento da eletroforese.

\subsection{Eletroforese em sequenciador automático MegaBACE e genotipagem dos animais}

Foram utilizados até 3 marcadores por capilar por placa. Os marcadores que corriam juntos na eletroforese eram escolhidos de acordo com fluorescência e tamanho esperado em pares de bases. Os primers foram marcados com fluorescências pela marcação “FAM” e “HEX”. O padrão de peso molecular é incluído em todas as amostras para posterior cálculo do tamanho das bandas utilizado pelo programa GENETIC PROFILER e indicado pela marcação “TAMRA”. Foram colocados no início 2,5 $\mu$ l de cada amostra para os microssatélites marcados com FAM, TET e HEX, além do padrão de peso molecular loadding 50-500, já diluído no "loadding buffer” na quantidade de 0,5 $\mu \mathrm{L}$ de padrão 
de peso molecular para 4,5 $\mu \mathrm{L}$ de tampão. Dessa solução foram misturadas 5,0 $\mu \mathrm{L}$ com a amostra que foi precipitada e que havia sido desnaturada a $95^{\circ} \mathrm{C}$ por 1 minuto e colocada imediatamente no gelo até o momento da eletroinjeção. Após otimização, as condições ideais de eletroinjeção foram 2 kv por 60 segundos, seguidos de 9 kv durante todo o tempo de corrida que foi em média 75 minutos para a entrada do último fragmento do marcador de peso molecular.

\subsection{Análise dos dados}

O programa estatístico Genepop version 3.1d (Raymond \& Rousset, 1995) foi utilizado para testar o desequilíbrio de ligação entre pares de locos (Opção 2, subopção 1 com 1000 desmemorizações, 100 lotes de dados e 1000 iterações por lote), freqüências dos alelos (Opção 5), medida de número de heterozigotos observados e de heterozigotos esperados segundo o equilíbrio de Hardy-Weinberg e teste exato para aderência ao equilíbrio de Hardy-Weinberg (Opção 1, subopção 3 com com 5000 desmemorizações, 500 lotes de dados e 5000 iterações por lote) teste de diferenciação gênica entre pares de poulações (Opção 3, subopção 2 com com 1000 desmemorizações, 100 lotes de dados e 1000 iterações por lote) e genotipica entre as populações entre pares de populações (Opção 3, subopção 4 com com 1000 desmemorizações, 100 lotes de dados e 1000 iterações por lote).

O calculo das estatísticas $\mathrm{F}$ de Wright ( $\left.\mathrm{F}_{\mathrm{IS}}, \mathrm{F}_{\mathrm{ST}}\right)$, foram estimadas utilizando o programa GDA (Lewis e Zaykin, 2000).

Em locos microssatélites, o processo mutacional não está de acordo com o que se admite no modelo de alelos infinitos com baixas taxas de mutação. Por este motivo, além da estimativa do $\mathrm{F}_{\mathrm{ST}}$, foi utilizada uma análoga a ela, denominada $\mathrm{R}_{\mathrm{ST}}$ (Slatkin, 1995), desenvolvida especificamente para dados de microssatélite. A estatística Rho e a distância $\delta^{2} \mu$ que é baseada na Rho foi estimada usando o programa RST Calc version 2.2 (Goodman, 1997) com 10000 permutações e 1000 
randomizações para as populações AL, RS IC, PB, RN, PoA, Pt, CH e DuF. Para a hipótese de a colônia em cativeiro de a ESALQ estar representando bem a diversidade gênica da espécie no Brasil foi realizada uma nova análise Rho comparando indivíduos não aparentado desta colônia com as demais populações.

O teste de Mantel, correlacionando a matriz de diferenciação genética $\left(\mathrm{R}_{\mathrm{ST}}\right)$ e a matriz de distancia geográfica calculada em linha reta, foi realizado por meio do programa NTSYS-pc 1.70 (Rohlf, 1992). Este teste foi realizado com intuito de verificar se existe correlação entre diferenciação genética e distância física.

O coeficiente de parentesco entre indivíduos foi calculado diretamente pela comparação entre os alelos de cada par de indivíduos testados, pelo método da informação usando o programa Sancho (Sistema de análise para o cálculo do coeficiente de herdabilidade e outros parâmetros), desenvolvido por Coelho (2001). 


\section{RESULTADOS E DISCUSSÃO}

\subsection{Variação Genética}

Os indivíduos selvagens provenientes das regiões AL, RS, IC, PB, RN, PoA, Pt, CH e DuF e os seis indivíduos da colônia em cativeiro da ESALQ foram genótipados com os marcadores Ami $\mu 08,11,13,20$, Cla $\mu 2,05,06,07,08,09,10$ e os seus genótipos são apresentados no APÊNDICE 2.

No total foram genotipados 132 indivíduos em nove populações naturais de Caiman latirostris. O número de alelos encontrados foi de 166, considerando todas populações. As diferenças quanto a presença e freqüências dos alelos estão no Anexo 1. Os totais de alelos por marcador foram Ami $\mu 8$ (2 alelos), Ami $\mu 11$ (9 alelos), Ami $\mu 13$ (16 alelos), Ami $\mu 20$ (18 alelos), Cla $\mu 2$ (20 alelos), Cla $\mu 5$ (19 alelos), Cla $\mu 6$ (14 alelos), Cla $\mu 7$ (12 alelos), Cla $\mu 8$ (16 alelos), Cla $\mu 9$ (20 alelos), Cla $\mu 10$ (20 alelos). Dos 166 alelos possíveis, considerando todos os marcadores, as populações apresentaram: AL (74 alelos), RS (46 alelos), IC (47 alelos), PoA (40 alelos), PT (58 alelos), CH (56 alelos) e DuF (55 alelos), demonstrando como se distribui a variabilidade nestas populações. Em estudos anteriores com a espécie amostrada no Estado de São Paulo, foi encontrado um total de 142 alelos, sendo assim vinte e quatro alelos neste estudo são novos.

Alguns alelos de algumas populações são exclusivos como pode ser observado na Tabela 3. 
Tabela 3. Alelos exclusivos encontrados nas nove populações de Caiman latirostris

\begin{tabular}{|c|c|c|c|c|c|c|c|}
\hline Pop & Locos & Alelo & frequência & Pop & Locos & Alelo & frequência \\
\hline $\mathrm{AL}$ & Аmi $\mu 11$ & 225 & 0,040 & IC & Cla $\mu 10$ & 264 & 0,056 \\
\hline $\mathrm{AL}$ & Ami $\mu 20$ & 162 & 0,020 & $\mathrm{IC}$ & Cla $\mu 10$ & 268 & 0,111 \\
\hline $\mathrm{AL}$ & 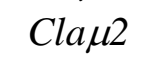 & 209 & 0,080 & IC & Cla $\mu 10$ & 274 & 0,222 \\
\hline $\mathrm{AL}$ & Cla 2 & 243 & 0,020 & IC & Cla $\mu 10$ & 272 & 0,222 \\
\hline $\mathrm{AL}$ & Cla 2 & 211 & 0,020 & PT & Ami $\mu 13$ & 254 & 0,475 \\
\hline $\mathrm{AL}$ & Cla 55 & 157 & 0,120 & PT & Ami $\mu 20$ & 108 & 0,026 \\
\hline $\mathrm{AL}$ & Сla 66 & 127 & 0,020 & PT & Ami $\mu 20$ & 106 & 0,026 \\
\hline $\mathrm{AL}$ & Cla 66 & 131 & 0,020 & $\mathrm{PT}$ & Ami $\mu 20$ & 146 & 0,026 \\
\hline $\mathrm{AL}$ & Cla 46 & 231 & 0,100 & PT & Cla $\mu 2$ & 241 & 0,175 \\
\hline $\mathrm{AL}$ & Cla $\mu 7$ & 185 & 0,360 & PT & Cla $\mu 5$ & 161 & 0,025 \\
\hline $\mathrm{AL}$ & Сlа $\mu 8$ & 113 & 0,180 & PT & Cla $\mu 7$ & 247 & 0,050 \\
\hline $\mathrm{AL}$ & Cla $\mu 8$ & 103 & 0,560 & $\mathrm{PT}$ & Cla $\mu 8$ & 133 & 0,175 \\
\hline $\mathrm{AL}$ & Сla 9 & 153 & 0,040 & $\mathrm{PT}$ & Сla $\mu 8$ & 149 & 0,025 \\
\hline $\mathrm{AL}$ & Сla 9 & 143 & 0,040 & $\mathrm{PT}$ & Cla $\mu 10$ & 248 & 0,025 \\
\hline $\mathrm{AL}$ & Cla 49 & 141 & 0,020 & $\mathrm{PT}$ & Cla $\mu 10$ & 244 & 0,250 \\
\hline $\mathrm{CH}$ & Аmi $\mu 11$ & 243 & 0,042 & PoA & $\operatorname{Ami} \mu 20$ & 116 & 0,056 \\
\hline $\mathrm{CH}$ & Ami $\mu 20$ & 140 & 0,045 & PoA & Cla $\mu 5$ & 187 & 0,167 \\
\hline $\mathrm{CH}$ & Cla 6 & 161 & 0,042 & PoA & Cla $\mu 7$ & 227 & 0,056 \\
\hline DuF & Ami $\mu 20$ & 120 & 0,023 & PoA & Cla $\mu 7$ & 223 & 0,055 \\
\hline DuF & Ami $\mu 20$ & 164 & 0,045 & PB & Ami $\mu 11$ & 217 & 0,083 \\
\hline DuF & Cla 66 & 219 & 0,043 & $\mathrm{~PB}$ & Ami $\mu 13$ & 274 & 0,083 \\
\hline DuF & Cla $\mu 7$ & 213 & 0,043 & PB & Cla $\mu 2$ & 213 & 0,125 \\
\hline DuF & Cla 49 & 179 & 0,234 & $\mathrm{~PB}$ & Cla $\mu 5$ & 197 & 0,042 \\
\hline IC & Ami $\mu 13$ & 256 & 0,055 & RN & Cla $\mu 2$ & 225 & 0,100 \\
\hline IC & Cla 2 & 239 & 0,1111 & RN & Cla $\mu 2$ & 219 & 0,300 \\
\hline IC & Cla 2 & 237 & 0,3333 & $\mathrm{RN}$ & Cla $\mu 10$ & 206 & 0,100 \\
\hline IC & Cla 55 & 203 & 0,0555 & RS & Сla $\mu 6$ & 241 & 0,088 \\
\hline IC & Cla 55 & 215 & 0,111 & RS & Cla $\mu 8$ & 141 & 0,205 \\
\hline IC & Cla 55 & 159 & 0,500 & $\mathrm{RS}$ & Cla $\mu 9$ & 167 & 0,088 \\
\hline IC & Cla $\mu 8$ & 105 & 0,222 & & & & \\
\hline
\end{tabular}


Segundo Frankel e colaboradores (1996), a maior equidade nas freqüências dos alelos numa população, seria um indicador de maior diversidade genética.

Populações que apresentam maior diversidade estariam mais protegidas dos efeitos de deriva do que as que têm alelos muito menos freqüentes do que outros, que estariam mais susceptíveis de serem perdidos. Embora tenham sido encontrados alelos privados de cada população, uma amostragem maior em cada local poderia revelar maior uniformidade de presença dos alelos encontrados em todas populações.

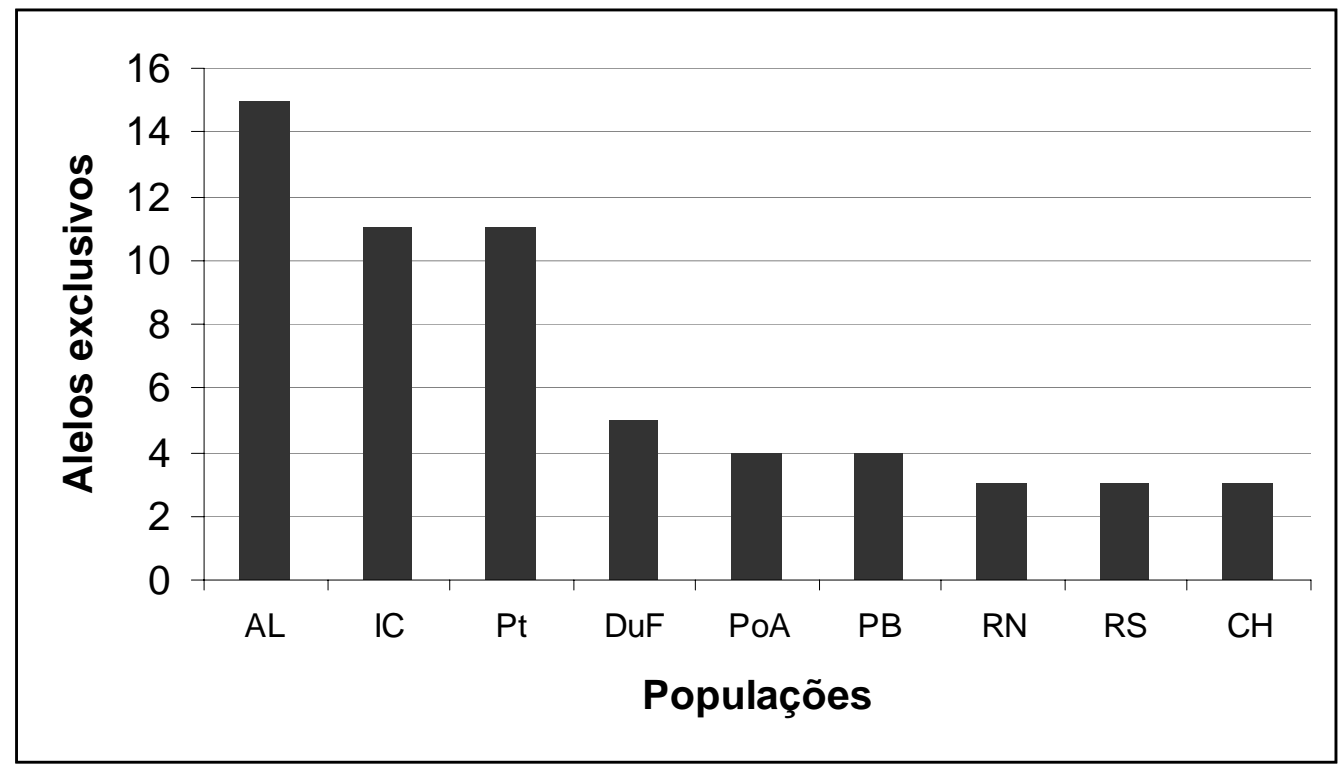

Figura 4 - Número de alelos exclusivos, identificados por microssatélites, em nove populações de Caiman latirostris

Como podemos observar foram detectado vários alelos exclusivos dentro das populações e alguns ocorrem com determinada freqüência, fato interessante para identificação forense (identificação da origem de carne, couro ou de determinado indivíduo).

Os onze locos microssatélites usados nas análises genéticas efetuadas nesse trabalho detectaram níveis elevados de diversidade alélica em todas as populações de Caiman latirostris, confirmando o elevado conteúdo de informação genética esperado 
para este tipo de marcador, em estrutura genética de populações. O conhecimento da distribuição da variabilidade genética entre e dentro de populações naturais é muito interessante para a adoção de estratégias eficientes para conservação e plano de manejo.

\subsection{Diferenciação gênica e genotípica}

A diferenciação gênica e genotípica para todos os pares de populações amostradas são apresentadas no APÊNDICE 3. Os testes mostraram que, de maneira geral, todas as populações diferem entre si. Algumas diferenças não significativas em algumas comparações merecem ser analisadas mais detalhadamente. Na maioria das vezes que ocorreu diferença gênica significativa entre duas populações, esta foi acompanhada de diferença genotípica significativa. As diferenças encontradas entre as populações é melhor estudada usando estatísticas Rho.

\subsection{Heterozigosidade observada $\left(\mathrm{H}_{0}\right)$, diversidade gênica $\left(\mathrm{H}_{\mathrm{e}}\right)$ e teste exato para equilíbrio de Hardy-Weinberg}

Para os 11 locos analisados, as populações apresentaram níveis elevados de diversidade gênica ou heterozigosidade esperada $\left(\mathrm{H}_{\mathrm{e}}\right)$, variando entre 0,559 (RS) e 0,673 (CH), nesta análise foi acrescentado indivíduos da população mantida em cativeiro da ESALQ e esta apresentou maior diversidade gênica $(0,738)$, o que era de se esperar pois o seus fundadores são provenientes de diversas regiões brasileiras. A heterozigosidade observada $\left(\mathrm{H}_{0}\right)$ variou entre 0,487 (IC) e 0,687 (PoA), Tabela 4.

Em razão da heterozigosidade média observada ter sido inferior a heterozigosidade esperada em quase todas as populações, ficou caracterizado a presença de excesso de homozigotos. O aumento de homozigotos indicou a possível existência de um processo endogâmico, decorrente de desvio de panmixia, e/ou 
deriva genética, em razão da fragmentação da população original, ou efeito do fundador.

A média de alelos por loco foi também considerada alta. O índice de fixação médio de todas as dez populações ( $\mathrm{f}=0,096$ ) revelou um nível relativamente baixo de endogamia, indicando pouco desvio de panmixia devido ao sistema reprodutivo, ou seja pouca endogamia dentro destas populações. A população com maior nível de endogamia ( $f=0,208$ ) foi a de Alagoas, cujo índice foi significativo, apesar de apresentar a maior riqueza alélica de todas as populações.

Tabela 4. Estimativa da diversidade gênica (h), heterozigosidade observada $\left(\mathrm{H}_{\mathrm{o}}\right)$ e Î́ndice de fixação (f)

\begin{tabular}{cccc}
\hline População & $\mathrm{h}$ & $\mathrm{H}_{\mathrm{o}}$ & $\mathrm{f}$ \\
\hline $\mathrm{AL}$ & 0,613 & 0,487 & 0,208 \\
RS & 0,559 & 0,508 & 0,094 \\
IC & 0,580 & 0,485 & 0,172 \\
PB & 0,584 & 0,492 & 0,162 \\
RN & 0,673 & 0,582 & 0,150 \\
PoA & 0,629 & 0,687 & $-0,098$ \\
CH & 0,673 & 0,612 & 0,096 \\
DuF & 0,580 & 0,553 & 0,046 \\
PT & 0,649 & 0,589 & 0,095 \\
CAT & 0,738 & 0,682 & 0,084 \\
\hline Média & 0,628 & 0,568 & 0,096 \\
\hline
\end{tabular}

Considerando o tamanho das amostras, apenas os desvios do equilíbrio de Hardy-Weinberg ocorridos ao nível de 1 \% serão analisados como importantes. Os desvios do equilíbrio de Hardy-Weinberg (Anexo 2), quando ocorreram foram na maioria característicos das populações e não dos marcadores. Houve deficiência significativa de heterozigotos ( $\mathrm{p} \leq 0,01$ ) na população AL para o marcador Cla 2 , 
Cla $\mu 5$, Cla $\mu 6$, Cla $\mu 7$ е Cla $\mu 9$, RS para Cla $\mu 7$, Cla $\mu 8$ е Cla $\mu 9$, PB para o marcador Cla $\mu 9$, PoA para Cla 22 , PT para os marcadores Ami $\mu 20$, Cla 22 e Cla $\mu 6, \mathrm{CH}$ para os marcadores Ami $\mu 11$ e Cla $\mu 2$, DuF para os marcadores Ami $\mu 20$ e Cla $\mu 6$. As populações IC e RN não apresentaram desvios do equilíbrio de Hardy-Weinberg ao nível de $1 \%$ para nenhum marcador. Na maioria das vezes que houve o desvio do equilíbrio, a heterozigosidade esperada foi maior que a observada mostrando assim uma deficiência de heterozigotos nas populações, apenas houve excesso de heterozigotos ( $\mathrm{p} \leq 0,01$ ) nas populações $\mathrm{RS}, \mathrm{CH}$ e DuF com o marcador Ami $\mu 11$, população PT com o marcador Cla $\mu 7$ e população DuF com o marcador Cla $\mu$ 9.

\subsection{Estrutura Genética}

$\mathrm{O}$ valor $\mathrm{R}_{\mathrm{ST}}$ estimado foi de 0,342 e o $\mathrm{F}_{\mathrm{ST}}$ foi de 0,271 . As duas estimativas foram significativamente diferentes de zero ao nível de 1 \%. Estas duas medidas de estruturação genética foram aqui consideradas em função de que as duas estimativas possuem importantes vantagens e quando comparadas numericamente, acredita-se ser possível detectar se houve problemas de erros durante a genotipagem dos marcadores microssatélite.

Enquanto o valor $F_{S T}$ é baseado na probabilidade de identidade por descendência através do modelo de alelos infinitos (infinite allele model), a estatistica $\mathrm{R}_{\mathrm{ST}}$ considera o modelo de mutação aos passos (stepwise mutation model) onde os alelos podem ser idênticos por estado, apenas porque a mutação agiu aumentando ou diminuindo o tamanho dos alelo unidades repetitivas (Rousset,1996).

De acordo com Slatkin (1995), este segundo modelo é mais apropriado para análise de locos com taxas de mutação elevada, como é o caso dos microssatélites.

Em estudo com duas populações de Alligator mississipiesis originárias do Rockfeller Wild Refuge (RWR) no Estado da Louisiania e do Everglades National 
Park no Estado da Florida, também foi encontrado divergências entre estas duas populações (Glenn, 1998). Os totais para onze locos analisados foram $R_{S T}=0,387 \mathrm{e}$ $F_{S T}=0,137$.

A incorporação do stepwise model ao cálculo do índice de divergência entre populações proposto por Slatkin (1995), foi capaz de detectar melhor a divergência entre as duas populações estudadas. Isto provavelmente deveu-se ao fato de que neste modelo os alelos com tamanhos próximos são considerados mais semelhantes do que aqueles com tamanhos muito diferentes, evidenciando sua vantagem em relação as estatísticas $F$, quando o marcador estudado é microssatélite. Em nossas análises foi considerada apenas a estimativa $R_{S T}$ para discussões, já que esta detectou melhor a divergência entre populações.

A estimativa de Rho foi alta na maioria dos locos utilizados indicando que há uma grande diferenciação entre estas populações, como pode ser observado na Tabela 5.

Tabela 5. Estatísticas Rho para as populações estudadas

\begin{tabular}{|c|c|c|c|c|c|}
\hline Locos & $2 n$ & $\begin{array}{c}\text { Média da } \\
\text { amostra }\end{array}$ & SA & SW & Rho \\
\hline Аті $\mu 08$ & 132 & 28,610 & 0,411 & 0,778 & 0,346 \\
\hline Атін11 & 132 & 28,610 & 0,084 & 0,987 & 0,078 \\
\hline Ami $\mu 13$ & 132 & 28,610 & 0,274 & 0,906 & 0,232 \\
\hline Аті $\mu 20$ & 129 & 27,965 & 0,133 & 0,767 & 0,148 \\
\hline Cla $\mu 02$ & 120 & 25,842 & 0,701 & 0,311 & 0,692 \\
\hline Cla $\mu 05$ & 131 & 28,412 & 0,031 & 1,330 & 0,023 \\
\hline Cla $\mu 06$ & 126 & 27,044 & 0,434 & 0,530 & 0,450 \\
\hline Cla $\mu 07$ & 132 & 28,610 & 0,516 & 0,529 & 0,494 \\
\hline Cla $\mu 08$ & 124 & 26,714 & 0,203 & 0,717 & 0,221 \\
\hline Cla $\mu 09$ & 132 & 28,610 & 0,683 & 0,387 & 0,638 \\
\hline Cla $\mu 10$ & 124 & 26,798 & 0,531 & 0,434 & 0,550 \\
\hline Média & & & 0,364 & 0,698 & 0,342 \\
\hline
\end{tabular}

Com base nos dados deste onze locos polimórficos verificou-se que 34,2 \% da variabilidade genética encontra-se entre populações e 65,8\% está dentro 
população, pois a média de Rho calculada sobre componentes de variação foi 0,342 (Tabela 6). Esse resultado foi indicativo que as populações de C. latirostris estudada encontra-se em forte processo de diferenciação. Espécie com ampla distribuição geográfica freqüentemente desenvolvem populações adaptadas localmente que, na maioria das vezes, são geneticamente distintas.

Esta média é considerada como alta. A estitística Rho teve seu intervalo de confiança estimado para o nível de 95\% construído com 1000 bootstrap, método de reamostragem onde pares de indivíduos foram a unidade de reamostragem. O conhecimento da distribuição da variabilidade genética entre e dentro de populações naturais é muito interessante para a adoção de estratégia eficiente para conservação e plano de manejo.

Tabela 6. Resultados das estatísticas Rho sobre os componentes de variação

\begin{tabular}{ccccccc}
\hline & Rho & \multicolumn{2}{c}{ IC 95 \% } & Média & Variância & Erro \\
\cline { 3 - 4 } Rho & observado & inferior & superior & de Rho & & padrão \\
& 0,34268 & 0,3412 & 0,3977 & 0,3686 & 0,00000 & 0,0012 \\
\hline
\end{tabular}
Obs.: Número de ramdomizações igual a 1000 .

As estimativas foram estaticamente diferente de zero para maior parte das comparações par a par entre as populações estudadas (Tabela 4), indicando assim uma subdivisão entre estas populações, exceção feita a comparação entre a população de Natal (RN) e a população de João Pessoa (PB), onde observamos o valor de $\mathrm{R}_{\mathrm{ST}}$ igual a -0,009, mostrando que não há diferença genética entre estas duas populações. Estes resultado podem ser confirmados pelas diferenças gênica e genotípica encontradas entre pares destas populações ( APÊNDICE 3) .

As estatísticas Rho e a distância $(\delta \mu)^{2}$ foram calculados para cada par de populações (Tabela 6). A maioria das comparações entre pares destas populações foi significativa ao nível de $1 \%$, mostrando que há uma alta variabilidade genética entre as populações, com exceção da comparação entre PB e RN como destacado anteriormente. 
Tabela 7. Valores de Rho e $(\delta \mu)^{2}$ comparando as populações de Caiman latirostris

\begin{tabular}{|c|c|c|c|c|c|}
\hline POP1 & POP2 & Rho & $\mathrm{P}$ & $(\delta \mu)^{2}$ & DG \\
\hline RN & PB & 0,0092 & $0,04540 *$ & 0,0733 & 157 \\
\hline PT & $\mathrm{CH}$ & 0,11439 & $0,00090 * *$ & 0,30612 & 12 \\
\hline PoA & $\mathrm{DuF}$ & 0,11458 & $0,00240 * *$ & 0,20776 & 95 \\
\hline $\mathrm{CH}$ & DUF & 0,13777 & $0,00010 * *$ & 0,28434 & 110 \\
\hline POA & $\mathrm{CH}$ & 0,16754 & $0,00080 * *$ & 0,39396 & 26 \\
\hline $\mathrm{AL}$ & PB & 0,20176 & $0,00000 * *$ & 0,31918 & 365 \\
\hline AL & $\mathrm{RN}$ & 0,20640 & $0,00140 * *$ & 0,34907 & 467 \\
\hline RS & RN & 0,21842 & $0,00160 * *$ & 0,36888 & 3466 \\
\hline PoA & PT & 0,21960 & $0,00000 * *$ & 0,52121 & 15 \\
\hline RS & PB & 0,25418 & $0,00010 * *$ & 0,41554 & 3352 \\
\hline PB & $\mathrm{CH}$ & 0,26470 & $0,00000 * *$ & 0,61749 & 2197 \\
\hline PT & DUF & 0,27313 & $0,00000 * *$ & 0,60622 & 105 \\
\hline $\mathrm{RN}$ & $\mathrm{CH}$ & 0,28681 & $0,00040 * *$ & 0,69820 & 2299 \\
\hline AL & RS & 0,29476 & $0,00000 * *$ & 0,43106 & 2986 \\
\hline RS & $\mathrm{CH}$ & 0,30133 & $0,00000 * *$ & 0,65187 & 1199 \\
\hline $\mathrm{RN}$ & PT & 0,30725 & $0,00050 * *$ & 0,76988 & 2311 \\
\hline PB & PoA & 0,31027 & $0,00000 * *$ & 0,64257 & 2223 \\
\hline RS & PT & 0,31289 & $0,00000 * *$ & 0,69575 & 1187 \\
\hline $\mathrm{RN}$ & PoA & 0,31616 & $0,00110 * *$ & 0,67215 & 2325 \\
\hline PB & PT & 0,31711 & $0,00000 * *$ & 0,78866 & 2209 \\
\hline RS & PoA & 0,36062 & $0,00000 * *$ & 0,69465 & 1175 \\
\hline $\mathrm{AL}$ & $\mathrm{CH}$ & 0,36708 & $0,00000 * *$ & 0,86517 & 1840 \\
\hline AL & IC & 0,36893 & $0,00000 * *$ & 0,94985 & 2062 \\
\hline IC & $\mathrm{RN}$ & 0,40154 & $0,00010^{* *}$ & 1,18714 & 2535 \\
\hline РB & DuF & 0,40633 & $0,00000 * *$ & 0,84143 & 2266 \\
\hline RS & $\mathrm{DuF}$ & 0,40702 & $0,00000 * *$ & 0,73135 & 1170 \\
\hline $\mathrm{RN}$ & $\mathrm{DuF}$ & 0,40863 & $0,00000 * *$ & 0,85342 & 2363 \\
\hline IC & $\mathrm{PT}$ & 0,41885 & $0,00000 * *$ & 1,50790 & 273 \\
\hline AL & PT & 0,42876 & $0,00000 * *$ & 1,13130 & 1851 \\
\hline IC & PB & 0,42916 & $0,00000 * *$ & 1,34450 & 2425 \\
\hline $\mathrm{AL}$ & POA & 0,42983 & $0,00000 * *$ & 0,92062 & 1866 \\
\hline RS & IC & 0,46264 & $0,00000 * *$ & 1,35540 & 935 \\
\hline IC & $\mathrm{CH}$ & 0,46803 & $0,00000 * *$ & 0,17900 & 284 \\
\hline $\mathrm{AL}$ & $\mathrm{DuF}$ & 0,47369 & $0,00000 * *$ & 0,96357 & 1912 \\
\hline IC & PoA & 0,52097 & $0,00000 * *$ & 1,91680 & 247 \\
\hline IC & DuF & 0,54546 & $0,00000 * *$ & 1,94610 & 307 \\
\hline
\end{tabular}

Número de permutação igual a 10000, DG = Distância Geográfica em Km. 
Os dados da Tabela 7 foram organizados em ordem crescente de diferenciação Rho entre os pares de populações. Desta forma pode-se dizer que as populações mais isoladas geneticamente são IC e DuF com Rho igual a 0,545 e com distância geográfica igual $307 \mathrm{Km}$, o que sugere previamente que a variação genética não esta acompanhando a distância geográfica. O par mais próximo foi PB e RN com Rho igual a -0,0092 e com distância geográfica igual 157Km. A diferença genética não significativa entre $\mathrm{PB}$ e RN indica que pode estar havendo um fluxo gênico entre estas populações e elas não estão isoladas por distância.

As diferenciações encontradas em populações próximas geograficamente como DuF, PoA, CH e Pt eram esperadas como descrito por Zucoloto (2003) e previamente discutido em Verdade et. al. (2002), onde os autores concluíram que o cenário que melhor explica a variação microgeográfica encontrada é o de metapopulações pequenas com pouco fluxo de indivíduos entre elas dificultando o fluxo gênico e fazendo com que as freqüências de alelos e de genótipos se diferenciem entre as populações ao longo do tempo.

As demais populações onde a distância geográfica é alta, apresentaram alto valor de Rho o que indica grande divergência entre as populações e fluxo gênico restrito. Estes resultados sugerem que as populações estudadas estão sofrendo os efeitos da deriva genética devido à ausência de fluxo, causada pelo isolamento por distância.

O intervalo de confiança de 95 \% para a estimativa das estatísticas Rho para os pares de populações testadas foi construído com 1000 randomizações e como pode ser observado na Tabela 8, tanto as medidas observadas quanto a média destas estimativas ficaram dentro do intervalo construído. 
Tabela 8 - Resultados das estatísticas Rho calculados sobre os componentes de variação para as populações de Caiman latirostris estudadas

\begin{tabular}{|c|c|c|c|c|c|c|c|}
\hline \multirow[t]{2}{*}{ Pop1 } & \multirow[t]{2}{*}{ Pop2 } & \multirow[t]{2}{*}{$\begin{array}{c}\text { Rho } \\
\text { observado }\end{array}$} & \multicolumn{2}{|c|}{ IC $\quad 95 \%$} & \multirow[t]{2}{*}{$\begin{array}{l}\text { Média } \\
\text { de Rho }\end{array}$} & \multirow[t]{2}{*}{ Variância } & \multirow[t]{2}{*}{$\begin{array}{c}\text { Erro } \\
\text { padrão }\end{array}$} \\
\hline & & & Inferior & Superior & & & \\
\hline $\mathrm{AL}$ & $\mathrm{RS}$ & 0,29476 & 0,2565 & 0,3689 & 0,3110 & 0,00002 & 0,0043 \\
\hline AL & IC & 0,36893 & 0,3303 & 0,4668 & 0,3966 & 0,00004 & 0,0059 \\
\hline $\mathrm{AL}$ & PB & 0,20176 & 0,1507 & 0,3229 & 0,2270 & 0,00005 & 0,0070 \\
\hline $\mathrm{AL}$ & $\mathrm{RN}$ & 0,20640 & 0,1462 & 0,4134 & 0,2584 & 0,00015 & 0,0123 \\
\hline $\mathrm{AL}$ & PoA & 0,42983 & 0,3982 & 0,5030 & 0,4502 & 0,00002 & 0,0047 \\
\hline $\mathrm{AL}$ & $\mathrm{Pt}$ & 0,42876 & 0,3762 & 0,5181 & 0,4469 & 0,00003 & 0,0054 \\
\hline $\mathrm{AL}$ & $\mathrm{CH}$ & 0,36708 & 0,3293 & 0,4452 & 0,3853 & 0,00002 & 0,0047 \\
\hline $\mathrm{AL}$ & DuF & 0,47369 & 0,4268 & 0,5379 & 0,4844 & 0,00002 & 0,0040 \\
\hline RS & IC & 0,46264 & 0,4429 & 0,5482 & 0,4881 & 0,00003 & 0,0053 \\
\hline RS & $\mathrm{PB}$ & 0,25418 & 0,1705 & 0,4051 & 0,2821 & 0,00012 & 0,0108 \\
\hline RS & $\mathrm{RN}$ & 0,21842 & 0,2164 & 0,3740 & 0,2775 & 0,00008 & 0,0087 \\
\hline $\mathrm{RS}$ & PoA & 0,36062 & 0,3349 & 0,4498 & 0,3857 & 0,00003 & 0,0058 \\
\hline RS & $\mathrm{PT}$ & 0,31289 & 0,2637 & 0,4092 & 0,3341 & 0,00004 & 0,0061 \\
\hline RS & $\mathrm{CH}$ & 0,30133 & 0,2596 & 0,3869 & 0,3240 & 0,00003 & 0,0058 \\
\hline $\mathrm{RS}$ & DuF & 0,40702 & 0,3692 & 0,4793 & 0,4223 & 0,00002 & 0,0043 \\
\hline IC & PB & 0,42916 & 0,3974 & 0,5403 & 0,4583 & 0,00006 & 0,0078 \\
\hline IC & $\mathrm{RN}$ & 0,40154 & 0,3944 & 0,5345 & 0,4486 & 0,00009 & 0,0092 \\
\hline IC & PoA & 0,52097 & 0,4911 & 0,6113 & 0,5455 & 0,00005 & 0,0071 \\
\hline IC & $\mathrm{Pt}$ & 0,41885 & 0,3722 & 0,5211 & 0,4439 & 0,00005 & 0,0068 \\
\hline IC & $\mathrm{CH}$ & 0,46803 & 0,4378 & 0,5476 & 0,4897 & 0,00004 & 0,0061 \\
\hline IC & DuF & 0,54546 & 0,5198 & 0,6242 & 0,5645 & 0,00002 & 0,0046 \\
\hline $\mathrm{PB}$ & $\mathrm{RN}$ & $-0,00929$ & $-0,0325$ & 0,2235 & 0,0687 & 0,00024 & 0,0154 \\
\hline $\mathrm{PB}$ & PoA & 0,31027 & 0,2457 & 0,4425 & 0,3390 & 0,00012 & 0,0108 \\
\hline $\mathrm{PB}$ & PT. & 0,31711 & 0,2719 & 0,4167 & 0,3420 & 0,00004 & 0,0065 \\
\hline $\mathrm{PB}$ & $\mathrm{CH}$ & 0,26470 & 0,2281 & 0,3551 & 0,2900 & 0,00005 & 0,0070 \\
\hline $\mathrm{PB}$ & DF & 0,40633 & 0,3444 & 0,5157 & 0,4247 & 0,00005 & 0,0074 \\
\hline $\mathrm{RN}$ & PoA & 0,31616 & 0,2816 & 0,4711 & 0,3699 & 0,00015 & 0,0124 \\
\hline $\mathrm{RN}$ & $\mathrm{Pt}$ & 0,30725 & 0,2331 & 0,4682 & 0,3480 & 0,00015 & 0,0121 \\
\hline $\mathrm{RN}$ & $\mathrm{CH}$ & 0,28681 & 0,2595 & 0,4095 & 0,3322 & 0,00009 & 0,0095 \\
\hline $\mathrm{RN}$ & DuF & 0,40863 & 0,3821 & 0,5347 & 0,4503 & 0,00005 & 0,0073 \\
\hline PoA & $\mathrm{Pt}$ & 0,21960 & 0,1474 & 0,3558 & 0,2469 & 0,00009 & 0,0097 \\
\hline PoA & $\mathrm{CH}$ & 0,16754 & 0,1087 & 0,3106 & 0,1997 & 0,00013 & 0,0114 \\
\hline PoA & DuF & 0,11458 & 0,0609 & 0,2454 & 0,1446 & 0,00007 & 0,0083 \\
\hline $\mathrm{Pt}$ & $\mathrm{CH}$ & 0,11439 & 0,0710 & 0,2299 & 0,1418 & 0,00005 & 0,0071 \\
\hline $\mathrm{Pt}$ & DuF & 0,27313 & 0,2120 & 0,3802 & 0,2930 & 0,00004 & 0,0066 \\
\hline $\mathrm{CH}$ & DuF & 0,13777 & 0,0946 & 0,2561 & 0,1590 & 0,00005 & 0,0068 \\
\hline
\end{tabular}

Obs.: Número de ramdomizações : 1000 
O padrão de diferenciação genética entre as nove populações de Caiman latirostris e a população de cativeiro da ESALQ foram definidos pelo critério de agrupamento UPGMA, resultando em um dendrograma apresentado na figura 5, cujo teste de associação entre a matriz de diferenciação genética $\left(\mathrm{R}_{\mathrm{ST}}\right)$ e a respectiva matriz cofenética obtida foi de $\mathrm{r}=0,93$ e probabilidade de $\mathrm{Z}$ aleatório ser menor que o Z observado $\mathrm{p}=1.0000$. Sob 9999 permutações o modelo respondeu com a consistência de 9999 terem sido menores que Z, 0 iguais a $\mathrm{Z}$ e 0 maiores que Z, com a comparação observada não incluída nesta contagem e desta forma o teste unicaudal foi p $(\mathrm{Z}$ aleatório $\geq \mathrm{Z})=0,0001$, indicando que a árvore de diferenciação explica 93\% dos dados da matriz original (Rho).

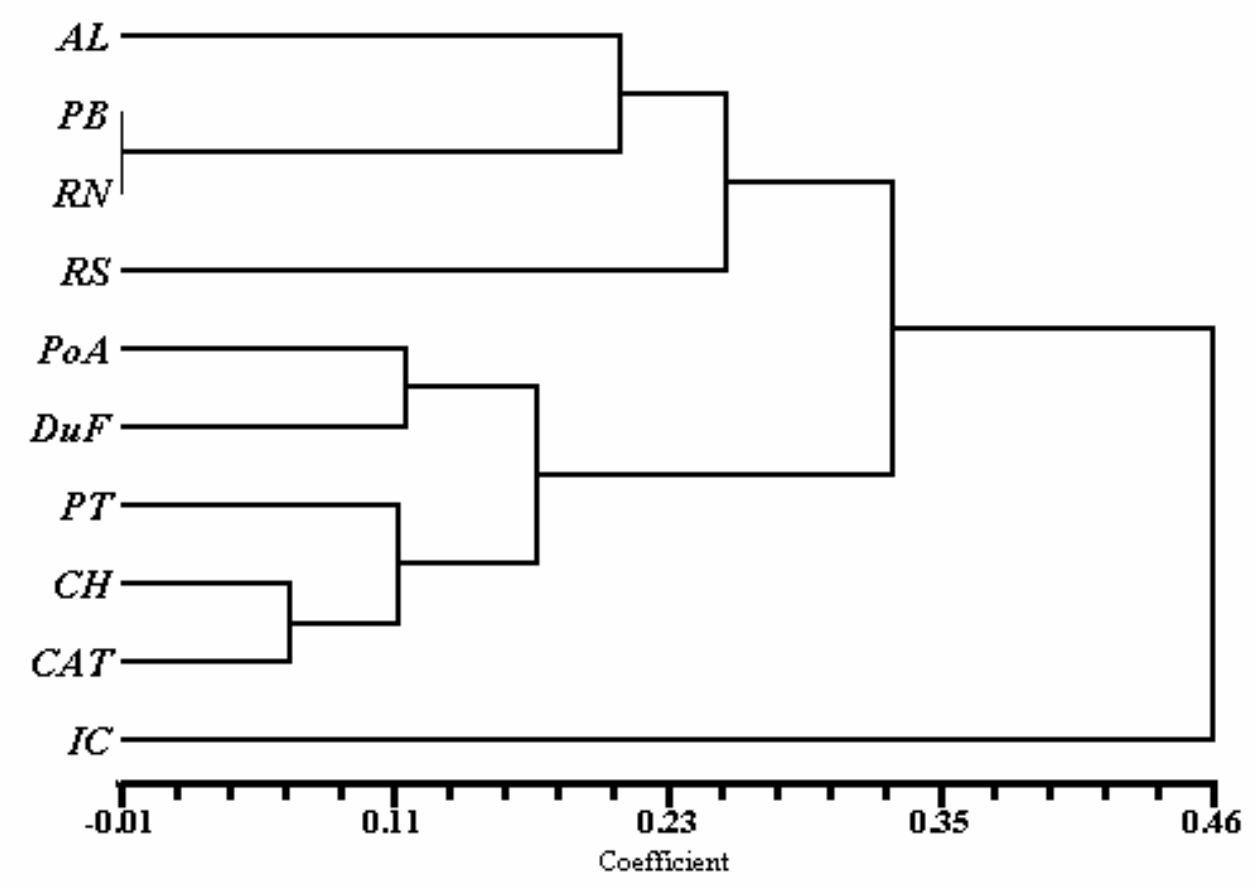

Figura 5 - Padrão de diferenciação genética obtido pela estatística Rho entre as populações de Caiman latirostris definidos pelo critério de agrupamento UPGMA 
A população do litoral (IC) mesmo não estando muito distante geograficamente das populações paulista apresentou maiores índices de diferenciação, indicando que a serra do mar possivelmente esta agindo como barreira geográfica, impedindo este fluxo ao longo do tempo, levando a um isolamento que parece maior do que seria resultado apenas da distância geográfica.

Com estes dados o que podemos dizer em relação à população de cativeiro da ESALQ é que esta população se agrupa com as populações da região de Piracicaba e apresenta altos valores de diferenciação em relação às demais populações, assim inferimos que não está representando a diversidade genética da espécie como um todo no Brasil, o que era esperado, pois com uma diferenciação genética tão grande como encontrada nestas populações, somente se fosse amostrado alguns individuo de cada região teríamos uma boa representatividade.

Podemos dizer que a população de Cativeiro está representando bem a diversidade das populações da região de Piracicaba e como mencionado anteriormente possui uma alta diversidade genética, maior do que todas as populações estudadas.

\subsection{Correlação entre distância geográfica e variação genética}

Para verificar se haviam correlação entre distância geográfica e diferenciação genética, submeteu-se as matrizes dessas distância ao teste de Mantel. O coeficiente de correlação obtido foi baixo e não significativo ( $r=0,236$, $p=0,1119$ ) indicando que não há correlação significativa entre as matrizes (Figura 6A).

Esta análise de correlação entre as matrizes de distância geográfica e genética foi novamente realizada retirando-se a população da Ilha do Cardoso (IC), pois no caso desta população, a Serra do Mar parece ser uma barreira eficiente, o que poderia estar “mascarando” o possível efeito da distância genética entre as outras populações dispostas ao longo do gradiente latitudinal da espécie (Figura 6B). 
A.

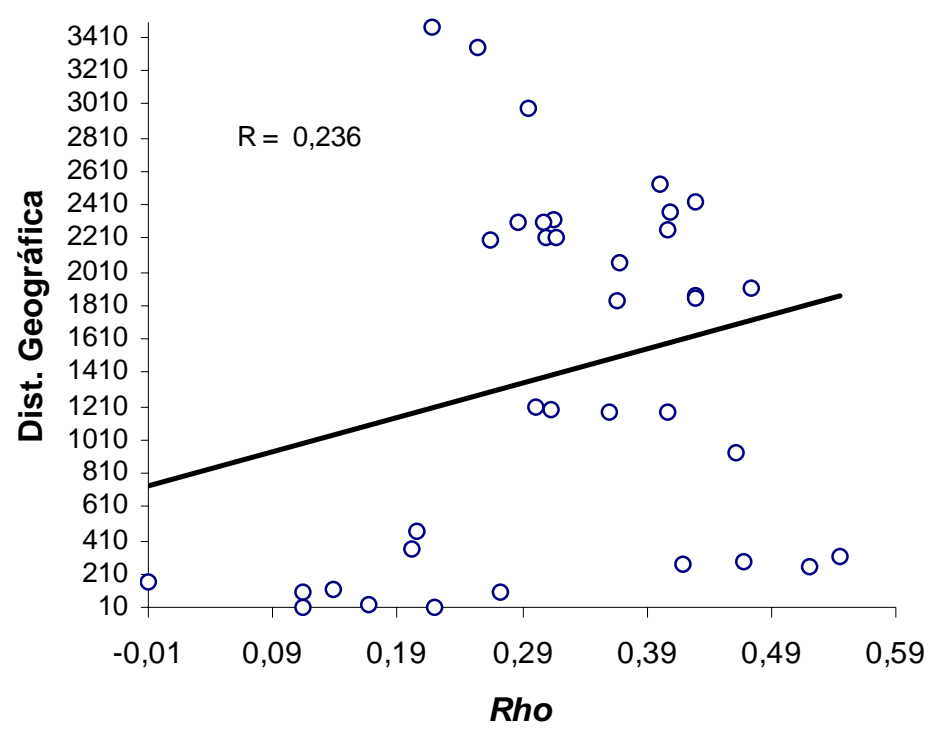

B.

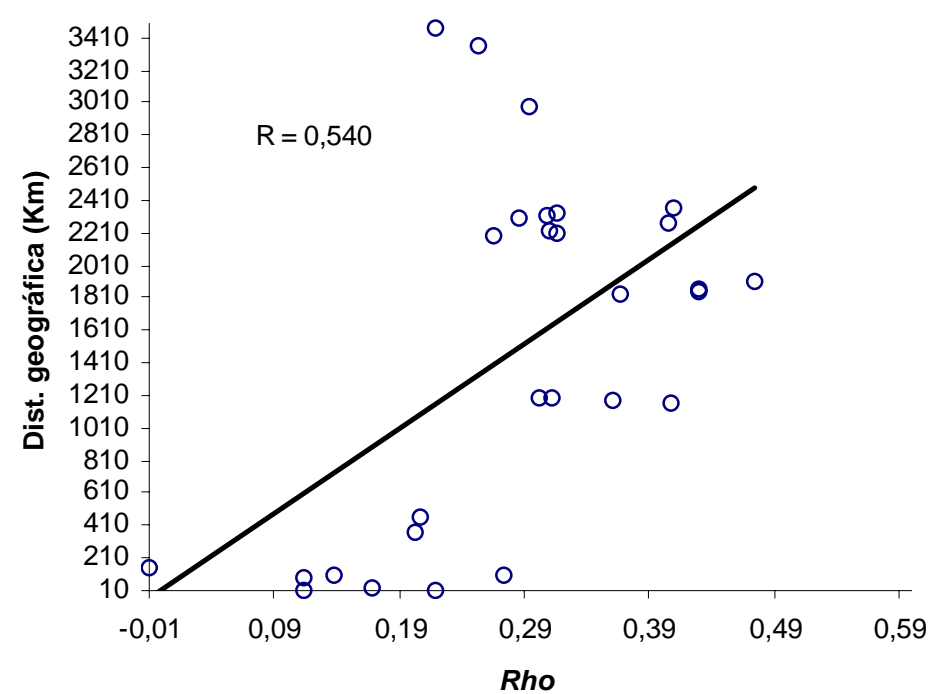

Figura 6 - Gráfico de correlação entre as matrizes de distância geográfica e diferenciação genética (Rho). Todas as nove populações de Caiman latirostris incluídas na análise (A); retirando-se a população da Ilha do Cardoso(B) 
Quando retirou-se a população da ilha do Cardoso nesta análise (Figura 6B) o teste de associação entre a matriz de diferenciação genética (Rho) e a matriz de distância geográfica teve índice de correlação $\mathrm{r}=0,540, \mathrm{p}=0,0110$ indicando que há correlação moderada significativa entre as matrizes, onde pode ser notado um maior padrão espacial da variabilidade genética. Esta correlação positiva entre as matrizes de divergência genética e distância geográfica indica que o modelo de isolamento por distância explica 54\% da divergência genética entre as populações. Desta forma podemos ter uma idéia de como o fluxo genico age em relação a escala geográfica .

\subsection{Estimação dos coeficientes parentesco}

A estimativa de coeficientes de parentesco entre pares de indivíduos foi calculada pelo método de Informação utilizando o programa SANCHO (Coelho, 2001). Este método foi utilizado neste trabalho, pois possui a vantagem de considerar a existência de endogamia nas populações.

A presença de alguns irmãos dentro de populações foi constatada, mas estes indivíduos não foram eliminados para análises posteriores, pois pode-se perder mais com a eliminação de um indivíduo do que trabalhar com possíveis erros na estimativa alélica, já que em algumas populações o número amostral é reduzido (Coelho, comunicação pessoal).

Zucoloto (2003), agrupou os indivíduos da colônia em cativeiro, pelo método UPGMA utilizando o parentesco de Coelho (2001) e como o parentesco em cativeiro já era conhecido o autor identificou que os irmãos completos se agrupavam com valor alto de parentesco $(0,236-0,259)$ e os indivíduos que tinham parentesco paterno ou materno se agrupavam com valores de 0,082 a 0,133. Isto tornou a análise capaz de identificar pares de indivíduos irmãos completos na natureza em amostragem de indivíduos com idades muito próximas, só que não é possível identificar é a relação de paternidade, maternidade ou outra relação de parentesco originária de diferentes gerações amostradas. 
Com estes dados de referência podemos ter uma estimativa do parentesco entre e dentro das nove populações estudadas. Na tabela 9 temos as médias dos parentescos encontrado nas populações estudadas.

Tabela 9. Médias dos parentescos encontrado nas nove populações de Caiman latrostris estudadas.

\begin{tabular}{lc}
\hline Categoria & Parentesco médio \\
\hline indivíduo, com ele mesmo & 0,497 \\
irmãos germanos & 0,245 \\
meios irmãos & 0,113 \\
outros & $-0,082$ \\
\hline
\end{tabular}

As médias dos coeficientes de parentesco entre as nove populações foram todas negativas, indicando assim que o parentesco médio entre estas populações pode ser considerado como nulo, o que era esperado devido a grande diferenciação genética encontrada.

O parentesco foi baixo mesmo entre os indivíduos das populações de João Pessoa (PB) e Natal (RN), onde a diferenciação genética não foi significativa. Entretanto mesmo o parentesco médio destas populações sendo negativo observamos agrupamento de alguns indivíduos, indicando assim parentesco entre eles .

Na Figura 7 podemos observar que os indivíduos 7, 8 e 9 da população de João Pessoa (PB) estão agrupados com os indivíduos 2 e 4 da população de Natal (RN), com o coeficiente de parentesco de aproximadamente 0,12. Este coeficiente de parentesco esta entre o parentesco de de 0,082 a 0,133 encontrado por Zucoloto (2003) para indivíduos que tinham parentesco paterno ou materno, confirmando assim migração destes indívídos de uma população para outra . 


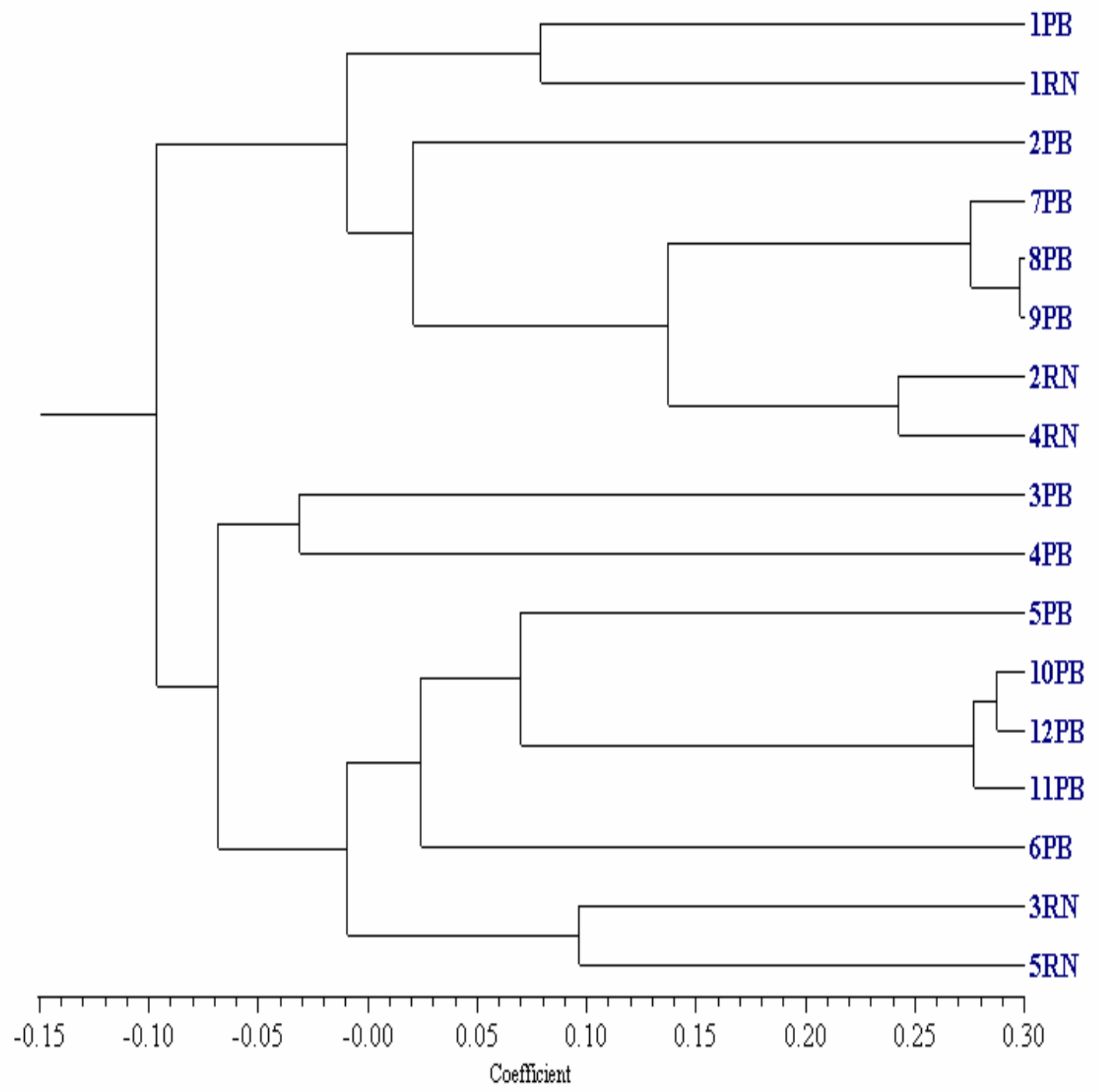

Figura 7 - Parentesco entre as populações de Caiman latirostris de João Pessoa (PB) e Natal (RN) 
Os parentescos dentro das populações foram agrupados pelo método UPGMA para cada uma das nove populações e estão apresentados na forma de dendrograma (Figuras 8 a 16), deste modo podemos avaliar como se distribui o parentesco dentro das nove populações estudadas.

Como conseqüência das observações anteriores, indivíduos que se apresentam agrupados com elevado nível de parentesco no dedrograma, devem ser pais e filhos (coeficientes superiores a 0,082) ou irmãos (coeficientes superiores a 0,236), estas informações têm que ser aliadas a informações de campo para que haja uma melhor interpretação de parentesco entre os indivíduos.

Na figura 8, referente ao Parentesco dos indivíduos da população da Ilha do Cardoso, observou-se um agupamento entre os indivíduos 2, 3 e 4 com o coeficiente de parentesco superior a 0,24, indicando assim que estes indivíduos são irmãos, fato confirmado pelos dados de campo onde os indivíduos capturados apresentaram a mesma coordenadas geográficas, o mesmo sexo e os tamanhos foram aproximadamente os mesmos (Tabela 10). Os agrupamentos superiores a 0,24 também foram confirmados com os dados de campo para indivíduos da população de João Pessoa (Tabela 11), pois os indivíduos que se agruparam foram amostrados no mesmo sítio e apresentavam aproximadamente o mesmo peso. Os indivíduos que foram considerados irmãos, estão em negrito nas tabelas 10 e 11 . Alguns indivíduos não tiveram os dados de campo coletado não podendo assim ser aliados para confirmar o parentesco.

O método de agrupamento de indivíduos por UPGMA utilizando o parentesco de Coelho (2001), parece estar correspondendo as relações de parentesco entre estes indivíduos, pois todos os coeficientes altos de parentesco que tinham os dados de campo coletado, foram confirmados. 


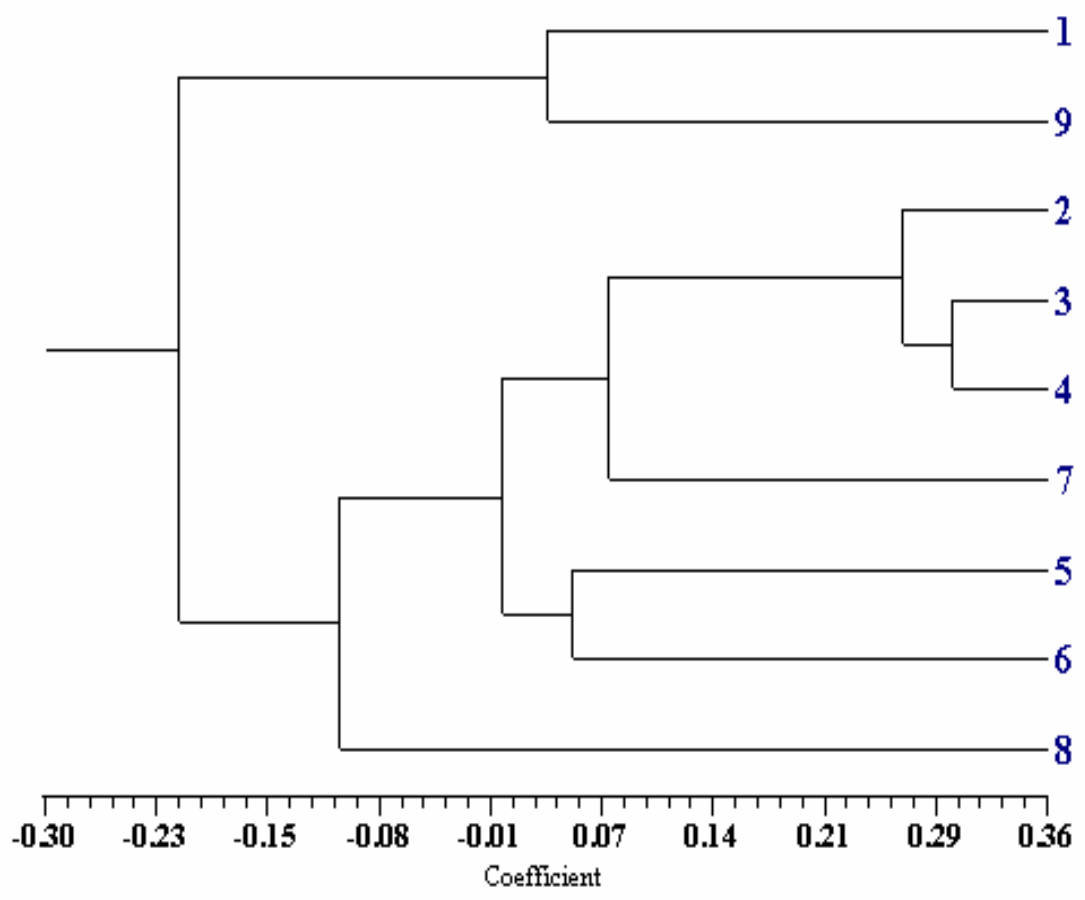

Figura 8 - Parentesco dentro da População de C. latirostris da Ilha do Cardoso (IC)

Tabela 10. Dados de campo dos indivíduos da população da Ilha do Cardoso (IC)

\begin{tabular}{|c|c|c|c|c|c|c|}
\hline Studbook & Ind. & SEXO & SVL & TTL & PESO (Kg) & Latitude - Longitude \\
\hline USP416 & 1 & Macho & 21.6 & 41.0 & 0,110 & $25^{\circ} 04.574{ }^{\prime} \mathrm{S}-47^{\circ} 54.913^{\prime} \mathrm{W}$ \\
\hline USP417 & 2 & Macho & 20.4 & 41.0 & 0,151 & $S-47^{\circ} 54.952 ’ W$ \\
\hline USP418 & 3 & Macho & 20.9 & 41.0 & 58 & $S-47^{\circ} 54.952 ’ W$ \\
\hline USP419 & 4 & Macho & 21.4 & 36.5 & 0,149 & 'S - 47 ${ }^{\circ} 54.952^{\prime} \mathrm{W}$ \\
\hline USP420 & 5 & Macho & 19.6 & 39.8 & 0,140 & $25^{\circ} 04.569^{\prime} \mathrm{S}-47^{\circ} 54.952^{\prime} \mathrm{W}$ \\
\hline USP421 & 6 & Macho & 19.6 & 39.5 & 0,131 & $25^{\circ} 04.569^{\prime} \mathrm{S}-47^{\circ} 54.952^{\prime} \mathrm{W}$ \\
\hline USP415 & 7 & Macho & 19.0 & 38.9 & 0,134 & $25^{\circ} 04.569^{\prime} \mathrm{S}-47^{\circ} 54.952^{\prime} \mathrm{W}$ \\
\hline USP422 & 8 & Fêmea & 80.5 & 148.5 & 15,0 & $25^{\circ} 04.183^{\prime} \mathrm{S}-47^{\circ} 54.987^{\prime} \mathrm{W}$ \\
\hline USP426 & 9 & Fêmea & 88.0 & 164.0 & 22,0 & $25^{\circ} 04.081^{\prime} \mathrm{S}-47^{\circ} 54.084^{\prime} \mathrm{W}$ \\
\hline
\end{tabular}

SVL = comprimento fucinho-cloaca; TTL = comprimento total; Ind. =indivíduo 


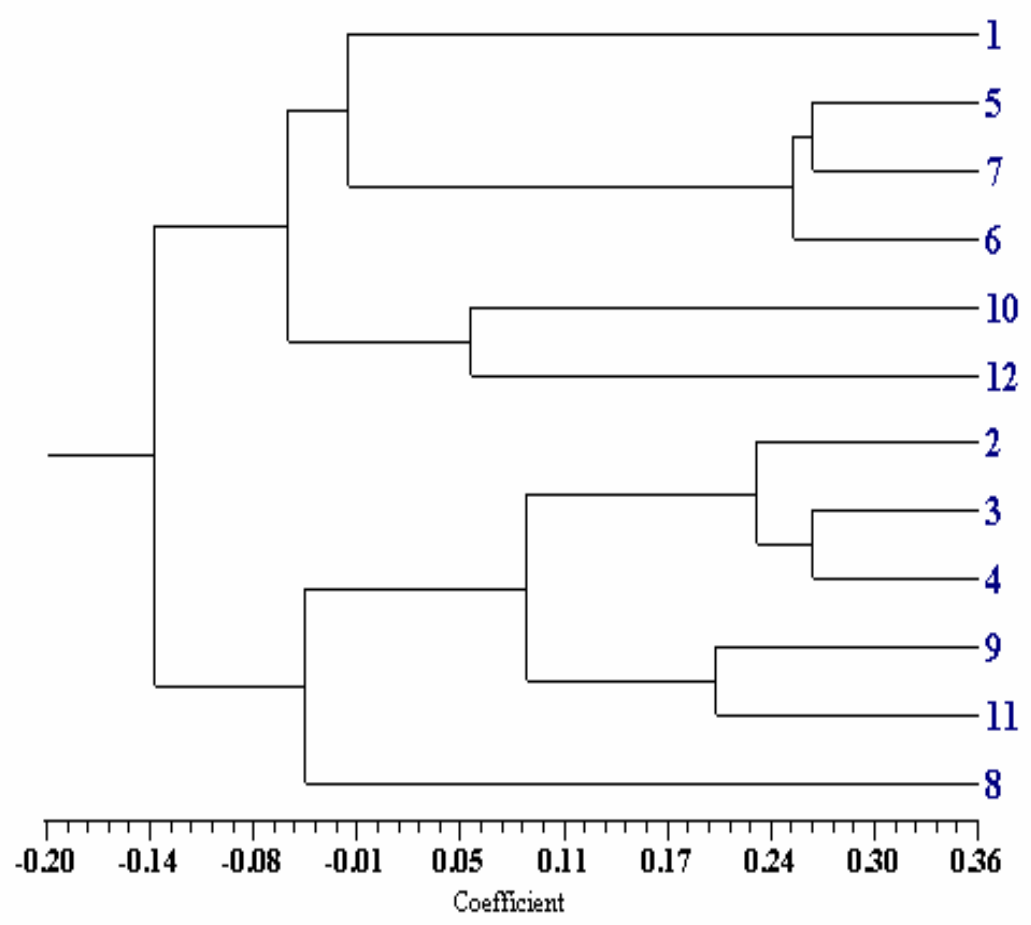

Figura 9 - Parentesco dentro da População de C. latirostris de João Pessoa (PB)

Tabela 11. Dados de campo dos indivíduos da população de João Pessoa.

\begin{tabular}{cccccc}
\hline Studbook & Indivíduos & SEXO & $\begin{array}{c}\text { SVL } \\
(\mathrm{cm})\end{array}$ & $\begin{array}{c}\text { TTL } \\
(\mathrm{cm})\end{array}$ & $\begin{array}{c}\text { PESO } \\
(\mathrm{Kg})\end{array}$ \\
\hline A & 1 & Macho & - & - & 0,200 \\
$\mathbf{B}$ & $\mathbf{2}$ & Macho & - & - & $\mathbf{0 , 1 6 5}$ \\
B & $\mathbf{3}$ & Macho & - & - & $\mathbf{0 , 1 7 0}$ \\
$\mathbf{B}$ & $\mathbf{4}$ & Macho & - & - & $\mathbf{0 , 1 4 0}$ \\
$\mathbf{C}$ & $\mathbf{5}$ & Macho & - & - & $\mathbf{0 , 0 7 0}$ \\
$\mathbf{C}$ & $\mathbf{6}$ & Macho & - & - & $\mathbf{0 , 0 5 5}$ \\
$\mathbf{C}$ & $\mathbf{7}$ & Macho & - & - & $\mathbf{0 , 0 5 0}$ \\
USP355 & 8 & Fêmea & 93,0 & 182,0 & 27,5 \\
USP356 & 9 & Macho & 105,5 & 204,5 & - \\
USP357 & 10 & Macho & 88,5 & 166,0 & - \\
USP358 & 11 & Macho & 111,0 & 213,0 & - \\
- & 12 & Macho & - & - & - \\
\hline SVL = comprimento fucinho-cloaca; TTL $=$ comprimento total; B=animais \\
coletados na ninhada B, C= animais coletados na ninhada C
\end{tabular}




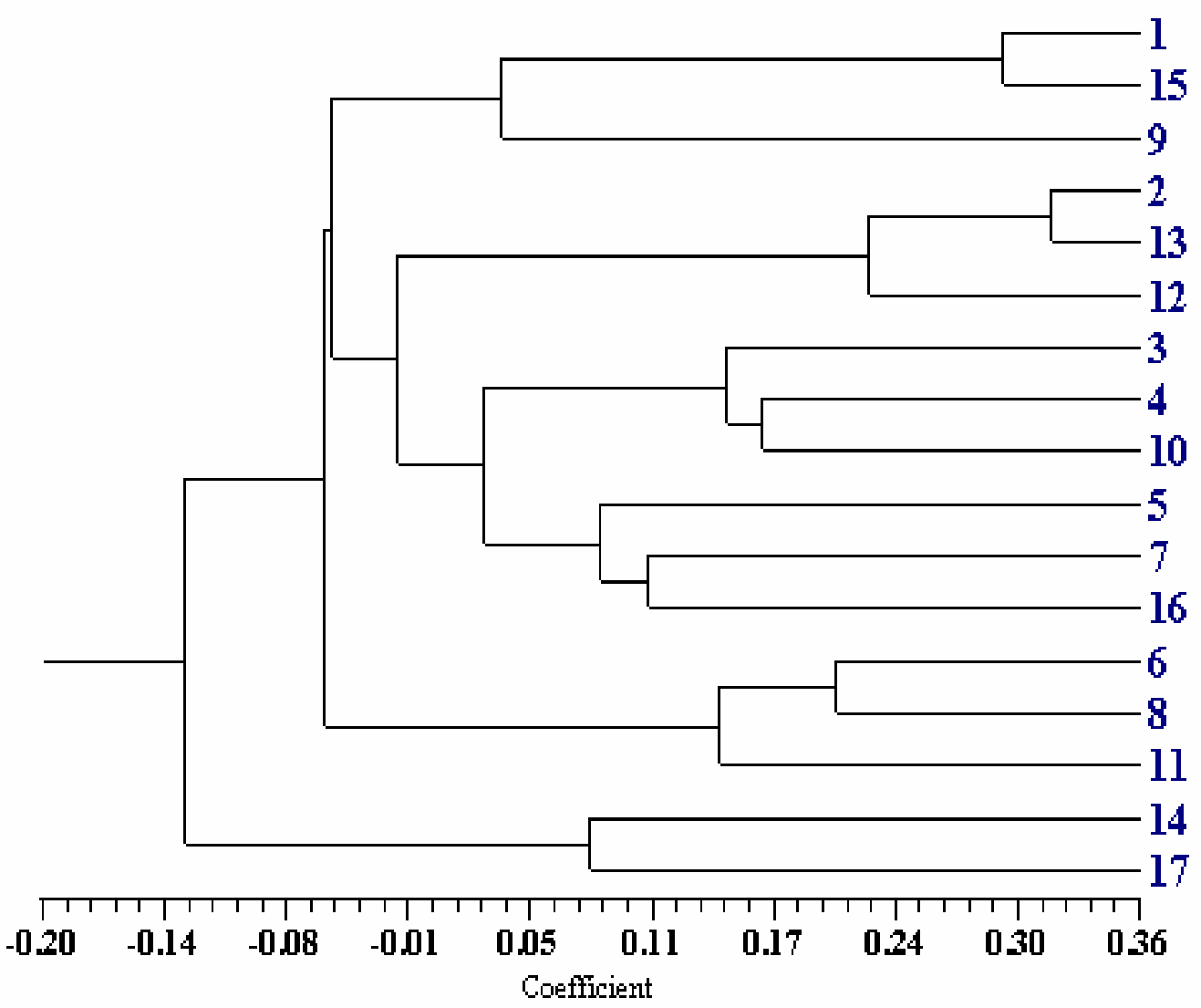

Figura 10 - Parentesco dentro da População de $\boldsymbol{C}$. latirostris do Banhado do Taim (RS) 


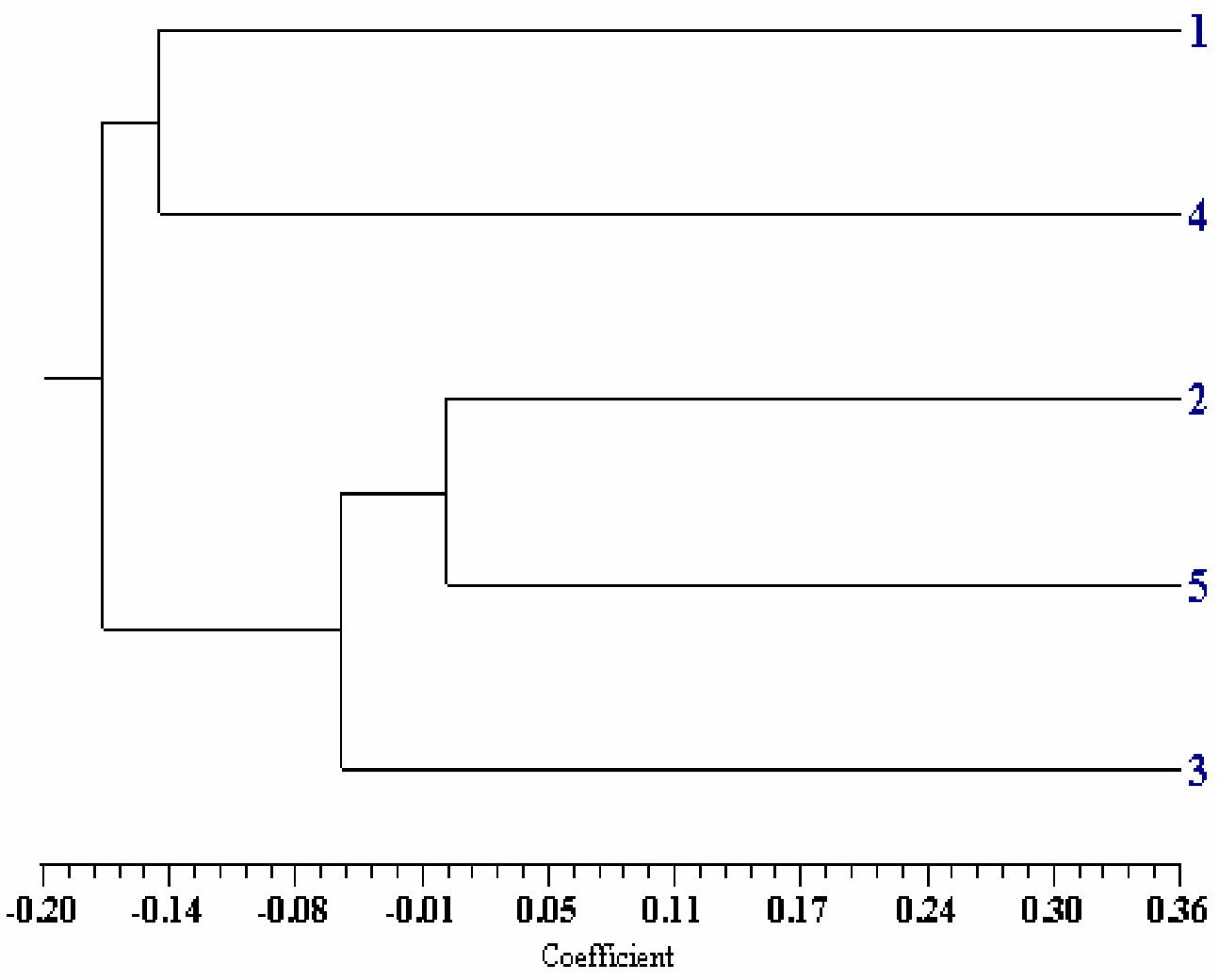

Figura 11 - Parentesco dentro da População de Caiman latirostris de Natal (RN) 


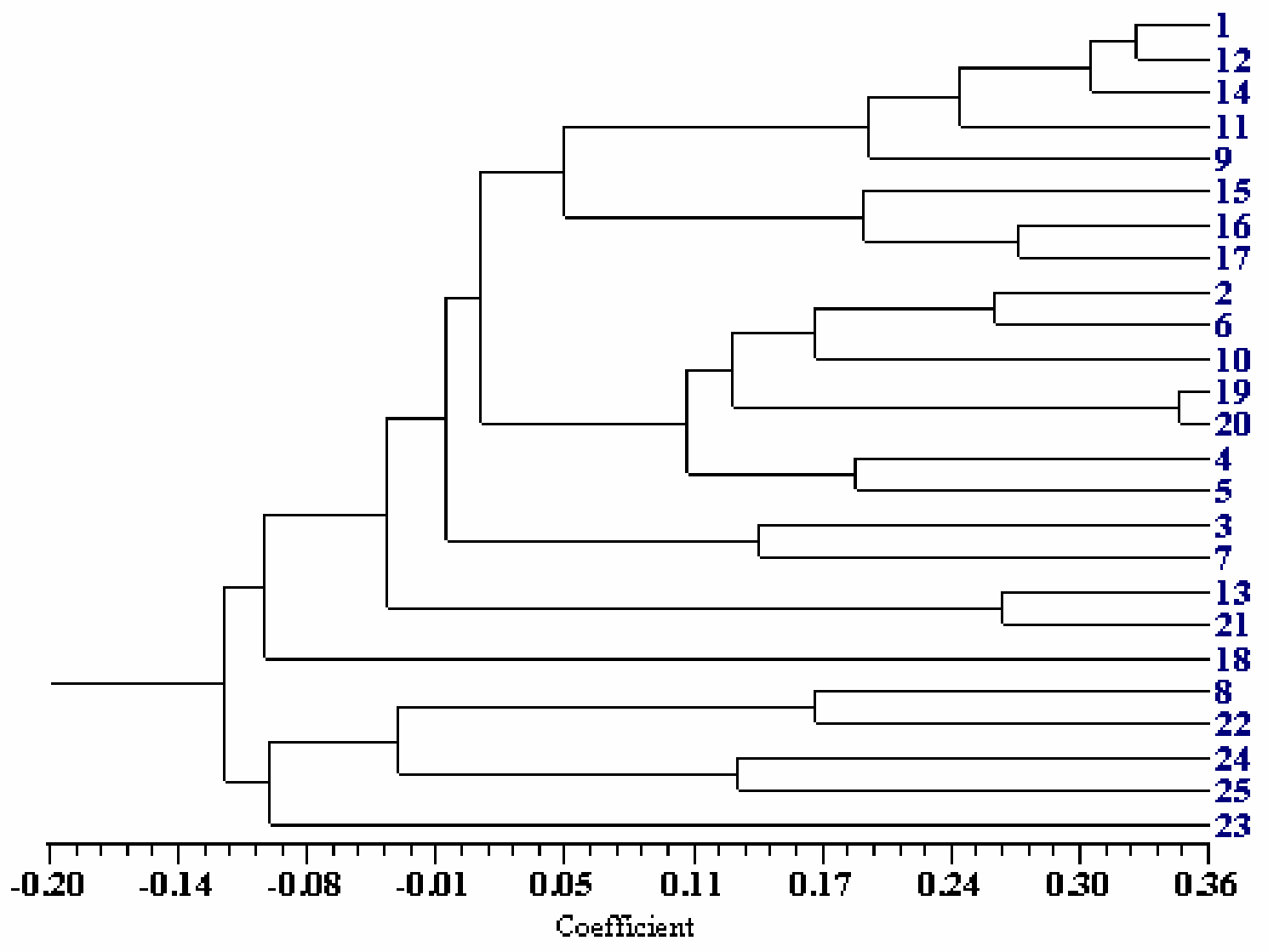

Figura 12 - Parentesco dentro da População de C. latirostris da Lagoa Vermelha (AL) 


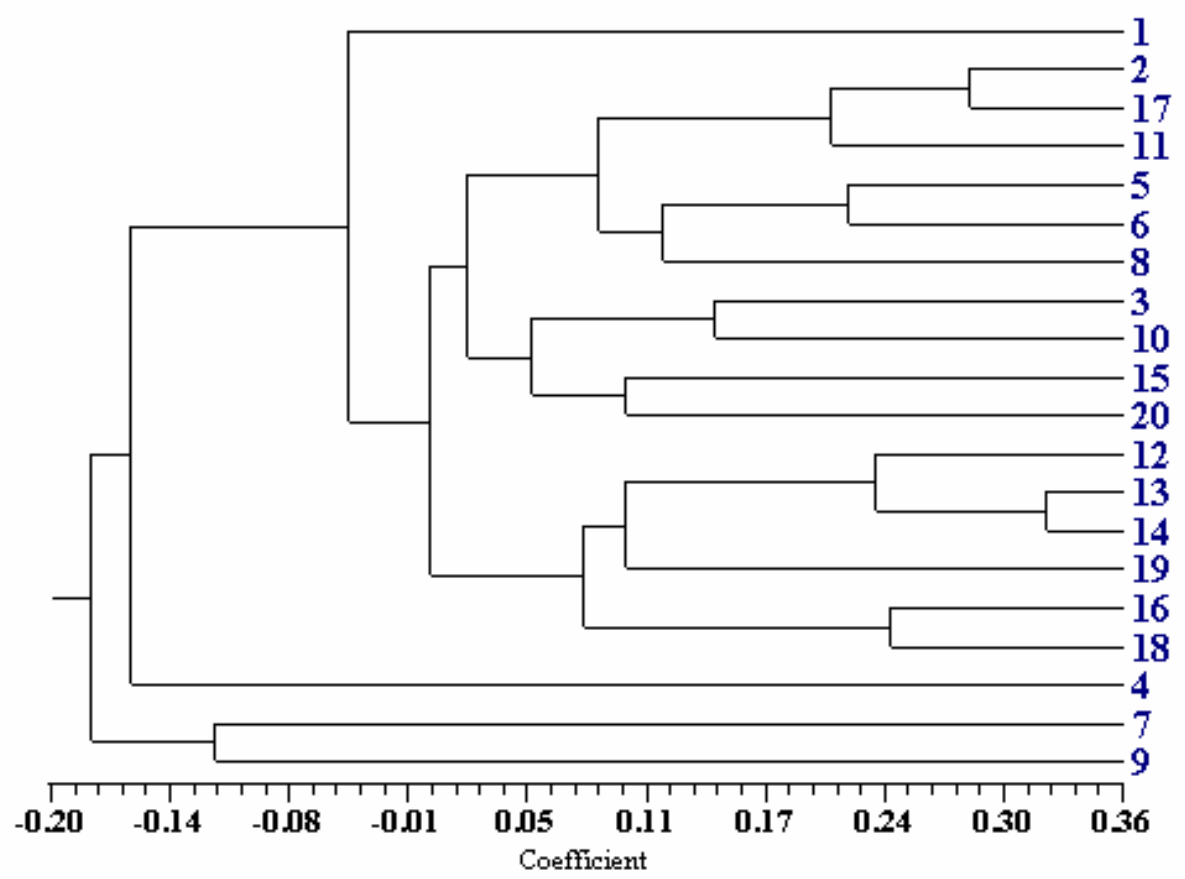

Figura 13 - Parentesco dentro da População de Caiman latirostris de Pantanal (Pt)

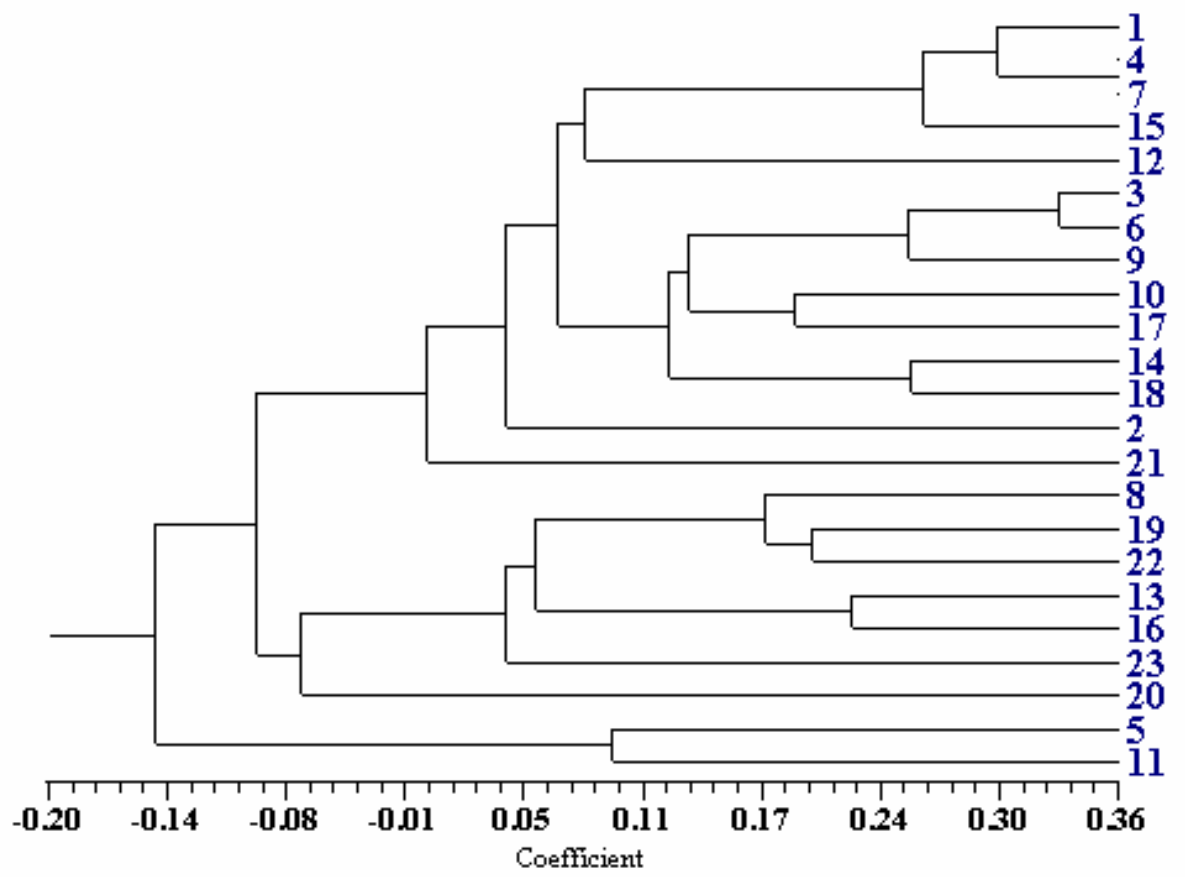

Figura 14 - Parentesco dentro da População de C. latirostris de duraflora (DuF) 


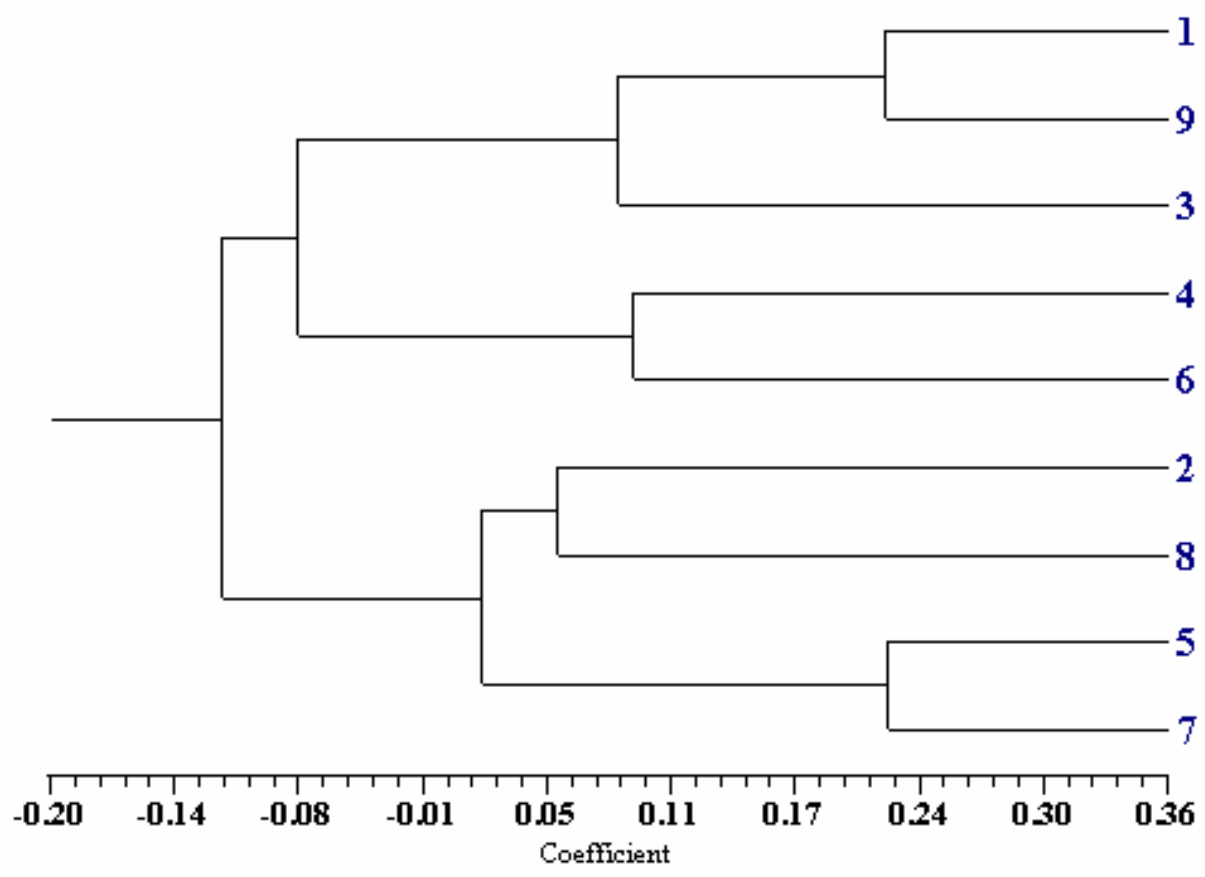

Figura 15 - Parentesco dentro da População de C. latirostris de Charqueada (CH)

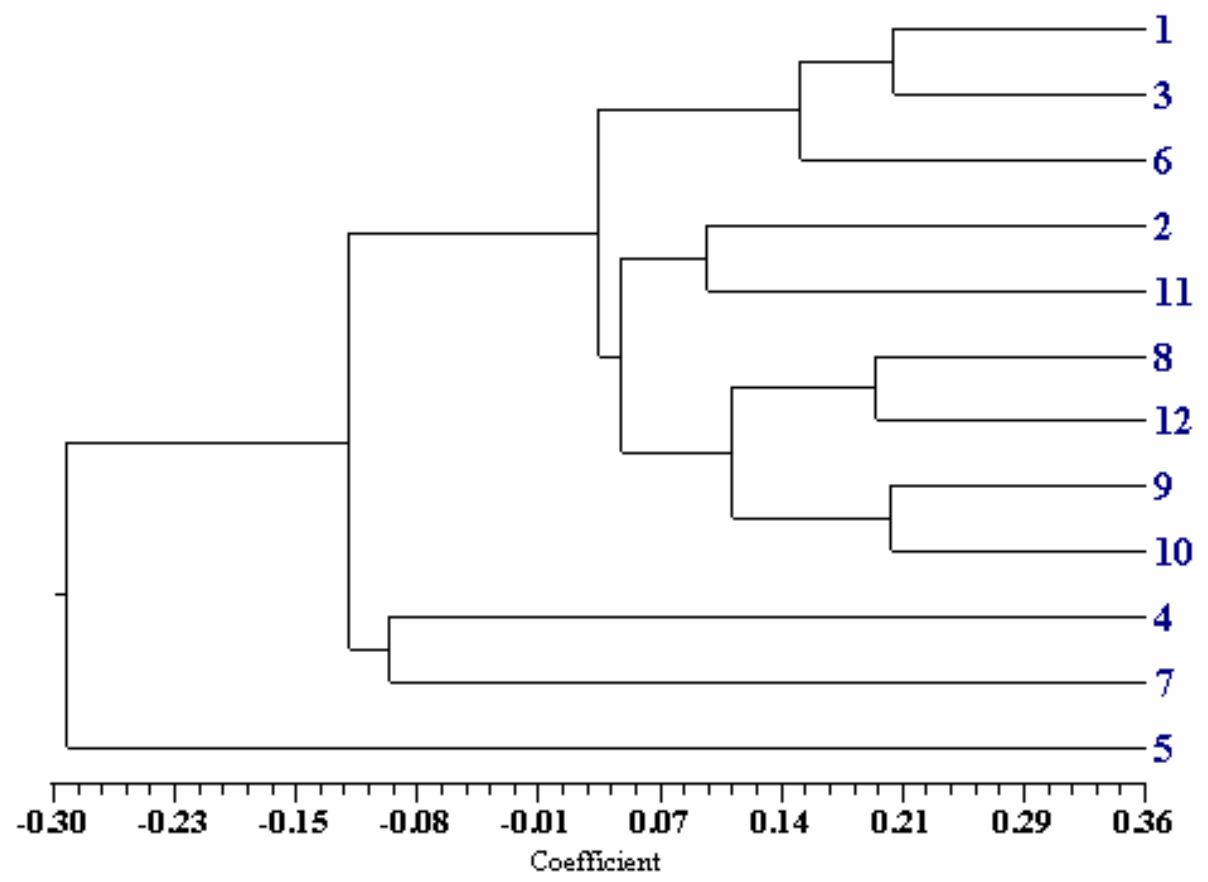

Figura 16- Parentesco dentro da População de C. latirostris de Porto de Areia (PoA) 


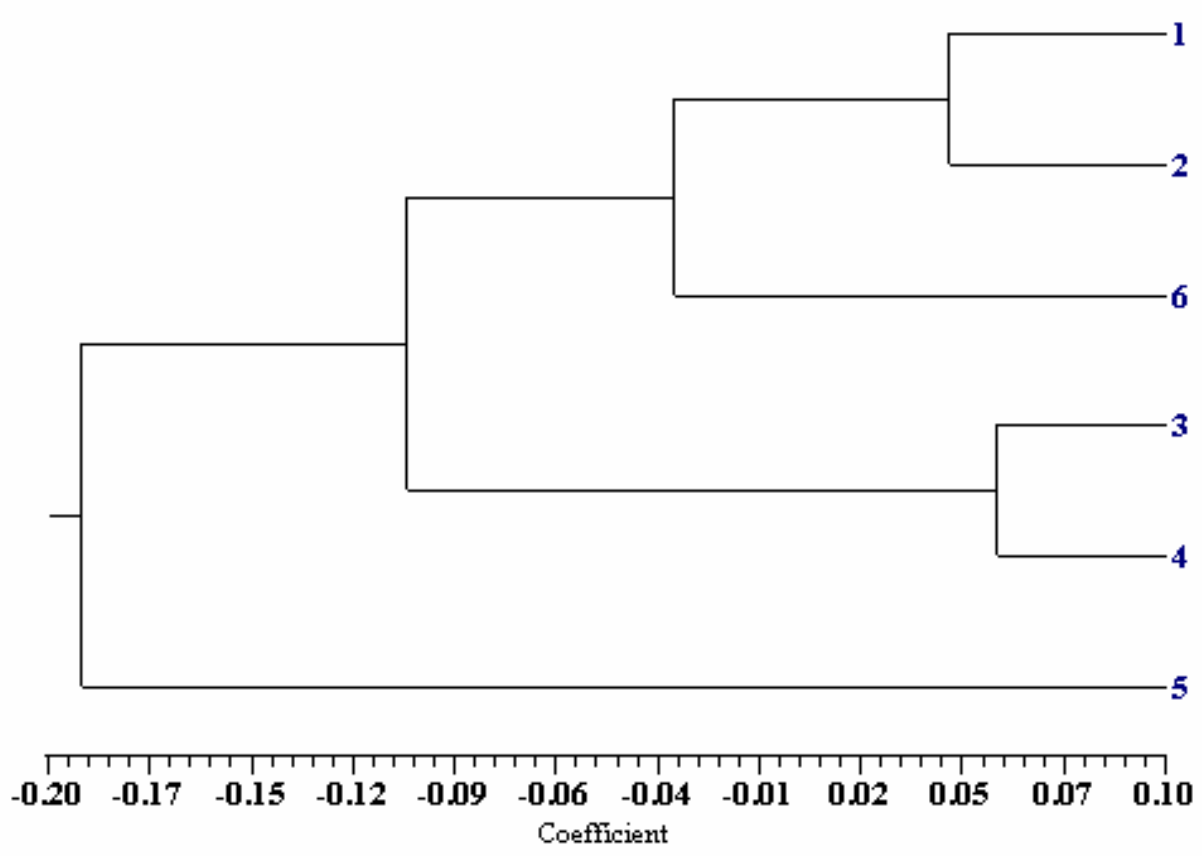

Figura 17 - Parentesco entre os indivíduos da colônia em cativeiro da ESALQ

O nível de parentesco médio encontrado entre indivíduos de uma mesma população sempre foi baixo, na maioria das vezes negativos. Isto sugere que as populações provavelmente originaram-se de muito poucos indivíduos aparentado.

A tabela 10 e 11 mencionado anteriormente descreve o numero de laboratório, o código do anilhamento, o sexo e tamanho de cada animal amostrado. O coeficiente de parentesco aliado a estes dados de campo confere maior eficácia as análises.

A identificação de parentesco entre indivíduos na natureza é muito importante para entender sua estrutura social. O conhecimento do parentesco entre indivíduos de populações naturais é considerado um refinamento da análise genética populacional, uma vez que pode auxiliar sobremaneira estudos de conservação, podendo auxiliar no estabelecimento de áreas de coleta, de maneira que a amostragem de indivíduos seja realizada entre aqueles menos aparentados. Assim, uma maior variabilidade genética pode ser mantida nas populações em cativeiro. 
Estas análises também são muito úteis para seleção genética de matrizes e reprodutores, pois com menor relação genética de parentesco, diminui a possibilidade de perda de variabilidade genética e ainda possibilita a certificação de origem de filhotes. 


\section{CONCLUSÕES}

- Os resultados obtidos demonstram a existência de alta variabilidade genética na espécie, ressaltada pelo elevado número de alelo por loco, alto nível de heterozigotos, e divergência entre as populações;

- A população paulista mesmo estando na zona intermediária de distribuição geográfica no Brasil não possui a maior variabilidade genética;

- A colônia em cativeiro da ESALQ representa bem a diversidade genética da espécie da região de São Paulo;

- A divergência entre as populações indica um processo preliminar de diferenciação. Esta divergência é mais acentuada em relação a população da Ilha do Cardoso, sugerindo que a distância genética entre a população do litoral e do interior é afetada pela existência da Serra do Mar como possível barreira geográfica;

- A divergência genética entre as populações acompanha em parte a distância geográfica, em termos de gradiente latitudinal. Isto sugere uma leve estruturação no espaço da variabilidade genética. Esta variabilidade provavelmente foi gerada por deriva e fluxo a pequenas distâncias. 


\section{CONSIDERAÇÕES FINAIS}

As implicações dessas análises de caracterização genética por meio de marcadores moleculares são importantes para o estudo de conservação, pois se uma espécie se apresenta estruturada em determinada área, então a estratégia de conservação deve procurar preservar a diversidade da espécie naquela área, uma vez que possíveis adaptações locais se perderiam caso uma população fosse misturada com outras. Então para estudos de recolonização ou conservação desta espécie (Caiman latirostris) não deve-se levar em conta somente a espécie, mas também as unidades de manejo, que no caso são as subpopulações diferenciadas geneticamente.

Em nossos estudos encontramos que as populações de Caiman latirostris estão estruturadas $\left(\mathrm{R}_{\mathrm{ST}}=0,342\right)$ e foi indicado uma relação entre diferenciação e distância geográfica ao longo de um transecto entre as latitudes de 5 e 32 graus sul, desde Rio Grande do Sul até o Rio Grande do Norte. A conseqüência para a conservação dessa espécie é que a preservação dos habitats deve ser feita ao longo da sua distribuição e se políticas de reintrodução forem necessária um dia, elas devem ser feitas a partir de estoques reprodutores específicos para cada região (estoque autóctones).

Os marcadores microssatélites revelaram grande variação em cada uma das nove populações estudadas. Além disso, as populações apresentaram significante grau de diferenciação e presença de alelos exclusivos o que pode ser utilizado em identificação forense para indicar populações ou regiões da qual indivíduos coletados são provenientes.

Com os dados gerados pelos genótipos individuais pode-se começar a entender com detalhe o sistema reprodutivo e dinâmica social de populações locais. Estas informações podem ser utilizadas para determinar o tamanho efetivo da população, 
estrutura reprodutiva e outras medidas relevante de determinada população, que podem auxiliar no uso sustentável das populações de crocodilianos que atualmente mantém número suficiente para suportar a pressão de caça.

Outros estudos podem ser realizados para resposta de perguntas relevantes como: Qual a magnitude da variabilidade e divergência dentro e entre populações no gradiente Longitudinal ?. O fluxo gênico e a variabilidade genética é limitada em diferentes rios e Bacias hidrográficas (S. Francisco, Paraná, bacias costeira, Bolívia) ou variação microgeográfica (microbacias)?. Existem híbridos interespeçifico de Caiman latirostris e Caiman yacare na borda oriental do Pantanal ?

Como percebemos, esta classe de marcador molecular pode apontar informações sobre variabilidade genética, mecanismos reprodutivo, parentesco, migração, tamanho efetivo populacional, distribuição geográfica, possíveis hibridações além de características economicamente importantes, pois é capaz de revelar o polimorfismo de locos gênicos que podem ser utilizado na seleção assistida por marcadores. Estes caracteres moleculares que estão disponíveis hoje, não podem e não devem substituir caracteres físicos e estudo de campo. No entanto revela uma ajuda inestimável para entender a biologia de uma dada espécie, proporcionando informações relevantes tanto em cativeiro como em populações selvagens.

Quanto mais se compreender sobre a biologia destes animais mais precisas serão decisões visando condições que permitam a existência continua da espécie. Quanto mais precisão se exercer sobre o uso eficiente dos recursos naturais, mais importante se torna o desenvolvimento de pauta de manejos legais e aplicação eficaz de leis de proteção à fauna. 
ANEXOS 
Anexo A - Freqüência de alelos nas populações estudadas

\begin{tabular}{cccccccccc}
\hline Ami $\mu \boldsymbol{8}$ & AL & RS & IC & PB & RN & PA & CH & DU & PT \\
$\boldsymbol{N}$ & $\mathbf{2 5}$ & $\mathbf{1 7}$ & $\mathbf{9}$ & $\mathbf{5}$ & $\mathbf{1 2}$ & $\mathbf{9}$ & $\mathbf{1 2}$ & $\mathbf{2 3}$ & $\mathbf{2 0}$ \\
\hline 115 & 0.980 & 1.000 & 0.944 & 0.542 & 0.700 & 0.778 & 0.500 & 0.978 & 0.300 \\
117 & 0.020 & 0.000 & 0.056 & 0.458 & 0.300 & 0.222 & 0.500 & 0.022 & 0.700 \\
Alelos & 2 & 1 & 2 & 2 & 2 & 2 & 2 & 2 & 2 \\
\hline
\end{tabular}

Anexo A - Freqüência de alelos nas populações estudadas

\begin{tabular}{cccccccccc}
\hline Ami $\mu \mathbf{1 1}$ & $\mathbf{A L}$ & $\mathbf{R S}$ & $\mathbf{I C}$ & $\mathbf{P B}$ & $\mathbf{R N}$ & $\mathbf{P A}$ & $\mathbf{C H}$ & $\mathbf{D U}$ & $\mathbf{P T}$ \\
$\boldsymbol{N}$ & $\mathbf{2 5}$ & $\mathbf{1 7}$ & $\mathbf{9}$ & $\mathbf{5}$ & $\mathbf{1 2}$ & $\mathbf{9}$ & $\mathbf{1 2}$ & $\mathbf{2 3}$ & $\mathbf{2 0}$ \\
\hline 217 & 0.000 & 0.000 & 0.000 & 0.083 & 0.000 & 0.000 & 0.000 & 0.000 & 0.000 \\
223 & 0.000 & 0.000 & 0.500 & 0.042 & 0.100 & 0.000 & 0.000 & 0.000 & 0.050 \\
225 & 0.040 & 0.000 & 0.000 & 0.000 & 0.000 & 0.000 & 0.000 & 0.000 & 0.000 \\
227 & 0.040 & 0.500 & 0.000 & 0.000 & 0.000 & 0.222 & 0.125 & 0.109 & 0.000 \\
229 & 0.340 & 0.000 & 0.000 & 0.000 & 0.100 & 0.278 & 0.000 & 0.326 & 0.525 \\
231 & 0.080 & 0.000 & 0.056 & 0.000 & 0.200 & 0.000 & 0.000 & 0.022 & 0.000 \\
235 & 0.060 & 0.500 & 0.222 & 0.083 & 0.500 & 0.500 & 0.375 & 0.174 & 0.325 \\
237 & 0.440 & 0.000 & 0.222 & 0.792 & 0.100 & 0.000 & 0.458 & 0.370 & 0.100 \\
243 & 0.000 & 0.000 & 0.000 & 0.000 & 0.000 & 0.000 & 0.042 & 0.000 & 0.000 \\
Alelos & $\mathbf{6}$ & $\mathbf{2}$ & $\mathbf{4}$ & $\mathbf{4}$ & $\mathbf{5}$ & $\mathbf{3}$ & $\mathbf{4}$ & $\mathbf{5}$ & $\mathbf{4}$ \\
\hline
\end{tabular}


Anexo A - Freqüência de alelos nas populações estudadas

\begin{tabular}{cccccccccc}
\hline Ami $\boldsymbol{\mu 1 3}$ & $\mathbf{A L}$ & $\mathbf{R S}$ & $\mathbf{I C}$ & $\mathbf{P B}$ & $\mathbf{R N}$ & $\mathbf{P A}$ & $\mathbf{C H}$ & $\mathbf{D U}$ & $\mathbf{P T}$ \\
$\boldsymbol{N}$ & $\mathbf{2 5}$ & $\mathbf{1 7}$ & $\mathbf{9}$ & $\mathbf{5}$ & $\mathbf{1 2}$ & $\mathbf{9}$ & $\mathbf{1 2}$ & $\mathbf{2 3}$ & $\mathbf{2 0}$ \\
\hline 228 & 0.000 & 0.000 & 0.000 & 0.000 & 0.000 & 0.000 & 0.042 & 0.000 & 0.025 \\
246 & 0.000 & 0.000 & 0.056 & 0.000 & 0.100 & 0.000 & 0.000 & 0.000 & 0.000 \\
248 & 0.000 & 0.000 & 0.056 & 0.042 & 0.000 & 0.000 & 0.000 & 0.000 & 0.000 \\
250 & 0.020 & 0.147 & 0.000 & 0.000 & 0.200 & 0.000 & 0.125 & 0.000 & 0.000 \\
252 & 0.040 & 0.088 & 0.222 & 0.125 & 0.000 & 0.000 & 0.000 & 0.000 & 0.000 \\
254 & 0.000 & 0.000 & 0.000 & 0.000 & 0.000 & 0.000 & 0.000 & 0.000 & 0.475 \\
256 & 0.000 & 0.000 & 0.056 & 0.000 & 0.000 & 0.000 & 0.000 & 0.000 & 0.000 \\
258 & 0.000 & 0.118 & 0.000 & 0.042 & 0.000 & 0.000 & 0.000 & 0.000 & 0.000 \\
260 & 0.000 & 0.294 & 0.000 & 0.000 & 0.000 & 0.000 & 0.000 & 0.000 & 0.225 \\
262 & 0.060 & 0.324 & 0.056 & 0.125 & 0.100 & 0.000 & 0.083 & 0.043 & 0.050 \\
264 & 0.000 & 0.000 & 0.000 & 0.000 & 0.000 & 0.222 & 0.250 & 0.065 & 0.050 \\
266 & 0.000 & 0.000 & 0.000 & 0.000 & 0.200 & 0.000 & 0.125 & 0.109 & 0.000 \\
268 & 0.800 & 0.029 & 0.500 & 0.417 & 0.200 & 0.000 & 0.042 & 0.674 & 0.000 \\
270 & 0.060 & 0.000 & 0.056 & 0.083 & 0.100 & 0.000 & 0.083 & 0.065 & 0.000 \\
272 & 0.020 & 0.000 & 0.000 & 0.083 & 0.100 & 0.778 & 0.250 & 0.043 & 0.175 \\
274 & 0.000 & 0.000 & 0.000 & 0.083 & 0.000 & 0.000 & 0.000 & 0.000 & 0.000 \\
Alelos & 6 & 6 & 7 & 8 & 7 & 2 & 8 & 6 & 6 \\
\hline
\end{tabular}


Anexo A - Freqüência de alelos nas populações estudadas

\begin{tabular}{cccccccccc}
\multicolumn{2}{c}{ Anexo A - } \\
\hline Ami $\mu 20$ & AL & RS & IC & PB & RN & PA & CH & DU & PT \\
$N$ & 25 & 17 & 9 & 5 & 12 & 9 & 11 & 22 & 19 \\
\hline 106 & 0.000 & 0.000 & 0.000 & 0.000 & 0.000 & 0.000 & 0.000 & 0.000 & 0.026 \\
108 & 0.000 & 0.000 & 0.000 & 0.000 & 0.000 & 0.000 & 0.000 & 0.000 & 0.026 \\
116 & 0.000 & 0.000 & 0.000 & 0.000 & 0.000 & 0.056 & 0.000 & 0.000 & 0.000 \\
120 & 0.000 & 0.000 & 0.000 & 0.000 & 0.000 & 0.000 & 0.000 & 0.023 & 0.000 \\
124 & 0.000 & 0.000 & 0.000 & 0.000 & 0.000 & 0.444 & 0.000 & 0.182 & 0.053 \\
126 & 0.020 & 0.529 & 0.000 & 0.083 & 0.300 & 0.167 & 0.364 & 0.500 & 0.211 \\
128 & 0.000 & 0.000 & 0.833 & 0.583 & 0.200 & 0.000 & 0.091 & 0.068 & 0.000 \\
130 & 0.560 & 0.088 & 0.000 & 0.250 & 0.300 & 0.111 & 0.045 & 0.023 & 0.000 \\
132 & 0.060 & 0.000 & 0.000 & 0.083 & 0.200 & 0.000 & 0.000 & 0.000 & 0.000 \\
140 & 0.000 & 0.000 & 0.000 & 0.000 & 0.000 & 0.000 & 0.045 & 0.000 & 0.000 \\
144 & 0.000 & 0.000 & 0.000 & 0.000 & 0.000 & 0.167 & 0.045 & 0.000 & 0.237 \\
146 & 0.000 & 0.000 & 0.000 & 0.000 & 0.000 & 0.000 & 0.000 & 0.000 & 0.026 \\
152 & 0.000 & 0.000 & 0.000 & 0.000 & 0.000 & 0.000 & 0.045 & 0.136 & 0.000 \\
154 & 0.020 & 0.000 & 0.000 & 0.000 & 0.000 & 0.000 & 0.000 & 0.023 & 0.000 \\
156 & 0.000 & 0.059 & 0.000 & 0.000 & 0.000 & 0.000 & 0.273 & 0.000 & 0.368 \\
158 & 0.320 & 0.324 & 0.167 & 0.000 & 0.000 & 0.056 & 0.091 & 0.000 & 0.053 \\
162 & 0.020 & 0.000 & 0.000 & 0.000 & 0.000 & 0.000 & 0.000 & 0.000 & 0.000 \\
164 & 0.000 & 0.000 & 0.000 & 0.000 & 0.000 & 0.000 & 0.000 & 0.045 & 0.000 \\
Alelos & 6 & 4 & 2 & 4 & 4 & 6 & 8 & 8 & 8
\end{tabular}


Anexo A - Freqüência de alelos nas populações estudadas

\begin{tabular}{cccccccccc}
\hline Cla 42 & AL & RS & IC & PB & RN & PA & CH & DU & PT \\
$N$ & 25 & 17 & 9 & 5 & 12 & 9 & 12 & 23 & 20 \\
\hline 195 & 0.000 & 0.000 & 0.000 & 0.000 & 0.000 & 0.167 & 0.208 & 0.804 & 0.050 \\
197 & 0.120 & 0.735 & 0.000 & 0.208 & 0.000 & 0.000 & 0.000 & 0.000 & 0.000 \\
199 & 0.240 & 0.265 & 0.000 & 0.000 & 0.000 & 0.000 & 0.083 & 0.022 & 0.000 \\
201 & 0.000 & 0.000 & 0.000 & 0.000 & 0.000 & 0.167 & 0.000 & 0.109 & 0.000 \\
203 & 0.000 & 0.000 & 0.000 & 0.083 & 0.100 & 0.667 & 0.167 & 0.000 & 0.575 \\
205 & 0.000 & 0.000 & 0.000 & 0.083 & 0.000 & 0.000 & 0.542 & 0.065 & 0.200 \\
209 & 0.080 & 0.000 & 0.000 & 0.000 & 0.000 & 0.000 & 0.000 & 0.000 & 0.000 \\
211 & 0.020 & 0.000 & 0.000 & 0.000 & 0.000 & 0.000 & 0.000 & 0.000 & 0.000 \\
213 & 0.000 & 0.000 & 0.000 & 0.125 & 0.000 & 0.000 & 0.000 & 0.000 & 0.000 \\
215 & 0.000 & 0.000 & 0.000 & 0.292 & 0.300 & 0.000 & 0.000 & 0.000 & 0.000 \\
217 & 0.000 & 0.000 & 0.000 & 0.042 & 0.200 & 0.000 & 0.000 & 0.000 & 0.000 \\
219 & 0.000 & 0.000 & 0.000 & 0.000 & 0.300 & 0.000 & 0.000 & 0.000 & 0.000 \\
223 & 0.120 & 0.000 & 0.000 & 0.167 & 0.000 & 0.000 & 0.000 & 0.000 & 0.000 \\
225 & 0.000 & 0.000 & 0.000 & 0.000 & 0.100 & 0.000 & 0.000 & 0.000 & 0.000 \\
227 & 0.300 & 0.000 & 0.333 & 0.000 & 0.000 & 0.000 & 0.000 & 0.000 & 0.000 \\
229 & 0.100 & 0.000 & 0.222 & 0.000 & 0.000 & 0.000 & 0.000 & 0.000 & 0.000 \\
237 & 0.000 & 0.000 & 0.333 & 0.000 & 0.000 & 0.000 & 0.000 & 0.000 & 0.000 \\
239 & 0.000 & 0.000 & 0.111 & 0.000 & 0.000 & 0.000 & 0.000 & 0.000 & 0.000 \\
241 & 0.000 & 0.000 & 0.000 & 0.000 & 0.000 & 0.000 & 0.000 & 0.000 & 0.175 \\
243 & 0.020 & 0.000 & 0.000 & 0.000 & 0.000 & 0.000 & 0.000 & 0.000 & 0.000 \\
Alelos & 8 & 2 & 4 & 7 & 7 & 5 & 3 & 4 & 4 \\
\hline
\end{tabular}


Anexo A - Freqüência de alelos nas populações estudadas

\begin{tabular}{cccccccccc}
\hline Cla $\mu 5$ & AL & RS & IC & PB & RN & PA & CH & DU & PT \\
$\mathrm{N}$ & 25 & 17 & 9 & 5 & 12 & 9 & 12 & 23 & 20 \\
\hline 157 & 0.120 & 0.000 & 0.000 & 0.000 & 0.000 & 0.000 & 0.000 & 0.000 & 0.000 \\
159 & 0.000 & 0.000 & 0.500 & 0.000 & 0.000 & 0.000 & 0.000 & 0.000 & 0.000 \\
161 & 0.000 & 0.000 & 0.000 & 0.000 & 0.000 & 0.000 & 0.000 & 0.000 & 0.025 \\
163 & 0.000 & 0.000 & 0.000 & 0.292 & 0.400 & 0.000 & 0.042 & 0.000 & 0.000 \\
165 & 0.420 & 0.118 & 0.000 & 0.083 & 0.200 & 0.000 & 0.000 & 0.000 & 0.050 \\
167 & 0.180 & 0.000 & 0.056 & 0.000 & 0.000 & 0.444 & 0.083 & 0.364 & 0.325 \\
169 & 0.060 & 0.000 & 0.000 & 0.333 & 0.000 & 0.278 & 0.042 & 0.000 & 0.000 \\
171 & 0.120 & 0.559 & 0.000 & 0.083 & 0.000 & 0.000 & 0.000 & 0.500 & 0.000 \\
173 & 0.000 & 0.265 & 0.000 & 0.000 & 0.000 & 0.000 & 0.000 & 0.000 & 0.025 \\
175 & 0.000 & 0.000 & 0.000 & 0.000 & 0.000 & 0.000 & 0.792 & 0.000 & 0.550 \\
177 & 0.060 & 0.000 & 0.056 & 0.000 & 0.000 & 0.000 & 0.000 & 0.000 & 0.000 \\
179 & 0.000 & 0.000 & 0.222 & 0.000 & 0.000 & 0.000 & 0.000 & 0.136 & 0.000 \\
181 & 0.040 & 0.059 & 0.000 & 0.000 & 0.100 & 0.000 & 0.000 & 0.000 & 0.000 \\
183 & 0.000 & 0.000 & 0.000 & 0.167 & 0.300 & 0.000 & 0.000 & 0.000 & 0.000 \\
187 & 0.000 & 0.000 & 0.000 & 0.000 & 0.000 & 0.167 & 0.000 & 0.000 & 0.000 \\
197 & 0.000 & 0.000 & 0.000 & 0.042 & 0.000 & 0.000 & 0.000 & 0.000 & 0.000 \\
199 & 0.000 & 0.000 & 0.000 & 0.000 & 0.000 & 0.111 & 0.042 & 0.000 & 0.025 \\
203 & 0.000 & 0.000 & 0.056 & 0.000 & 0.000 & 0.000 & 0.000 & 0.000 & 0.000 \\
215 & 0.000 & 0.000 & 0.111 & 0.000 & 0.000 & 0.000 & 0.000 & 0.000 & 0.000 \\
Alelos & 7 & 4 & 6 & 6 & 4 & 4 & 5 & 3 & 6 \\
\hline
\end{tabular}


Anexo A - Freqüência de alelos nas populações estudadas

\begin{tabular}{cccccccccc}
\hline Cla 46 & AL & RS & IC & PB & RN & PA & CH & DU & PT \\
$N$ & 25 & 17 & 9 & 5 & 12 & 9 & 12 & 23 & 20 \\
\hline 127 & 0.020 & 0.000 & 0.000 & 0.000 & 0.000 & 0.000 & 0.000 & 0.000 & 0.000 \\
131 & 0.020 & 0.000 & 0.000 & 0.000 & 0.000 & 0.000 & 0.000 & 0.000 & 0.000 \\
155 & 0.000 & 0.000 & 0.000 & 0.000 & 0.000 & 0.000 & 0.042 & 0.109 & 0.000 \\
159 & 0.000 & 0.000 & 0.000 & 0.000 & 0.000 & 0.278 & 0.375 & 0.370 & 0.125 \\
161 & 0.000 & 0.000 & 0.000 & 0.000 & 0.000 & 0.000 & 0.042 & 0.000 & 0.000 \\
219 & 0.000 & 0.000 & 0.000 & 0.000 & 0.000 & 0.000 & 0.000 & 0.043 & 0.000 \\
223 & 0.300 & 0.000 & 0.000 & 0.000 & 0.000 & 0.389 & 0.375 & 0.478 & 0.400 \\
225 & 0.040 & 0.000 & 0.000 & 0.000 & 0.000 & 0.000 & 0.167 & 0.000 & 0.450 \\
227 & 0.440 & 0.000 & 0.000 & 0.000 & 0.000 & 0.333 & 0.000 & 0.000 & 0.025 \\
229 & 0.020 & 0.000 & 0.444 & 0.000 & 0.000 & 0.000 & 0.000 & 0.000 & 0.000 \\
231 & 0.100 & 0.000 & 0.000 & 0.000 & 0.000 & 0.000 & 0.000 & 0.000 & 0.000 \\
237 & 0.020 & 0.176 & 0.000 & 0.042 & 0.200 & 0.000 & 0.000 & 0.000 & 0.000 \\
239 & 0.040 & 0.735 & 0.556 & 0.958 & 0.800 & 0.000 & 0.000 & 0.000 & 0.000 \\
241 & 0.000 & 0.088 & 0.000 & 0.000 & 0.000 & 0.000 & 0.000 & 0.000 & 0.000 \\
Alelos & 9 & 3 & 2 & 2 & 2 & 3 & 5 & 4 & 4 \\
\hline
\end{tabular}


Anexo A - Freqüência de alelos nas populações estudadas

\begin{tabular}{ccccccccccc}
\hline Cla $\mu 7$ & AL & RS & IC & PB & RN & PA & CH & DU & PT \\
$N$ & 25 & 17 & 9 & 5 & 12 & 9 & 12 & 23 & 20 \\
\hline 181 & 0.160 & 0.000 & 0.111 & 0.458 & 0.400 & 0.056 & 0.458 & 0.217 & 0.050 \\
183 & 0.480 & 0.559 & 0.889 & 0.000 & 0.000 & 0.000 & 0.000 & 0.000 & 0.000 \\
185 & 0.360 & 0.000 & 0.000 & 0.000 & 0.000 & 0.000 & 0.000 & 0.000 & 0.000 \\
203 & 0.000 & 0.176 & 0.000 & 0.542 & 0.600 & 0.111 & 0.167 & 0.000 & 0.525 \\
213 & 0.000 & 0.000 & 0.000 & 0.000 & 0.000 & 0.000 & 0.000 & 0.043 & 0.000 \\
215 & 0.000 & 0.265 & 0.000 & 0.000 & 0.000 & 0.333 & 0.292 & 0.630 & 0.000 \\
223 & 0.000 & 0.000 & 0.000 & 0.000 & 0.000 & 0.056 & 0.000 & 0.000 & 0.000 \\
227 & 0.000 & 0.000 & 0.000 & 0.000 & 0.000 & 0.056 & 0.000 & 0.000 & 0.000 \\
239 & 0.000 & 0.000 & 0.000 & 0.000 & 0.000 & 0.000 & 0.042 & 0.022 & 0.000 \\
243 & 0.000 & 0.000 & 0.000 & 0.000 & 0.000 & 0.278 & 0.042 & 0.065 & 0.375 \\
245 & 0.000 & 0.000 & 0.000 & 0.000 & 0.000 & 0.111 & 0.000 & 0.022 & 0.000 \\
247 & 0.000 & 0.000 & 0.000 & 0.000 & 0.000 & 0.000 & 0.000 & 0.000 & 0.050 \\
Alelos & 3 & 3 & 2 & 2 & 2 & 7 & 5 & 6 & 4 \\
\hline
\end{tabular}


Anexo A - Freqüiência de alelos nas populações estudadas

\begin{tabular}{cccccccccc}
\hline Clau 8 & AL & RS & IC & PB & RN & PA & CH & DU & PT \\
$N$ & 25 & 17 & 9 & 5 & 12 & 8 & 12 & 23 & 20 \\
\hline 101 & 0.180 & 0.529 & 0.000 & 0.750 & 0.700 & 0.000 & 0.292 & 0.000 & 0.325 \\
103 & 0.560 & 0.000 & 0.000 & 0.000 & 0.000 & 0.000 & 0.000 & 0.000 & 0.000 \\
105 & 0.000 & 0.000 & 0.222 & 0.000 & 0.000 & 0.000 & 0.000 & 0.000 & 0.000 \\
109 & 0.000 & 0.000 & 0.000 & 0.083 & 0.000 & 0.250 & 0.000 & 0.522 & 0.000 \\
111 & 0.040 & 0.206 & 0.278 & 0.042 & 0.200 & 0.000 & 0.042 & 0.000 & 0.000 \\
113 & 0.180 & 0.000 & 0.000 & 0.000 & 0.000 & 0.000 & 0.000 & 0.000 & 0.000 \\
115 & 0.000 & 0.029 & 0.000 & 0.000 & 0.100 & 0.000 & 0.083 & 0.000 & 0.025 \\
117 & 0.000 & 0.029 & 0.056 & 0.125 & 0.000 & 0.000 & 0.000 & 0.022 & 0.000 \\
119 & 0.000 & 0.000 & 0.000 & 0.000 & 0.000 & 0.000 & 0.042 & 0.174 & 0.025 \\
121 & 0.040 & 0.000 & 0.000 & 0.000 & 0.000 & 0.000 & 0.042 & 0.000 & 0.000 \\
123 & 0.000 & 0.000 & 0.000 & 0.000 & 0.000 & 0.250 & 0.000 & 0.043 & 0.025 \\
125 & 0.000 & 0.000 & 0.444 & 0.000 & 0.000 & 0.500 & 0.250 & 0.239 & 0.300 \\
133 & 0.000 & 0.000 & 0.000 & 0.000 & 0.000 & 0.000 & 0.000 & 0.000 & 0.175 \\
135 & 0.000 & 0.000 & 0.000 & 0.000 & 0.000 & 0.000 & 0.250 & 0.000 & 0.100 \\
141 & 0.000 & 0.206 & 0.000 & 0.000 & 0.000 & 0.000 & 0.000 & 0.000 & 0.000 \\
235 & 0.000 & 0.000 & 0.000 & 0.000 & 0.000 & 0.000 & 0.000 & 0.000 & 0.025 \\
Alelos & 5 & 5 & 4 & 4 & 3 & 3 & 7 & 5 & 8 \\
& & & & & & & & & \\
\hline
\end{tabular}


Anexo A - Freqüência de alelos nas populações estudadas

\begin{tabular}{cccccccccc}
\hline Cla $\mu 9$ & AL & RS & IC & PB & RN & PA & CH & DU & PT \\
N & 25 & 17 & 9 & 5 & 12 & 9 & 12 & 23 & 20 \\
\hline 135 & 0.120 & 0.088 & 0.444 & 0.000 & 0.000 & 0.000 & 0.000 & 0.000 & 0.000 \\
137 & 0.140 & 0.029 & 0.056 & 0.000 & 0.000 & 0.000 & 0.000 & 0.000 & 0.000 \\
139 & 0.280 & 0.206 & 0.056 & 0.167 & 0.100 & 0.000 & 0.000 & 0.000 & 0.000 \\
141 & 0.020 & 0.000 & 0.000 & 0.000 & 0.000 & 0.000 & 0.000 & 0.000 & 0.000 \\
143 & 0.040 & 0.000 & 0.000 & 0.000 & 0.000 & 0.000 & 0.000 & 0.000 & 0.000 \\
145 & 0.040 & 0.059 & 0.000 & 0.000 & 0.000 & 0.000 & 0.000 & 0.000 & 0.000 \\
147 & 0.020 & 0.029 & 0.056 & 0.000 & 0.000 & 0.000 & 0.000 & 0.000 & 0.000 \\
149 & 0.040 & 0.000 & 0.111 & 0.000 & 0.000 & 0.000 & 0.000 & 0.000 & 0.000 \\
151 & 0.040 & 0.059 & 0.222 & 0.208 & 0.100 & 0.000 & 0.000 & 0.000 & 0.000 \\
153 & 0.040 & 0.000 & 0.000 & 0.000 & 0.000 & 0.000 & 0.000 & 0.000 & 0.000 \\
155 & 0.000 & 0.176 & 0.000 & 0.333 & 0.200 & 0.000 & 0.000 & 0.000 & 0.000 \\
157 & 0.100 & 0.059 & 0.000 & 0.125 & 0.000 & 0.000 & 0.000 & 0.000 & 0.000 \\
159 & 0.120 & 0.000 & 0.056 & 0.000 & 0.000 & 0.000 & 0.000 & 0.000 & 0.000 \\
161 & 0.000 & 0.000 & 0.000 & 0.000 & 0.100 & 0.500 & 0.542 & 0.239 & 0.575 \\
163 & 0.000 & 0.000 & 0.000 & 0.000 & 0.300 & 0.000 & 0.000 & 0.000 & 0.075 \\
165 & 0.000 & 0.176 & 0.000 & 0.042 & 0.200 & 0.500 & 0.208 & 0.261 & 0.225 \\
167 & 0.000 & 0.088 & 0.000 & 0.000 & 0.000 & 0.000 & 0.000 & 0.000 & 0.000 \\
169 & 0.000 & 0.029 & 0.000 & 0.125 & 0.000 & 0.000 & 0.000 & 0.000 & 0.000 \\
177 & 0.000 & 0.000 & 0.000 & 0.000 & 0.000 & 0.000 & 0.250 & 0.261 & 0.125 \\
179 & 0.000 & 0.000 & 0.000 & 0.000 & 0.000 & 0.000 & 0.000 & 0.239 & 0.000 \\
Alelos & 12 & 11 & 7 & 6 & 6 & 2 & 3 & 4 & 4 \\
\hline
\end{tabular}


Anexo A - Freqüência de alelos nas populações estudadas

\begin{tabular}{cccccccccc}
\hline Cla $\mu 10$ & AL & RS & IC & PB & RN & PA & CH & DU & PT \\
$N$ & 25 & 17 & 9 & 5 & 12 & 9 & 12 & 23 & 20 \\
\hline 206 & 0.000 & 0.000 & 0.000 & 0.000 & 0.100 & 0.000 & 0.000 & 0.000 & 0.000 \\
216 & 0.000 & 0.000 & 0.000 & 0.000 & 0.000 & 0.056 & 0.000 & 0.196 & 0.025 \\
220 & 0.000 & 0.147 & 0.000 & 0.083 & 0.000 & 0.000 & 0.000 & 0.022 & 0.000 \\
222 & 0.120 & 0.000 & 0.000 & 0.167 & 0.200 & 0.389 & 0.458 & 0.152 & 0.125 \\
224 & 0.580 & 0.088 & 0.000 & 0.583 & 0.700 & 0.056 & 0.083 & 0.022 & 0.000 \\
226 & 0.140 & 0.588 & 0.000 & 0.167 & 0.000 & 0.000 & 0.000 & 0.000 & 0.000 \\
228 & 0.000 & 0.147 & 0.000 & 0.000 & 0.000 & 0.278 & 0.000 & 0.130 & 0.000 \\
242 & 0.000 & 0.000 & 0.000 & 0.000 & 0.000 & 0.000 & 0.000 & 0.000 & 0.100 \\
244 & 0.000 & 0.000 & 0.000 & 0.000 & 0.000 & 0.000 & 0.000 & 0.000 & 0.250 \\
246 & 0.000 & 0.000 & 0.000 & 0.000 & 0.000 & 0.222 & 0.042 & 0.000 & 0.400 \\
248 & 0.000 & 0.000 & 0.000 & 0.000 & 0.000 & 0.000 & 0.000 & 0.000 & 0.025 \\
250 & 0.000 & 0.000 & 0.000 & 0.000 & 0.000 & 0.000 & 0.375 & 0.000 & 0.050 \\
252 & 0.020 & 0.000 & 0.111 & 0.000 & 0.000 & 0.000 & 0.042 & 0.000 & 0.000 \\
254 & 0.140 & 0.000 & 0.000 & 0.000 & 0.000 & 0.000 & 0.000 & 0.087 & 0.000 \\
256 & 0.000 & 0.029 & 0.056 & 0.000 & 0.000 & 0.000 & 0.000 & 0.370 & 0.025 \\
258 & 0.000 & 0.000 & 0.222 & 0.000 & 0.000 & 0.000 & 0.000 & 0.022 & 0.000 \\
264 & 0.000 & 0.000 & 0.056 & 0.000 & 0.000 & 0.000 & 0.000 & 0.000 & 0.000 \\
268 & 0.000 & 0.000 & 0.111 & 0.000 & 0.000 & 0.000 & 0.000 & 0.000 & 0.000 \\
272 & 0.000 & 0.000 & 0.222 & 0.000 & 0.000 & 0.000 & 0.000 & 0.000 & 0.000 \\
274 & 0.000 & 0.000 & 0.222 & 0.000 & 0.000 & 0.000 & 0.000 & 0.000 & 0.000 \\
Alelos & 5 & 5 & 7 & 4 & 3 & 5 & 5 & 8 & 8 \\
\hline Total & & & & & & & & & 50 \\
Alelos & $\mathbf{7 4}$ & $\mathbf{4 6}$ & $\mathbf{4 7}$ & $\mathbf{4 9}$ & $\mathbf{4 3}$ & $\mathbf{4 0}$ & $\mathbf{5 6}$ & $\mathbf{5 5}$ & $\mathbf{5 8}$ \\
\hline
\end{tabular}


ANEXO B. Heterozigozidade nas populações estudadas. He - Número de indivíduos heterozigotos esperados segundo o equilíbrio de Hardy-Weinberg, Ho - Número de indivíduos heterozigotos observados, Fis - Índice de fixação de Weir \& Cockerham (1994), HW Teste exato de aderência ao equilíbrio de Hardy-Weinberg, EP - Erro padrão da estimativa da probabilidade do teste exato de aderência ao equilíbrio de HardyWeinberg, Sig. - Significância do teste, ns - Não significativo, nt - Não testado, *(p $\leq$ $0,05), * *(\mathrm{p} \leq 0,01)$

\begin{tabular}{|c|c|c|c|c|c|c|c|c|c|}
\hline Ami8 & $\overline{\mathrm{AL}}$ & RS & IC & PB & RN & PA & $\mathrm{CH}$ & DU & $\mathrm{PT}$ \\
\hline $\mathrm{HE}$ & 1,0 & & 1,0 & 6,2 & 2,3 & 3,3 & 6,3 & 1,0 & 8,6 \\
\hline $\mathrm{HO}$ & 1,0 & & 1,0 & 3,0 & 1,0 & 0,0 & 4,0 & 1,0 & 8,0 \\
\hline FIS & 0,000 & 0,000 & 0,000 & $+0,529$ & $+0,600$ & 1,000 & $+0,371$ & 0,000 & $+0,073$ \\
\hline HW & - & . & - & 0,1031 & 0,333 & 0,012 & 0,282 & - & 1,000 \\
\hline EP & & & & I & I & I & 1 & & 1 \\
\hline Sig, & $\mathrm{nt}$ & $\mathrm{nt}$ & $\mathrm{nt}$ & ns & ns & $*$ & ns & $\mathrm{nt}$ & ns \\
\hline Ami11 & $\mathrm{AL}$ & $\mathrm{RS}$ & IC & $\mathrm{PB}$ & RN & $\mathrm{PA}$ & $\mathrm{CH}$ & $\mathrm{DU}$ & PT \\
\hline $\mathrm{HE}$ & 17,3 & 8,7 & 6,2 & 4,5 & 3,8 & 5,9 & 7,9 & 16,8 & 12,4 \\
\hline $\mathrm{HO}$ & 25,0 & 17,0 & 8,0 & 3,0 & 4,0 & 9 & 4,0 & 21,0 & 10,0 \\
\hline FIS & $-0,460$ & $-1,000$ & $-0,320$ & $+0,340$ & $-0,067$ & $-0,565$ & $+0,506$ & $-0,257$ & $+0,200$ \\
\hline HW & 0,0000 & 0,0001 & 0,2365 & 0,1056 & 0,4966 & 0,0470 & 0,0042 & 0,0000 & 0,3317 \\
\hline EP & 0,0000 & I & I & I & 0,0050 & I & 1 & 0,0000 & I \\
\hline Sig, & $* *$ & $* *$ & ns & ns & ns & $*$ & $* *$ & $* *$ & ns \\
\hline Ami13 & $\mathrm{AL}$ & $\mathrm{RS}$ & IC & $\mathrm{PB}$ & RN & $\mathrm{PA}$ & $\mathrm{CH}$ & $\mathrm{DU}$ & PT \\
\hline $\mathrm{HE}$ & 8,9 & 13,4 & 6,5 & 9,6 & 4,7 & 3,3 & 10,3 & 12,2 & 14,1 \\
\hline $\mathrm{HO}$ & 8,0 & 11,0 & 5,0 & 8,0 & 3,0 & 4,0 & 8,0 & 9,0 & 14,0 \\
\hline FIS & $+0,107$ & $+0,183$ & $+0,245$ & $+0,178$ & $+0,385$ & $-0,231$ & $+0,235$ & $+0,271$ & $+0,007$ \\
\hline HW & 0,1992 & 0,1650 & 0,2635 & 0,0674 & 0,0611 & 1,0000 & 0,0131 & 0,0602 & 0,0908 \\
\hline EP & 0,0092 & 0,0036 & 0,0095 & 0,0060 & 0,0041 & I & 0,0016 & 0,0038 & 0,0039 \\
\hline Sig, & ns & ns & ns & ns & ns & ns & $*$ & ns & ns \\
\hline Ami20 & $\mathrm{AL}$ & $\mathrm{RS}$ & IC & PB & RN & $\mathrm{PA}$ & $\mathrm{CH}$ & DU & PT \\
\hline $\mathrm{HE}$ & 14,8 & 10,6 & 2,6 & 7,3 & 4,1 & 6,9 & 8,9 & 15,5 & 14,8 \\
\hline $\mathrm{HO}$ & 18,0 & 12,0 & 1,0 & 5,0 & 5,0 & 6,0 & 8,0 & 9,0 & 10,0 \\
\hline FIS & $-0,224$ & $-0,139$ & $+0,636$ & $+0,325$ & $-0,250$ & $+0,143$ & $+0,101$ & $+0,426$ & $+0,328$ \\
\hline HW & 0,6731 & 0,7039 & 0,1765 & 0,1866 & 1,0000 & 0,1129 & 0,5251 & 0,0005 & 0,0014 \\
\hline EP & 0,0066 & I & I & I & I & 0,0043 & 0,0097 & 0,0004 & 0,0007 \\
\hline Sig, & ns & ns & ns & ns & ns & ns & ns & $* *$ & $* *$ \\
\hline Clau2 & $\mathrm{AL}$ & $\mathrm{RS}$ & IC & PB & RN & PA & $\mathrm{CH}$ & DU & PT \\
\hline $\mathrm{HE}$ & 20,6 & 6,8 & 6,8 & 10,2 & 4,2 & 4,8 & 7,9 & 7,9 & 12,2 \\
\hline $\mathrm{HO}$ & 9,0 & 5,0 & 5,0 & 8,0 & 3,0 & 1,0 & 3,0 & 8,0 & 6,0 \\
\hline FIS & $+0,568$ & $+0,273$ & $+0,279$ & $+0,221$ & $+0,314$ & $+0,800$ & $+0,629$ & $-0,011$ & $+0,516$ \\
\hline HW & 0,0000 & 0,5254 & 0,2566 & 0,0976 & 0,3485 & 0,0045 & 0,0015 & 0,2405 & 0,0000 \\
\hline EP & 0,0000 & I & I & 0,0035 & 0,0047 & I & 1 & I & I \\
\hline Sig, & $* *$ & ns & ns & ns & ns & $* *$ & $* *$ & ns & $* *$ \\
\hline
\end{tabular}


ANEXO B. Heterozigozidade nas populações estudadas. He - Número de indivíduos heterozigotos esperados segundo o equilíbrio de Hardy-Weinberg, Ho - Número de indivíduos heterozigotos observados, Fis - Índice de fixação de Weir \& Cockerham (1994), HW Teste exato de aderência ao equilíbrio de Hardy-Weinberg, EP - Erro padrão da estimativa da probabilidade do teste exato de aderência ao equilíbrio de HardyWeinberg, Sig. - Significância do teste, ns - Não significativo, nt - Não testado, *(p $\leq$ $0,05), * *(\mathrm{p} \leq 0,01)$.

\begin{tabular}{|c|c|c|c|c|c|c|c|c|c|}
\hline Clau5 & $\mathrm{AL}$ & RS & IC & $\mathrm{PB}$ & $\mathrm{RN}$ & PA & $\mathrm{CH}$ & DU & PT \\
\hline $\mathrm{HE}$ & 19,2 & 10,5 & 4,7 & 9,5 & 3,8 & 6,5 & 4,5 & 13,49 & 12,0 \\
\hline $\mathrm{HO}$ & 16,0 & 14,0 & 4,0 & 10,0 & 3,0 & 9,0 & 3,0 & 13,0 & 12,0 \\
\hline FIS & $+0,171$ & $-0,345$ & $+0,077$ & $-0,053$ & $+0,250$ & $-0,412$ & $+0,347$ & $+0,037$ & $+0,004$ \\
\hline HW & 0,0085 & 0,4403 & 0,5776 & 0,1642 & 0,6952 & 0,4384 & 0,0294 & 0,5019 & 0,0480 \\
\hline EP & 0,0009 & 1 & 0,0064 & 0,0046 & 1 & I & 0,0024 & l & 0,0034 \\
\hline Sig, & $* *$ & ns & ns & ns & $\mathrm{ns}$ & ns & $*$ & ns & $*$ \\
\hline Clau6 & $\mathrm{AL}$ & RS & IC & PB & RN & PA & $\mathrm{CH}$ & DU & $\mathrm{PT}$ \\
\hline $\mathrm{HE}$ & 17,9 & 7,4 & 1,9 & 1,0 & 1,8 & 6,3 & 8,6 & 14,6 & 12,7 \\
\hline $\mathrm{HO}$ & 6,0 & 4,0 & 0,0 & 1,0 & 2,0 & 5,0 & 8,0 & 8,0 & 5,0 \\
\hline FIS & $+0,669+$ & $+0,464$ & $+0,158$ & 0,000 & $-0,143$ & $+0,216$ & 0,074 & $+0,458$ & $+0,614$ \\
\hline HW & 0,0000 & 0,0147 & 1,0000 & - & 1,0000 & 0,1126 & 0,0248 & 0,0018 & 0,0000 \\
\hline EP & 0,0000 & I & / & & I & I & 0,0000 & 1 & I \\
\hline Sig & $* *$ & * & ns & $\mathrm{nt}$ & ns & ns & $*$ & $* *$ & $* *$ \\
\hline Clau7 & $\mathrm{AL}$ & $\mathrm{RS}$ & IC & $\mathrm{PB}$ & $\mathrm{RN}$ & PA & $\mathrm{CH}$ & DU & $\mathrm{PT}$ \\
\hline $\mathrm{HE}$ & 15,7 & 10,3 & 6,4 & 6,2 & 2,7 & 7,4 & 804 & 12,9 & 11,9 \\
\hline $\mathrm{HO}$ & 10,0 & 5 & 4,0 & 7,0 & 2,0 & 8,0 & 10,0 & 9,0 & 15,0 \\
\hline FIS & $+0,367$ & $+0,521$ & 1 & $-0,132$ & $+0,273$ & $-0,085$ & $-0,196$ & $+0,306$ & $-0,272$ \\
\hline HW & 0,0050 & 0,0010 & 0,0588 & 1,0000 & 1,0000 & 0,9676 & 0,7144 & 0,0608 & 0,0011 \\
\hline EP & l & I & I & I & / & 0,002 & 0,0039 & 0,0034 & I \\
\hline Sig, & $* *$ & $* *$ & ns & ns & $\mathrm{ns}$ & ns & ns & ns & $* *$ \\
\hline Clau8 & $\mathrm{AL}$ & $\mathrm{RS}$ & IC & $\mathrm{PB}$ & $\mathrm{RN}$ & $\mathrm{PA}$ & $\mathrm{CH}$ & DU & $\mathrm{PT}$ \\
\hline$\overline{\mathrm{HE}}$ & 15,8 & 11,1 & 6,9 & 5,2 & 2,6 & 5,3 & 9,7 & 15,0 & 15,6 \\
\hline $\mathrm{HO}$ & 14,0 & 4,0 & 7,0 & 5,0 & 1,0 & 8,0 & 12,0 & 16,0 & 14,00 \\
\hline FIS & $+0,115$ & $+0,646$ & $+0,390$ & $+0,035$ & $+0,636$ & $-0,556$ & $-0,245$ & $-0,068$ & $+0,106$ \\
\hline HW & 0,6770 & 0,0005 & 0,1415 & 0,5606 & 0,1111 & 0,0552 & 0,1865 & 0,1757 & 0,0132 \\
\hline EP & 0,0040 & 0,0002 & I & I & I & I & 0,0059 & 0,0039 & 0,0021 \\
\hline Sig, & ns & $* *$ & ns & ns & $\mathrm{ns}$ & ns & ns & ns & $*$ \\
\hline Clau9 & $\mathrm{AL}$ & $\mathrm{RS}$ & IC & $\mathrm{PB}$ & $\mathrm{RN}$ & $\mathrm{PA}$ & $\mathrm{CH}$ & DU & $\mathrm{PT}$ \\
\hline $\mathrm{HE}$ & 21,8 & 15,2 & 7,8 & 9,8 & 4,5 & 4,8 & 7,5 & 17,6 & 12,3 \\
\hline $\mathrm{HO}$ & 15,0 & 12,0 & 7,0 & 9,0 & 5,0 & 9,0 & 9,0 & 22,0 & 15,0 \\
\hline FIS & $+0,316$ & $+0,215$ & $-0,009$ & $+0,088$ & $-0,143$ & $-1,000$ & $-0,207$ & $-0,256$ & $-0,231$ \\
\hline HW & 0,0000 & 0,0064 & 0,6551 & 0,0022 & 1,0000 & 0,0105 & 0,1877 & 0,0000 & 0,4244 \\
\hline EP & 0,0000 & 0,0013 & 0,0070 & 0,0004 & 0,0000 & I & I & I & I \\
\hline Sig, & $* *$ & $* *$ & ns & ** & ns & * & ns & $* *$ & ns \\
\hline
\end{tabular}


ANEXO B. Heterozigozidade nas populações estudadas. He - Número de indivíduos heterozigotos esperados segundo o equilíbrio de Hardy-Weinberg, Ho - Número de indivíduos heterozigotos observados, Fis - Índice de fixação de Weir \& Cockerham (1994), HW Teste exato de aderência ao equilíbrio de Hardy-Weinberg, EP - Erro padrão da estimativa da probabilidade do teste exato de aderência ao equilíbrio de HardyWeinberg, Sig. - Significância do teste, ns - Não significativo, nt - Não testado, *(p $\leq$ $0,05),{ }^{* *}(\mathrm{p} \leq 0,01)$

\begin{tabular}{llllllllll}
\hline Clau10 & AL & RS & IC & PB & RN & PA & CH & DU & PT \\
\hline HE & 15,5 & 10,6 & 6,2 & 7,4 & 2,6 & 6,8 & 8,0 & 18,2 & 15,3 \\
HO & 12,0 & 11,0 & 3,0 & 6,0 & 3,0 & 8,0 & 11,0 & 23,0 & 20,0 \\
FIS & $+0,232$ & $-0,045$ & $+0,111$ & $+0,205$ & $-0,200$ & $-0,185$ & $-0,399$ & $-0,268$ & $-0,315$ \\
HW & 0,0178 & 0,1666 & 0,0415 & 0,0851 & 1,0000 & 1,0000 & 0,0210 & 0,0104 & 0,0126 \\
EP & 0,0012 & 0,0041 & 0,0026 & $/$ & $/$ & 0,0000 & 0,0016 & 0,0016 & 0,0022 \\
Sig, & $*$ & ns & $*$ & ns & ns & ns & $*$ & $*$ & $*$ \\
\hline
\end{tabular}




\section{REFERÊNCIAS BIBLIOGRÁFICAS}

ARRANZ, JJ; BAYÓN, Y; SAN PRIMITIVO, F. Genetic variation at five microsatellite loci in four breeds of cattle. Journal of Agricultural Science, v.127, p.533-538,1996.

AVISE, J. C. Natural history and evolution. Molecular markers .New York: Chapman \& hall, 1994. 1v.

AYRES, KAREN L. Relatedness testing in subdivided populations. Forensic Science International, v.114, p.107-115, 2000.

BENTZEN, P; OLSEN, JB; MCLEAN, JE; SEAMONS, TR; QUINN, TP. Kinship analysis of Pacific Salmon: Insights into mating, homing, and timing of reproduction. The American genetic association, v.92, p.127-136, 2001.

BERNARDES, AT; MACHADO, ABM; RYLANDS, AB. Fauna brasileira ameaçada de extinção. Brasília : IBAMA, 1990, 65p.

BINNS, MM; HOLMES, NG; HOLLIMAN, A; SCOTT, AM. The indentification of polymorphic microsatellite loci in the horse and their use in thoroughbred parentage testing. British Veterinary journal, v.151, v.1, p.9-15, 1995.

BOWLING, A.T.; EGGLESTON-SCOTT, M.L.; Byrns, G; Clark,. Validation of microsatellite markers for routine horse parentage testing. Animal Genetics, n.28, p.247-252, 1997. 
BRAZAITIS, P. The identification of living crocodilians. Zoologica, v.58, n.3/4, p.59101, 1973.

BRAZAITIS, P., YAMASSSHITA, C.; REBELO, C. A summary report of the CITES central South American caiman study. Phase I:Brazil. In Crocodiles: their Ecology, Management, and Conservacion. Gland, Suiça. IUCN - The World Conservation Union, 1990, p.100-115.

BROCKMANN, H.J.; COLSON, T.; POTTS, W. Sperm competition in horseshoe crabs (Limulus polyphemus). Behavioral Ecology and Sociobiology, n.35, p.153-160, 1994.

BRODERS, H. G., MAHONEY, S.O., MONTEVECCHI, A., DAVIDSON, W.S. Population genetic structure and the effect of founder events on the genetic variability of moose, Alces alces, in Canada. Molecular Ecology. v. 8, p. 13091315.

BUCHANN, F. C.; FRIESEN, M.K.; LITTLEJOHN, R. P.; CLAYTON, J.W. Microsatellites from the beluga whale Delphinapterus leucas. Molecular Ecology. v.5, p.571-575. 1996.

BULL, J.J. Sex determination en reptiles. The Quarterly Review f Biology, v.55, n.1, p.3-21,1980.

CARLINI-GARCIA, LA; VENCOVSKY, R; COELHO, ASG. Método bootstrap aplicados em níveis de reamostragem na estimação de parâmetros genéticos populacionais. Scientia Agrícola, v.58, n.4, p.785-793, 2001.

CAUGHLEY, G. Sampling in aerial survey. Journal Wildlife.Manage. v.41, p.605615, 1977.

CAUGHLEY, G.; SINCLAIR, A. R. E. Wildlife Ecollogy and Management. Boston: Blackwell Science, 1994. 334p. 
CHAMBERS, J.K.; MAC AVOY, E.S. Microsatellete: Consensus and controversy. Comparative Biochemistry and Physiology, v126, p.455-476, 2000.

CIAMPOLINI, R.; MOAZAMI-GOUDARZI, K.; VAIMAN, D.; DILLMANN, C.; MAZZANTI, E.; FOULlEY, J.; LEVEZIEL, H.; CIANCI, D. Multilocus genotypes using microsatellite polymorphisms to permit the analysis of the genetic variability within and between Italian Beef Catle breeds. Journal of Animal Science, v.11, n.73, p.3259-3268, 1995.

CIOFI, C. E BRUFORD, M.W. Genetic structur and gene flow among Komodo dragon populations inferred by microsatellite loci analysis. Molecular Ecology. v8, p. S17S30, 1999.

COELHO A. S. G. Programa Sancho: Sistema de análise para o cálculo do coeficiente de herdabilidade e outros parâmetros. Goiânia, GO: Departamento de Biologia Geral, Instituto de Ciências Biológicas, Universidade Federal de Goiás, 2001.

CRAIGHEAD, L; PAETKAU, D; REYNOLDS, HV; VYSE, ER; STROBECK, C. Microsatellite analysis of paternity and reproduction in arctic grizzly bears. Journal of Heredity, v.86, p.255-261, 1995.

CROW, J.F.; KIMURA, M. An introduction to population genetics theory. New York: Herper International Edition, 1970. 591p.

DAVIS, LM; GLENN, TC; ELSEY, RM; DESSAUERS, HC; SAWYER, RH. Multiple paternity and mating patterns in the american alligator, Alligator mississipiensis. Molecular Ecology, n.10, p.1011-1034, 2001a. 
DAVIS, L.M.; GLENN, T.C.; ELSEY, R.M.; BRISBINJUNIOR, I.L.; RHODES,W.E.; DESSAUER,H.C.; SAWYER, R.H. Genetic structura of six populations of American alligators: a microsatellite analysis. In : GRIGC, G; SEEBACHER, G.;FRANKLIN, C. (Ed). Crocodilian Biology and Evolution. Chipping Norton: Surrey Beatty, 2001b. p.38-51.

DEWOODY, J.A.; AVISE, J.C. Genetic perspectives on the natural history of fish mating systems. The Journal of heredity, v.92, n.2, p.167-172, 2000.

DEMAS, S.; WACHTEL, S. DNA fingerprinting in reptiles: Bkm hybridization patterns in Crocodilia and Chelonia. Genome, v.34,p.472-476,1991.

DESMORE III, L.D. Biochemical and immunological systematics o the order Crocodilia. In: HECHT, M.K.; WALLACE, B.; PRANCE, G. T. (Ed.) Evolutionary Biology. new York : Plenum, 1983. v.15, p. 397-465.

DESMORE III, L.D.; OWEN, R.D. Molecular systematics of the order Crocodilia. American Zoology, v.29,p.831-841, 1989.

DIEFENBACH, C.O. Ampularid gastropods: Staple food of Caiman latirostris? Copeia, p.162-163, 1979.

DONAYO, P.; PINÃ, C.; LARRIERA, A. Período de incubación, banda de calcificación, peso de los huevos y desarrollo embrionario de Caiman latirostris a tres temperaturas diferentes. In: VERDADE, L.M.;LARRIERA, A. (Ed.) Conservação e Manejo de Jacarés e Crocodilos da América Latina. Piracicaba: C.N.Editora,2002.v.2,p.79-90.

EISEN, J.A. Mechanistic basis for microsatellite instabilility. In: GOLDSTEIN, D. B. AND SCHLOTTERER, C.(Ed). Microsatellites evolution and applications. Oxford, UK: Oxford University Press. 1999, cap.4, p.34-48 
ELLEGREN, H., JOHANSSON, M., SANDBERG, K., ANDERSSON, L. Cloning of highly polumorphic microsatellites in the horse. Animal Genetics. v.23, p.133-142, 1992.

ENCALADA, S.E.; LAHANAS, P.N.; BJORNDAL, K.A.; BOLTEN, A. B.; MIYAMOTO, M.M.; BOWENS, B.W. Philogeography and population structure of the Atlantic and Mediterranean grenn turtle Chelonia mydas : a mitochondrial DNA control region sequence assesment. Molecular Ecology, v.5, p.473 - 484. 1996

ENGLAND, P.R.; BRISCOE, D.A.; FRANKHAM, R. Microsatellite polymorphisms in a wild population of Drosophila melanogaster. Genetic Research, n.67, p.285-290, 1996.

ESTOUP, A.; CORNUET, J.M.; ROUSSET, F.; GUYOMARD, R. Uxtaposed microsatellite systems as diagnostic markers for admixtene: theorical aspect. Molecular Biology and Eolution,v.16,p.898-908,1999.

EWERT M. A.; JACKSON D.R.; NELSON C.E. Patterns of temperature-dependent sex determination in turtles. Journal of Experimental Zoology. v. 270, p.3-15, 1994.

FALCONER, D.S.; MACKAY, T.F.C. Introdution to quantitative genetics. New York: Longman Scientific \& Technicals, 1989. 438p.

FARAH, S. B. DNA Segredos \& Mistérios. São Paulo: SARVIER, 1997, p.78-81.

FERGUNSON, M.W.; JOANEN, T. Temperature of egg incubation determines Sex in Alligator mississipiensis. Nature, v.296, p.850-853, 1982.

FINCATTI, C.R.; VERDADE, L.M. Variação térmica microclimática em estufa plástica e suas aplicações para a manutenção de filhotes de jacarés. In: VERDADE, L.M.;LARRIERA, A. (Ed.). Conservação e manejo de jacarés e crocodilos da América Latina. Piracicaba: C.N.Editora,2002.v.2,p.91-97. 
FITZSIMMONS, N.N.; TANKSLEY, S.; FORSTNER, M.R.; LOUIS, E.E.; DAGLISH, R.; GRATTEN, J.; DAVIS, S. microsatellite markers for Crocodylus : new genetic tiils for population genetics, mating system studies and forensis. In : GRIGC, G; SEEBACHER, G.;FRANKLIN, C. (Ed.). Crocodilian Biology and Evolution. Chipping Norton: Surrey Beatty, 2001b. p.51-57.

FORSTNER, MRJ; FORSTNER, JM. Applications of genetics in crocodilian conservation. In: VERDADE, LM; LARRIERA, A (Ed.). La conservacion y el manejo de caimanes y cocodrilos de America Latina. Piracicaba: C.N. Editora, 2002, v.2, p.99-117,.

FRANKEL, O.H.; BROWN, A.H.D.; BURDON, J.J. The conservation of plant biodiversity. Cambridge: Cambrigge University Press, 1995. 299p.

FREDHOLM, M.; WINTERO, A.K. Efficient resolution of parentage in dogs by amplification of microsatellite. Animal Genetics, n.27, p.19-23, 1996.

FUTUYMA, D. J. Evolutionary Biology, 3. ed. Sunderland, MA: Sinauer Associates. 1998, 196p.

GAIOTTO, F. A., Inferências sobre herança quantitativa e estrutura genética em populações naturais de Euterpe edulis utilizando marcadores microssatélites. Piracicaba, 2001. Tese (Doutorado) - Escola Superior de Agricultura "Luiz de Queiroz”, Universidade de São Paulo.

GALBRAITH, DA; WHITE, BN; BROOKS, RJ; BOAG, PT. Multiple paternity in clutches of snapping turtles (Chelydra serpentina) detected using DNA fingerprints. Canadian Journal of Zoology, v.71, p.318-324, 1993.

GARCIA-MORENO, J.; MATOCQ, M.D.; ROY, M.S.; GEFFEN, E.; WAYNE, R.K. Relationships and genetic purity of endangered mexican wolf based on analysis of microsatellite loci. Conservation Biology, v.2, n.10, p.376-389, 1996. 
GLENN, T. C.; DESSAUER H. C.; BRAUN M. J.. Characterization of microsatellite DNA loci in American alligators. Copeia. P.591-601. 1998.

GLENN, TC; STEPHAN, W.; DESSAUER, H.C.; BRAUN, M.J. Allelic diversity in alligator microsatellite loci is negatively correlated with GC content of flanking sequences and evolutionary conservation of PCR amplifiability. Molecular Biology and Evolution, v.13,n.8,p.1151-1154, 1996.

GOODMAN, S.J. RST calc: A cllection of computer prograns for calculationg unbiased estimates of genetic differentiation and determining their significance for microsatellite data. Molecular Ecology, v.6,p.881-885,1997.

GROOMBRIDGE, B. IUCN Amphibia - Reptilia red data book Part 1. Testudines, crocodylia, rhyncocephalia. Cambridge: IUCN Conservation Monitoring Centre, 1982. p.201-207.

HOEZEL, A.R. Molecular genetic analysis of populations. Oxford: IRL press, 1992. p. $59-88$.

HOULDEN, BA; ENGLAND, P; SHERWIN, WB. Paternity exclusion in koalas using hypervariable microsatellites. Journal of Heredity, v.87,n.2,p.149-152, 1996.

HUTTON, J.M.; LOVERIDGE, J.P.; BLAKE, D.K. Capture methods for the nile crocodile in Zimbabwe. In: WEBB, G.J.W.; MANOLIS, S.C.; WHITEHEAD, P.J. (Ed.). Wildlife Managment: Crocodiles and Alligators. Chipping Norton, Australia: Surrey Beatty, 1987. p.211-216.

JEFFREYS, A.J.; BROOKFIELD, J.F.Y.; SEMEONOFF, R. Positive identification of an immigration test-case using human DNA fingerpirnts. Nature , n.317, p.818-819, 1985a. 
JEFFREYS, A.J.; TAMAKI, K.; MACLEOD, A.; MONCKTON, D.G.; NEIL, D.L.; ARMOUR, J. A. L. Complex gene conversion events in germline mutation at human minisatellites. Nature Genetetics, n.6, p.136-145, 1994.

KIMURA, M., CROW, J. F. The number of alleles that can be maintaneid in a finite population. Genetics, v.49, p.725-738, 1964.

KIMURA, M., OHTA, T. Stepwise mutation model and distribution of allelic frequencies in a finite population. Proceedings of the National Academy of Sciences of the USA, v.75, p.2868 - 2872, 1978.

KING, FW; BRAZAITIS, P. Species identification of commercial crocodilian skins. Zoológica, v.56, n.2, p.15-70, 1971.

LANG, JW; ANDREWS, H.V. Temperature-dependent sex determination in crocodilians. The Journal of Experimental Zoology, v.270, p.28-44, 1994.

LEVINSON,G.;GUTMAN, G. A. Slipped-strand mispairing: a major mechanisms for DNA séquense evolution. Molecular Biology and Evolution, v.4, p.203-221, 1987b.

LEWIS, P.O.; ZAYKIN,D. Genetic Data Analysis : Computer program for the analysis of allelic data. version 1.0 (d15). Free program distributed by the author over the Internet from the GDA Home Page at http://alleyn.eeb.uconn.edu/gda/,2000.

LI, W.H., GRAUR, D. Gene structure of molecular evolution. Massachussets: Sinauror Associates, Publishers Suderland. 1991. cap. 1, p.3-9.

LIFJELD, J. T.; SLAGSVOLD, T.; ELLEGREN, H. Experimental mate switching in pied flycatchers, male copulatory acess and fertilization success. Animal Behaviour, n.53, p.1225-1232, 1997.

LYNCH, M. Estimation of relatedness by DNA fingerprinting. Molecular Biology and Evolution, v.5,n.5,p.584-599, 1988. 
LYNCH, M. Estimating genetic correlations in natural populations. Genetics Research, v.74,p.255-264, 1999.

LYNCH, M; RITLAND, K. Estimation of pairwise relatedness with molecular markers. Genetcs, v.152,p.1753-1766, 1999.

MAGNUSSON, W.E. Economics, developing countries, and the captive propagation of crocodilians. Wildlife Society Bulletin, n.12, p.194-197, 1984.

MEDEM, F. Los Crocodylia de sul america., Bogota,Colombia: Colciencies, v. 2, p.279,1981.

MELO, M. T. Q. Dieta do Caiman latirostris no sul do Brasil. IN: VERDADE, L.V. ; LARRIERA, A. Conservação e manejo de jacarés e crocodilos da américa latina. Piracicaba: C.N.Editora, 2002.v.2,p.119-125.

MICHALAKIS, Y.; VEUILLE, M. Length variation of CAG/CAA trinucleotide repeats in natural populations of Drosophila melanogaster and its relation to the recombination rate. Genetics, n.143, p.1713-1725, 1996.

MOLINA, F.B.; SAJDAK, R.A. Oberservação sobre a preferência térmica e o comportamento de termorregulação no jacaré-de-papo-amarelo, Caiman latirostris, em cativeiro: variação ontogenéticas e algumas comparações com outras espécies de jacarés neotropicais. In: WORKSHOP SOBRE CONSERVAÇÃO E MANEJO DO JACARÉ-DE PAPO-AMARELO. Piracicaba 1993. Anais. Piracicaba: ESALQ/USP,.p.93-132.

MOORE, S.S.; SARGEANT, L.L.; KING, T.J.; MATTICK, J.S.; GEORGES, M.;HETZEL, J.S.The conservation of dinucleotide microsatellite among mammalian genomes alows the use of heterolous PCR primer pair in closely realted species. Genomicas, v.10,p.654-660, 1991. 
OLSEN, JB; BUSACK, C; BRITT, J; BENTZEN, P. The aunt and uncle effect: An empirical evaluation of the confouding influence of ull sibs of parents on pedigree reconstruction. The American Genetic Association, v.92, p.243-247, 2001.

OLERUP, O.; ZETTERQUIST, H. HLA-DR typing by PCR amplification with sequence-specific primers (PCR-SSP) in 2 hours, an alternative to serological DR typing in clinical pratice including donor-recipient matching in cadaveric transplantations. Tissue Antigens, n.39, p.225-235, 1992.

PAETKAU, D.; WAITS, L.P.; CLARKSON, P.L.; CRAIGHEAD, L; VYSE, E.; WARD, R.; STROBECK, C. Variation in genetic diversity across the range of north american brow bears. Conservetion Biology, v.12, p. 418-429, 1998.

PARKER, P. G.; WHITEMAN, H.H. Genetic diversity in fragmented populations of Clemmys guttata and Chrysemys picta marginata as shown by DNA fingerprinting. Copeia, n.1993, p.841-846, 1993.

PIHKANEN, S.; VÄINÖLÄ, R.; VARVIO, S. Characterizing dog breed differentiation with microsatellite markers. Animal Genetics, n.27, p.343-346, 1996.

PIÑA C.; LARRIERA, A. Caiman latirostris growth: the effect of a management technique on the supplied temperature. Aquaculture, v. 211, p.387-392, 2002.

PIÑA, C.; IMHOF, A.; FRUTOS, N.; MEDINA, M.; LARRIERA, A. Tamaño de postura y medidas de huevos de Caiman latirostris en las Provinvias de Santa Fe y Entre rios. In: In: VERDADE, LM; LARRIERA, A (Ed.).Conservação e Manejo de Jacarés e Crocodilos da América latina. Piracicaba: C.N.Editora, 2002.v.2,p.127-134.

PINHEIRO, MS; LAVORENTI, A. Growth of Broad-nosed caiman, Caiman latirostris (Daudin, 1802) hatchlings, fed with diets of animal origin. Brazilian Journal of Biology, v.61,n.3,p.421-429, 2001. 
PROSSER, M.R., GIBBS, H.L., WEATHERHEAD, P. J. Microgeograf population genetic structure in the norther water snake, Nerodia sipedon sipedon detected using microsatellite DNA loci. Molecular Ecology, v.8, p.329-333, 1999.

QUELLER, DC; STRASSMANN, JE; HUGHES, CR.. Microsatellite and kinship. TREE, v.8,n.8,p.285-288, 1993.

RAYMOND,M.; ROUSSET, F. GENEPOP (version 1.2): population genetics software for exact tests and ecumenicism. Journal of Heredity, v.86,p.248-249,1995.

REGITANO, L.C.A. Polimorfismo molecular em gerações de bovinos da raça Canchim, Piracicaba, 1996. 132p. Tese (Doutorado). Escola Superior de Agricultura "Luiz de Queiroz”, Universidade de São Paulo.

RITLAND, K. Gene identy and the genetic demography of plant populations. In: BROWN, A.H.D.; CLEGG, M.T.; KAHLER, A.L.; WEIR, B.S. PlantPpopulation Genetics, Breeding, and Genetic Resources, v.11, p.181-199, 1989.

RITLAND, K. Estimators for pairwise relatedness and inbreeding coefficients.Genetic Research, v.67,p.175-186, 1996.

RITLAND, K. Marker-inferred relatedness as a tool for detecting heritability in nature. Molecular Ecology. V.9, p.1195-1204. 2000.

ROHLF, F.J. NTSYS-pc 1.70, numerical taxonomy and multivariate analysis system (Compact disc). Setauket: Applied Biostatistics inc., 1992.

RON, M; BLANC, Y; BAND, M; EZRA, E; WELLER, JI. Misidentification rate in the israeli dairy cattle population and its implication for genetic improvement. Journal of Dairy Science, v.79,p.676-681, 1996.

ROSA, A.J.M. Caracterização da raça nelore e teste de paternidade por marcadores moleculares. Piracicaba,1997.125p. Dissertação (Mestrado) - Escola Superior de Agricultura “Luiz de Queiroz”, Universidade de São Paulo. 
ROSS, KG. Crocodiles: Status Survey and Conservation Action Plan, 2. ed. IUCN: Switzerland, 1998

ROSS, KG. Molecular ecology of social behaviour: analyses of breeding systems and genetic structure. Molecular Ecology, n.10,p.365-384, 2001.

ROUSSET, F. Equilibrium values of measure of population subdivision for stepwise mutation process. Genetics, v.142, p. 1357-1362, 1996.

ROY, M.S., GEFFEN, E., SMITH, D., OSTRANDER, E. A., WAYNE, R.K. Patterns of differenciation and hybridation in North american wolflide canids, revealead by analysis of microsatellite loci. Molecular Biology and Evolution, v.1, p. 553-570, 1994.

SAINO, N; PRIMMER, CR; ELLEGREN, H; MOLLER, AP. An experimental study of paternity and tail ornamentation in the barn swallow (Hirunda rustica). Evolution, v.2, n.51, p.562-570, 1997

SARKIS-GONÇALVES, F; MIRANDA-VILELA, MP; BASETTI, LAB; VERDADE, LM. Manejo de jacarés-de-papo-amerelo (Caiman latirostris) em cativeiro. In: MATTOS, W.K.S. (Ed). A produção animal na visão dos brasileiros. Brazília: Sociedade Brasileira de Zootecnia, 2001.p.565-579.

SARKIS-GONÇALVES, F.; MIRANDA-VILELLA M. P. ; BASSETTI L. A. Caiman latirostris (broad-snouted caiman) new record of age at sexual maturity. Herpertological Review, v.34, p.225-226, 2003.

SCHLÖTTERER, C; VOGL, C; TAUTZ, D. Polymorphism and locus-specific effects on polymorphism at microsatellite loci in natural Drosophila melanogaster populations.Genetics, v.146,p.309-320, 1997.

SLATKIN, M. A measure of population subdivision based on microsatellite allele frequencies. Genetics, v.139,p.457-462,1995. 
SMITH, C.A.; JOSS, J.M.P. Gonadal sex differentiation in Alligator mississipiensis, a species whit temperature-dependent sex determination. Cell \& Tissue Reaserch, v.273, p.149-162, 1993.

SMITH, B. R; HERBINGER, C. M; MERRY, H. R. Accurate partition of individuals into full-sib families from genetic data without parental information. Genetics, v.158,p.1329-1338, 2001.

STRAND, M.; PROLLA, T. A.; LISKAY, R.M.; PETERS, T. D. Destabilization of tracts of simple repetitive DNA in yeast by mutations affecting DNA mismatch repair. Nature, n.365, p.274-276, 1993.

TAUTZ, D.; RENZ, M. Simple sequences are ubiquitous repetitive components of eukaryotic genomes, Nucleic Acids Research., v.12, p. 4127-4138, 1984.

TAYLOR,J.A.; WEBB, G.J.W.; MAGNUSSON W.E.. Methods of obtaining stomach contents from live crocodilians. Journal of Herpetology, v.12, p.415-417,1978.

TEGELSTRÖM, H.; HÖGGREN. M. Paternity determination in the adder (Vipera berrus), DNA fingerprinting or random amplified polymorphic DNA? Biochemical Genetics, n.32, p.249-256, 1994.

VAC, M.H.; VERDADE, L.M.; MEIRELLES, C.F; LARSEN, R.E.; MICHELOTTI,F.; RANGEL, M.C.; SALEM, C.Z.; LAVORENTI, A.Ultrasound evaluation of the follicle development in adult female broad-nosed caiman (Caiman latirostris). In: WORK. MEET. CROC. SPEC. GROUP/SSC/IUCN, Gland, 1992.Proceedings. Gland:IUCN - The World Conservation Union, 1992, p.176-183.

VAN VLEVK, L.D.; POLLAK, E.J.; OLTENACU, E.A.B. Genetics for the Animal Sciences. 1987, 391p. 
VANZOLINI, P.E. Répteis e anfíbios ameaçados de extinção no Brasil. In: ESPÉCIES DA FAUNA BRASILEIRA AMAÇADAS DE EXTINÇÃO. Rio de Janeiro: Academia Brasileira de Ciências. 1972. p.155-157.

VERDADE, L.M. Manejo e conservação do jacaré-de-papo-amarelo (Caiman latirostris) em São Paulo, Brasil.. In: VALLADARES-PÁDUA, C.B.; BODMER, R.E. E CULLEN, L., JUNIOR. (Ed..). Manejo de vida silvestre para a conservação., Mamirauá, AM: Sociedade Civil Mamirauá. 1997, p. 222-232.

VERDADE, LM. Caiman latirostris. in : ROSS, J.P. (Ed.). Crocodile status survey an conservation action plain. gland: IUCN; The World conservation Union, 1998, p.18-20.

VERDADE, LM. Caiman latirostris (Broad-snouted caiman).behavior. Herpetological Review, v.30,n.1, p.38-39,1999.

VERDADE, L.M. Allometry of reproduction in broad-snouted caiman (Caiman latirotris).Brazilian journal of Biology, v.61, n.3,p.431-435, 2001a.

VERDADE, L.M. O programa experimental de criação em cativeiro de jacaré-de-papoamarelo (Caiman Latirostris) da ESALQ/USP: Histórico e perpectivas. In: MATTOS, W.K.S. (Ed). A produção animal na visão dos brasileiros. Brasília: sociedade Brasileira de Zootecnia, 2001b. p.559-564.

VERDADE, L.M. Cranial sexual dimorphism in Caiman latirostris. Amphibia-Reptilia, v.24, n.1,p.92-99, 2003.

VERDADE, L.M.; LAVORENTI, A.. Preliminary notes on the status and conservation of Caiman latirostris in the State of São Paulo, Brazil: directions of the captive reeding, reintroduction and management program. p.231-237. IN: CROCODILES. PROC. 10TH WORK. MEET. CROC. SPEC. GROUP - The World Conservation Union. Glan, Switzerland: . IUCN. v.2, p. 1-345, 1990. 
VERDADE, L.M.; KASSOUF-PERINA, S. (Ed.). Studbook regional do Jacaré-depapo-amarelo (Caiman latirostris), 1992/1993. Sorocaba: Sociedade de Zoológicos do Brasil, 1993. 46p.

VERDADE, L.M; MOLINA, F.B. (Ed.). Studbook regional do Jacaré-de-papoamarelo (Caiman latirostris). Piracicaba: ESALQ/USP, 1993. 55p

VERDADE, L.M.; F. SARKIS. Age at first reproduction in captive Caiman latirostris (broad-snouted caiman). Herpetological Review, v. 29, n.4, p:227-228, 1998.

VERDADE, L.M; ZUCOLOTO, R.B; COUTINHO, L.L. Microgeographic variation in Caiman latirostris. Journal of Experimental Zoology, v.294, n.4,p.387-396, 2002.

VIARD, F.; BREMOND., P.; LABBO, R.; JUSTY, F.; DELAY, B.; JARNE, P. Microsatellites and the genetics of highly selfing populations in the freshwater snail Bulinus truncatus. Genetics, n.142, p.1237-1247, 1996.

VICTOR, M.A.M. A devastação florestal. São Paulo: Sociedade Brasileira de Silvicultura, 1975. 48p.

VILLAREAL, X.; BRICKER, J.; REINERT, H.K.; GELBERT, L.; BUSHAR, L.M. Isolation and characterization of microsatellite loci for use in population genetic analysis in the timber rattlesnake, Crotalus horridus. The Journal of Heredity, v.2, n.87, p.152-155, 1995.

WALSH, B. Crocodile capture methods used in the Northern Territory of Austrália. In: WEBB, G.J.W.; MANOLIS, S.C.; WHITEHEAD, P.J. (Ed.). Wildlife Managment: Crocodiles and alligators. Chipping Norton, Austrália: Surrey Beatty, 1987. p.249252.

WEBB, G.J.W.; BEAL, A.M.; MANOLIS, S.C. The effects of incubation temperature on sex determination and embryonic development rate in Crocodylus johnstoni an Crocodylus porosus. In: WEBB, G. J.W.; MANOLIS, S.C.; WHITEHEAD, P.J. 
(Ed.). Wildlife management: crocodiles and alligators. Chippng Norton : Surrey Beatty, 1987. p.507-531.

WEBB, G.J.W.; MANOLIS, S.C; BUCKWORTH, R. Crocodylus johnstoni in the Mckinlay River area, N.T.1. Variation in diet, and a new method of assessing the relative importance of prey. Australian Journal of Zoology, v.30, p.877-899, 1982.

WEBER, J.L.Informativeness of human (dC-dA $)_{n}(\mathrm{dG}-\mathrm{dT})_{\mathrm{n}}$ polymorphism. Genomics, v.7, p.524-530, 1990.

WEBER, J.L; WONG, C. Mutation of human short tandem repeats. Human Molecular Genetics,v.2, p.1123-1128, 1993.

WEIR, B.S. Genetic data analysis II. Massachusetts: Sinauer ,1996. 445p.

WIBBELS, T.; COWAN, J.; LEBOEUF, R. Temperature-dependent sex determination in the red-fared slider turtle, trachemys scripta. Journal of Experimental Zoology, v. 281. n.5, p.409-416, 1988.

ZUCOLOTO, R.B. Avaliação da diversidade genética e teste de maternidade em jacaréde-papo-amarelo (Caiman latirostris) através do uso de seqüências de DNA microssatélite. Piracicaba, 1998.Dissertação (Mestrado), Escola Superior de Agricultura “Luiz de Queiroz”, Universidade de São Paulo.

ZUCOLOTO, R.B. Desenvolvimento de sequências microssatélite para estudo de populações remanescentes de Jacaré-de-Papo-Amarelo (Caiman latirostris), da região central do Estado de São Paulo. Piracicaba, 2003. p.118. Tese (Doutorado), Escola Superior de Agricultura “Luiz de Queiroz”, Universidade de São Paulo.

ZUCOLOTO, R. B.; VERDADE, L.M.; COUTINHO, L.L. Microsatellite DNA library for Caiman latirostris. Journal of Experimental Zoology, v.294, n.4, p.346-351, 2002. 
APÊNDICES 
APÊNDICE 1 - Indivíduos amostrados com seus números de laboratório, registro no Studbook e sexo

\begin{tabular}{|c|c|c|c|c|}
\hline Amostra & População & $\begin{array}{l}\text { Número de } \\
\text { laboratório }\end{array}$ & Identificação & Sexo \\
\hline A1 & PoA01 & 151 & VG01 & $\mathrm{M}$ \\
\hline $\mathrm{A} 2$ & PoA02 & 152 & VG02 & M \\
\hline A3 & PoA03 & 153 & VG03 & M \\
\hline A4 & PoA04 & 154 & VG04 & M \\
\hline A5 & PoA05 & 155 & VG05 & M \\
\hline A6 & PoA06 & 156 & VG06 & M \\
\hline A7 & PoA07 & 157 & VG07 & M \\
\hline A8 & PoA08 & 158 & VG08 & M \\
\hline A9 & PoA09 & 159 & VG09 & M \\
\hline A10 & Pt01 & 162 & VG12 & $\mathrm{F}$ \\
\hline A11 & Pt02 & 163 & VG13 & $\mathrm{F}$ \\
\hline A12 & Pt03 & 164 & VG14 & M \\
\hline A13 & Pt04 & 184 & VG19 & $?$ \\
\hline A14 & Pt05 & 185 & VG20 & ? \\
\hline A15 & Pt06 & 186 & VG21 & $?$ \\
\hline A16 & Pt07 & 188 & VG22 & $?$ \\
\hline A17 & Pt08 & 235 & USP508 & ? \\
\hline A18 & Pt09 & 263 & USP409 & M \\
\hline A19 & Pt10 & 264 & USP189 & M \\
\hline A20 & Pt11 & 265 & USP413 & M \\
\hline A21 & Pt12 & 266 & USP414 & M \\
\hline A22 & Pt13 & 267 & USP412 & M \\
\hline A23 & Pt14 & 268 & USP411 & M \\
\hline A24 & Pt15 & 269 & USP410 & M \\
\hline A25 & Pt16 & 270 & USP200 & $\mathrm{F}$ \\
\hline A26 & Pt17 & 271 & USP199 & F \\
\hline A27 & Pt18 & 272 & USP451 & M \\
\hline A28 & Pt19 & 273 & USP407 & M \\
\hline A29 & Pt20 & 274 & USP408 & M \\
\hline A30 & Ch01 & 165 & VG15 & M \\
\hline A31 & Ch02 & 166 & VG16 & M \\
\hline A32 & Ch03 & 167 & VG17 & M \\
\hline A33 & Ch04 & 180 & VG18 & $?$ \\
\hline
\end{tabular}


APÊNDICE 1 - Indivíduos amostrados com seus números de laboratório, registro no Studbook e sexo

\begin{tabular}{|c|c|c|c|c|}
\hline Amostra & População & $\begin{array}{l}\text { Número de } \\
\text { laboratório }\end{array}$ & Identificação & Sexo \\
\hline A34 & Ch05 & 242 & USP701 & ? \\
\hline A35 & Ch06 & 243 & USP702 & ? \\
\hline A36 & Ch07 & 244 & USP703 & ? \\
\hline A37 & Ch08 & 245 & USP704 & ? \\
\hline A38 & Ch09 & 246 & USP705 & ? \\
\hline A39 & Ch10 & 247 & USP706 & ? \\
\hline $\mathrm{A} 40$ & Ch11 & 248 & USP707 & ? \\
\hline A41 & Ch12 & 249 & USP708 & ? \\
\hline A42 & DuF01 & 168 & DF01 & M \\
\hline A43 & DuF02 & 169 & DF02 & $\mathrm{F}$ \\
\hline A44 & DuF03 & 170 & DF03 & M \\
\hline A45 & DuF04 & 171 & DF04 & M \\
\hline A46 & DuF05 & 172 & DF05 & $\mathrm{F}$ \\
\hline A47 & DuF06 & 173 & DF06 & M \\
\hline A48 & DuF07 & 174 & DF07 & M \\
\hline A49 & DuF08 & 175 & DF08 & M \\
\hline A50 & DuF09 & 176 & DF09 & M \\
\hline A51 & DuF10 & 177 & DF10 & M \\
\hline A52 & DuF11 & 178 & DF11 & M \\
\hline A53 & DuF12 & 179 & DF12 & M \\
\hline A54 & DuF13 & 252 & USP401 & ? \\
\hline A55 & DuF14 & 253 & USP402 & ? \\
\hline A56 & DuF15 & 254 & USP403 & ? \\
\hline A57 & DuF16 & 255 & USP404 & ? \\
\hline A58 & DuF17 & 256 & USP405 & ? \\
\hline A59 & DuF18 & 257 & USP406 & ? \\
\hline A60 & DuF19 & 258 & USP631 & ? \\
\hline A61 & DuF20 & 259 & USP632 & ? \\
\hline A62 & DuF21 & 260 & USP633 & ? \\
\hline A63 & DuF22 & 261 & USP634 & ? \\
\hline A64 & DuF23 & 262 & USP635 & ? \\
\hline A65 & AL01 & 191 & AL001 & $\mathrm{F}$ \\
\hline A66 & AL02 & 192 & AL004 & $\mathrm{F}$ \\
\hline A67 & AL03 & 193 & AL005 & M \\
\hline
\end{tabular}


APÊNDICE 1 - Indivíduos amostrados com seus números de laboratório, registro no Studbook e sexo

\begin{tabular}{|c|c|c|c|c|}
\hline Amostra & População & $\begin{array}{l}\text { Número de } \\
\text { laboratório }\end{array}$ & Identificação & Sexo \\
\hline A68 & AL04 & 194 & AL006 & $\mathrm{F}$ \\
\hline A69 & AL05 & 195 & AL007 & M \\
\hline A70 & AL06 & 196 & AL008 & M \\
\hline A71 & AL07 & 197 & AL009 & M \\
\hline A72 & AL08 & 198 & AL020 & $\mathrm{F}$ \\
\hline A73 & AL09 & 199 & AL033 & $\mathrm{F}$ \\
\hline A74 & AL10 & 200 & AL034 & $\mathrm{F}$ \\
\hline A75 & AL11 & 201 & AL035 & M \\
\hline A76 & AL12 & 202 & AL039 & M \\
\hline A77 & AL13 & 203 & AL040 & $\mathrm{F}$ \\
\hline A78 & AL14 & 204 & AL061 & M \\
\hline A79 & AL15 & 205 & AL062 & $\mathrm{F}$ \\
\hline A80 & AL16 & 206 & AL063 & $\mathrm{F}$ \\
\hline A81 & AL17 & 207 & AL064 & $\mathrm{F}$ \\
\hline A82 & AL18 & 208 & AL066 & $\mathrm{F}$ \\
\hline A83 & AL19 & 209 & AL067 & M \\
\hline A84 & AL20 & 210 & AL070 & $\mathrm{F}$ \\
\hline A85 & AL21 & 211 & AL071 & M \\
\hline A86 & AL22 & 212 & AL072 & $\mathrm{F}$ \\
\hline A87 & AL23 & 213 & AL074 & $\mathrm{F}$ \\
\hline A88 & AL24 & 214 & AL077 & $\mathrm{F}$ \\
\hline A89 & AL25 & 215 & AL100 & $\mathrm{F}$ \\
\hline A90 & RS01 & 216 & RS001 & ? \\
\hline A91 & RS02 & 217 & RS002 & $?$ \\
\hline A92 & RS03 & 218 & RS003 & ? \\
\hline A93 & RS04 & 219 & RS004 & ? \\
\hline A94 & RS05 & 220 & RS005 & ? \\
\hline A95 & RS06 & 221 & RS006 & ? \\
\hline A96 & RS07 & 222 & RS007 & ? \\
\hline A97 & RS08 & 223 & RS008 & ? \\
\hline A98 & RS09 & 224 & RS009 & ? \\
\hline A99 & RS10 & 225 & RS010 & ? \\
\hline A100 & RS11 & 226 & RS011 & ? \\
\hline A101 & RS12 & 227 & RS012 & ? \\
\hline A102 & RS13 & 228 & RS013 & ? \\
\hline A103 & RS14 & 229 & RS014 & ? \\
\hline A104 & RS15 & 230 & RS015 & ? \\
\hline A105 & RS16 & 231 & RS016 & ? \\
\hline
\end{tabular}


APÊNDICE 1 - Indivíduos amostrados com seus números de laboratório, registro no Studbook e sexo

\begin{tabular}{|c|c|c|c|c|}
\hline Amostra & População & $\begin{array}{l}\text { Número de } \\
\text { laboratório }\end{array}$ & Identificação & Sexo \\
\hline A106 & RS17 & 232 & RS017 & $?$ \\
\hline A107 & IC01 & 275 & USP416 & M \\
\hline A108 & IC02 & 276 & USP417 & M \\
\hline A109 & IC03 & 277 & USP418 & M \\
\hline A110 & IC04 & 278 & USP419 & M \\
\hline A111 & IC05 & 279 & USP420 & M \\
\hline A112 & IC06 & 280 & USP421 & M \\
\hline A113 & IC07 & 281 & USP415 & M \\
\hline A114 & IC08 & 282 & USP422 & $\mathrm{F}$ \\
\hline A115 & IC09 & 283 & USP426 & $\mathrm{F}$ \\
\hline A116 & JP01 & 284 & - & M \\
\hline A117 & JP02 & 285 & - & M \\
\hline A118 & JP03 & 286 & - & M \\
\hline A119 & JP04 & 287 & - & M \\
\hline A120 & JP05 & 288 & - & M \\
\hline A121 & JP06 & 289 & - & M \\
\hline A122 & JP07 & 290 & - & M \\
\hline A123 & JP09 & 292 & USP355 & $\mathrm{F}$ \\
\hline A124 & JP10 & 293 & USP356 & M \\
\hline A125 & JP11 & 294 & USP357 & M \\
\hline A126 & JP12 & 295 & USP358 & M \\
\hline A127 & JP13 & 296 & - & M \\
\hline A128 & RN01 & 297 & USP351 & $\mathrm{F}$ \\
\hline A129 & RN02 & 298 & USP352 & M \\
\hline A130 & RN03 & 299 & USP353 & M \\
\hline A131 & RN04 & 300 & USP354 & $\mathrm{F}$ \\
\hline A132 & RN05 & 301 & USP450 & M \\
\hline A133 & САТ01 & & CL203 & M \\
\hline A134 & САT02 & & CL25 & $\mathrm{F}$ \\
\hline A135 & САТ03 & & CL53 & $\mathrm{F}$ \\
\hline A136 & САT04 & & CL106 & $\mathrm{F}$ \\
\hline A137 & САT05 & & CL30 & M \\
\hline 138 & САT06 & & CL01 & M \\
\hline
\end{tabular}


APÊNDICE 2 - Genótipos de todos os indivíduos em formato de três dígitos para cada alelo

\begin{tabular}{|c|c|c|c|c|c|c|c|c|c|c|c|}
\hline Indv. & Аmi $\mu 8$ & Ami $\mu 11$ & Аmi $\mu 13$ & Аті $\mu 20$ & Cla 2 & Cla $\mu 5$ & Cla $\mu 6$ & Cla 47 & Сla $\mu 8$ & Cla $\mu 9$ & Cla 410 \\
\hline AL01 & 15115 & 229237 & 268268 & 130158 & 199199 & 65165 & 223223 & 183185 & 101103 & 39139 & 224226 \\
\hline & & 9237 & 252268 & 0158 & & 67 & 7227 & 3183 & & & \\
\hline AL03 & 115115 & 229237 & 268268 & 30132 & 197197 & 157169 & 223239 & 181183 & 113113 & 135137 & 24224 \\
\hline AL04 & 15115 & 229237 & 268268 & 130132 & 227227 & 169177 & 227227 & 183183 & 103113 & 137159 & 4224 \\
\hline AL05 & 15115 & 229237 & 262268 & 130130 & 227227 & 157167 & 227227 & 183183 & 10 & 135 & 224 \\
\hline & & 37 & 268 & & & 167 & 227227 & 3183 & & & \\
\hline AL07 & 115 & 229237 & 268268 & & 197197 & 157165 & 223239 & 185185 & & & 26226 \\
\hline AL08 & 115115 & 229237 & 262270 & 30 & 227229 & 165171 & 227229 & 181181 & 10 & 139141 & 222224 \\
\hline 99 & 5 & 37 & 68 & 58 & 15 & 65 & 27 & 5 & 1 & 39 & 24 \\
\hline & & 2 & 26 & & & 67 & 227227 & 35 & & & \\
\hline AL11 & 115 & 229237 & 68 & & & 165 & 223227 & 85 & & & 224224 \\
\hline 12 & 15 & 229237 & 268268 & 58 & 19 & 65 & 22 & 35 & 10 & 53 & 224 \\
\hline 13 & & 29237 & 70 & 30 & 2 & 55 & 2 & 33 & 10 & 57 & 224 \\
\hline 14 & & 1237 & 68 & & 15 & 65 & 223 & 35 & & & 2224 \\
\hline AL15 & & 231237 & 262268 & 130 & 223 & 169177 & 223223 & 83 & 10 & 59 & 224224 \\
\hline AL16 & 115115 & 231237 & 268268 & 13 & 223227 & 177 & 223223 & 18 & 10 & 39 & 222222 \\
\hline 17 & & 37 & 268 & 58 & 2 & 67 & 223223 & 35 & 10 & 39 & 6254 \\
\hline AL18 & 115 & 225237 & 252268 & 32 & 227243 & 65 & 227227 & 181183 & 10 & 53 & 224254 \\
\hline AL19 & 115115 & 229237 & 268268 & 130158 & 209209 & 165167 & 227227 & 183185 & 103101 & 157157 & 224224 \\
\hline AL20 & 115115 & 229237 & 268268 & 130158 & 209209 & 157165 & 227227 & 183185 & 103103 & 159159 & 224224 \\
\hline & & 229237 & 268268 & & 229229 & 165165 & 231231 & 183185 & 10 & 157159 & 226226 \\
\hline AL22 & 115115 & 229237 & 268270 & 130154 & 199227 & 171171 & 231231 & 181181 & 111101 & 135139 & 226254 \\
\hline AL23 & 115115 & 229235 & 268272 & 130162 & 199227 & 171181 & 237127 & 183183 & 103111 & 145145 & 252254 \\
\hline L24 & 115115 & 227235 & 268268 & 130130 & 227227 & 165171 & 227227 & 185185 & 121103 & 149159 & 224224 \\
\hline
\end{tabular}


APÊNDICE 2 - Genótipos de todos os indivíduos em formato de três dígitos para cada alelo

\begin{tabular}{|c|c|c|c|c|c|c|c|c|c|c|c|}
\hline Indv. & Аті $\mu 8$ & Ami $\mu 11$ & Ami $\mu 13$ & Аті $\mu 20$ & Cla 2 & Cla 45 & Cla $\mu 6$ & Cla $\mu 7$ & Cla 48 & Cla $\mu 9$ & Сla $\mu 10$ \\
\hline $\mathrm{L} 25$ & 115 & 227235 & 268268 & 130130 & 9227 & 171181 & 225225 & 181181 & 113113 & 147149 & 224254 \\
\hline 501 & 5 & 7235 & 262262 & 126126 & 197197 & 171173 & 237239 & 183183 & & 139139 & 28 \\
\hline 2 & & 35 & 60 & 12 & 97 & 3 & 39 & 03 & & 39 & 26 \\
\hline 03 & & 235 & & & 97 & & 39 & & & 67 & \\
\hline 04 & 5 & 227235 & 250260 & 126158 & 197197 & 165171 & 239239 & 215215 & 101115 & 139157 & 226228 \\
\hline 505 & & 227235 & 250 & 126 & 19 & 16 & 239239 & 83 & & 69 & 24 \\
\hline 06 & & 235 & 58 & 12 & 19 & 73 & 237237 & 83 & & & 26 \\
\hline 07 & & 35 & 58 & 12 & 19 & 71 & 239239 & 83 & & 65 & 26 \\
\hline 08 & & 227235 & 260260 & 126 & 197197 & 171 & 241241 & 183 & & 55 & 226226 \\
\hline S09 & & 227235 & 260 & 12 & 197 & 171 & 239239 & 183215 & 14 & 37 & 220224 \\
\hline 10 & & 235 & 62 & 12 & 7 & 31 & 239239 & 15 & 1 & & 28 \\
\hline 11 & & 235 & 252 & 130 & 197 & 71 & 239239 & 215 & & 67 & 226226 \\
\hline 12 & & 227235 & 250260 & 126 & 197 & & 239239 & 203203 & & & 220226 \\
\hline S13 & 5 & 227235 & 260260 & 126 & 199199 & 73 & 239239 & 203203 & 01 & 45 & 226226 \\
\hline 14 & 5 & 7235 & 260262 & 126 & 197199 & 81 & 237241 & 215215 & 10 & 55 & 220225 \\
\hline 515 & & 227235 & 262262 & 126156 & 197199 & 171173 & 237239 & 183215 & 14 & 155 & 226228 \\
\hline 516 & 115 & 227235 & 258262 & 126158 & 197197 & 165173 & 239239 & 183183 & 10 & 47 & 226226 \\
\hline S17 & 115115 & 227235 & 262268 & 130158 & 199199 & 171171 & 237239 & 183183 & 101117 & 155155 & 220256 \\
\hline 01 & 15 & 223237 & 248270 & 158158 & 229227 & 177179 & 229229 & 183183 & 125 & 159 & 272272 \\
\hline IC02 & 115 & 223235 & 252268 & 128128 & 227237 & 159159 & 239239 & 183183 & 125125 & 137151 & 258274 \\
\hline С03 & 115115 & 223235 & 268268 & 128128 & 227237 & 159215 & 229239 & 183183 & 125125 & 135151 & 258274 \\
\hline 04 & 115115 & 223235 & 268268 & 128128 & 227237 & 159159 & 229239 & 183183 & 11 & 135151 & 258274 \\
\hline C05 & 115115 & 223237 & 262268 & 128128 & 227227 & 159159 & 229239 & 183183 & 105105 & 135149 & 268272 \\
\hline IC06 & 115115 & 231237 & 268268 & 128128 & 239239 & 179215 & 239239 & 183183 & 105117 & 135135 & 268274 \\
\hline IC07 & 115115 & 223235 & 246268 & 128128 & 229237 & 179159 & 229239 & 183183 & 111111 & 135135 & 258264 \\
\hline
\end{tabular}


APÊNDICE 2 - Genótipos de todos os indivíduos em formato de três dígitos para cada alelo

\begin{tabular}{|c|c|c|c|c|c|c|c|c|c|c|c|}
\hline V. & $\mu 8$ & $i i \mu 11$ & $i \mu 13$ & пі $\mu 20$ & Cla 2 & Cla 5 & Cla 46 & $\operatorname{la} \mu 7$ & Сla $\mu 8$ & $\operatorname{la\mu } 9$ & $a \mu$ \\
\hline IC08 & 117 & 23223 & 52256 & 8128 & 37237 & 203 & 39239 & 3183 & 111 & & \\
\hline & & & & & & & & & & & \\
\hline & & & & & & & & & & & \\
\hline 302 & & & & & 3213 & & 9239 & & & & \\
\hline & & & & & & & & & & & \\
\hline & & & & & & & 239 & & & & \\
\hline & & & & & & & & & & & \\
\hline & & & & & & & & & & & \\
\hline & & & & & & & 39 & & & & \\
\hline & & & & & & & & & & & \\
\hline & & & & & & & & & & & \\
\hline & & & & & & & & & & & \\
\hline & & & & & & & & & & & \\
\hline & & & & & & & & & & & \\
\hline & & & & & & & & & & & \\
\hline & & & & & & & & & & & \\
\hline & & & & & & & & & & & \\
\hline & & & & & & & & & & & \\
\hline & & & & & & & & & & & \\
\hline & & & & & & & & & & & \\
\hline & & 9235 & 264272 & & 203203 & & 223227 & & & & 224 \\
\hline & & & & & & & & & & & \\
\hline & & & & & & & & & & & \\
\hline & & & 272272 & & & & & & & & \\
\hline A06 & 17117 & 227235 & 264272 & 124144 & 203203 & 167169 & 159159 & 215245 & 123125 & 161165 & 8 \\
\hline
\end{tabular}


APÊNDICE 2 - Genótipos de todos os indivíduos em formato de três dígitos para cada alelo

\begin{tabular}{|c|c|c|c|c|c|c|c|c|c|c|c|}
\hline Idv. & Аті $\mu 8$ & Аті $\mu 11$ & Аті $\mu 13$ & Аmi $\mu 20$ & Cla 2 & Cla 45 & Cla $\mu 6$ & Cla $\mu 7$ & Сla $\mu 8$ & Сla 9 & Cla 10 \\
\hline PA07 & 115115 & 227235 & 272272 & 124124 & 201201 & 167169 & 223227 & 215215 & 109125 & 161165 & 222246 \\
\hline A08 & 117 & 9235 & 264272 & 124124 & 203 & 169187 & 223227 & 243 & 9125 & 65 & \\
\hline PA09 & 115115 & 229235 & 272272 & 116130 & 203203 & 167199 & 223223 & 203243 & 123125 & 161165 & 222228 \\
\hline PT01 & 115115 & 235235 & 260264 & 156156 & 205241 & 175175 & 223223 & 203243 & 125235 & 161165 & 222246 \\
\hline Г02 & 117 & 229229 & 254254 & 144156 & 203203 & 167175 & 223223 & 203243 & 25 & 161177 & 14246 \\
\hline Г03 & 117117 & 229229 & 260260 & 126144 & 203203 & 7175 & 159225 & 203243 & & 161165 & 222246 \\
\hline T04 & 117117 & 229237 & 254260 & 124124 & 205205 & 165165 & 223223 & 181181 & 115125 & 161177 & 222246 \\
\hline PT05 & 117117 & 229235 & 254254 & 156156 & 203203 & 175175 & 159225 & 203243 & 01 & 161165 & 244246 \\
\hline 06 & 117 & 237237 & 25 & 56 & 203 & 1 & 223223 & 43 & 01 & 16 & 46 \\
\hline 07 & 15 & 229237 & 26 & 46 & 20 & 99 & 159227 & 247 & & 77 & 50 \\
\hline РT08 & 117 & 223229 & 228254 & 56 & 24 & & 225225 & 43 & & & 4246 \\
\hline Г09 & 117 & 229229 & 254272 & & & 167 & 225 & 247 & & & 222246 \\
\hline PT10 & 117 & 229235 & 254260 & 126 & 203203 & 167173 & 225225 & 203203 & 5 & 16 & 222256 \\
\hline & 17 & 229229 & 2 & 44 & 20 & 1 & 223 & 43 & & & 4246 \\
\hline$\Gamma 12$ & 117 & 229229 & 25 & 56 & 203 & 175 & 223223 & 243 & & 16 & 242246 \\
\hline PT13 & 117 & 229235 & 254272 & 08 & 203203 & 167175 & 225225 & 203203 & & 16 & 242246 \\
\hline PT14 & 117117 & 223235 & 254272 & 156156 & 203203 & 175175 & 225225 & 203243 & 13 & 16 & 242244 \\
\hline 15 & 117 & 229235 & 254260 & 26 & 20 & 16 & 225225 & 243 & & 16 & 244246 \\
\hline PT16 & 117117 & 235235 & 254260 & 126156 & 203203 & 161175 & 225225 & 203243 & 12 & 161163 & 242246 \\
\hline PT17 & 117117 & 229229 & 254254 & 000000 & 205241 & 167175 & 223223 & 203203 & 101125 & 161163 & 244246 \\
\hline & 117 & 235235 & 260264 & & 203203 & 175175 & 225225 & 203203 & 125135 & 16 & 244248 \\
\hline PT19 & 115117 & 229235 & 260272 & 126144 & 203205 & 167175 & 223223 & 203243 & 133135 & 161161 & 246250 \\
\hline РT20 & 115117 & 229235 & 254272 & 144144 & 205241 & 167175 & 159225 & 203243 & 101125 & 161165 & 244246 \\
\hline CH01 & 115117 & 235235 & 264270 & 126126 & 205205 & 175175 & 223223 & 181215 & 115125 & 161165 & 222250 \\
\hline СH02 & 115117 & 227235 & 272272 & 126158 & 195205 & 175175 & 159225 & 203215 & 115135 & 161161 & 222250 \\
\hline
\end{tabular}


APÊNDICE 2 - Genótipos de todos os indivíduos em formato de três dígitos para cada alelo

\begin{tabular}{|c|c|c|c|c|c|c|c|c|c|c|c|}
\hline Indv. & Аті $\mu 8$ & Аті $\mu 11$ & Аmi $\mu 13$ & Аті $\mu 20$ & Cla 2 & Cla 45 & Cla $\mu 6$ & Cla 7 & Сla $\mu 8$ & Cla $\mu$ & Cla $\mu 10$ \\
\hline$\overline{\mathrm{CH} 03}$ & 115117 & 235235 & 264272 & 128156 & 205205 & 175175 & 159223 & 181215 & 101125 & 161161 & 222250 \\
\hline H04 & 5115 & 227237 & 264264 & 8144 & 203 & 199 & 223 & 215 & 1 & 177 & 2 \\
\hline 05 & 17 & 243 & 4 & 52 & 199 & 57 & 1 & 39 & & 65 & 2 \\
\hline H06 & 115117 & 35235 & 266268 & 6156 & 205205 & 75 & & 203215 & & 177 & 2250 \\
\hline CH07 & 117117 & 227235 & 262262 & 156158 & 203203 & 169175 & 223223 & 181243 & 101135 & 161165 & 222246 \\
\hline H08 & 117117 & 237237 & 228266 & 156156 & 195205 & 175175 & 159159 & 181181 & 101135 & 161177 & 222222 \\
\hline 109 & 15 & 237 & 72 & 26 & 205 & 75 & 25 & 5 & 12 & 65 & 4250 \\
\hline $\mathrm{H} 10$ & 1 & 237 & 272 & 40 & 195205 & 75 & & 18 & & 177 & 2250 \\
\hline CH11 & 117117 & 237237 & 250272 & 000000 & 195195 & 175175 & 223223 & 203215 & 101 & 161177 & 222250 \\
\hline 112 & 5 & 237237 & 70 & 56 & 205 & 75 & 25 & 03 & 10 & 177 & 250 \\
\hline 01 & 1 & 227235 & 68 & 126 & 19 & 71 & 23 & 21 & 10 & 179 & 228256 \\
\hline J02 & 1 & 235 & 68 & 154 & 95 & 171 & 22 & 215215 & 19 & 165 & 254258 \\
\hline U03 & 11 & 227235 & 268 & 124124 & 195 & 167167 & 223 & 15 & 109 & 165 & 254256 \\
\hline 04 & 1 & 227235 & 2 & 126 & 15 & 71 & 223 & 21 & 09 & 65 & 228256 \\
\hline 05 & 1 & 229235 & 64 & 164 & 05 & 79 & 23 & 215243 & 11 & 65 & 216256 \\
\hline DU06 & 115 & 227235 & 268 & 124124 & 195 & 167167 & 159223 & 181215 & 123 & 177179 & 222256 \\
\hline DU07 & 115115 & 229237 & 268268 & 126126 & 195195 & 171171 & 223223 & 215215 & 109125 & 161165 & 224228 \\
\hline J08 & 115 & 229237 & 66 & 126 & 15 & 171 & 159 & 181215 & 109109 & 177177 & 220222 \\
\hline DU09 & 115 & 229237 & 268268 & 124124 & 195195 & 167171 & 159223 & 215215 & 123125 & 165179 & 222256 \\
\hline DU10 & 115115 & 229237 & 268268 & 126152 & 195195 & 167167 & 159159 & 215215 & 109125 & 161165 & 254256 \\
\hline DU11 & 115115 & 231237 & 268268 & 128164 & 195205 & 171179 & 155155 & 215215 & 109119 & 161165 & 216256 \\
\hline J12 & 115 & 229237 & 268268 & 126128 & 195195 & 167171 & 223223 & 213213 & 109125 & 161165 & 222256 \\
\hline DU13 & 115115 & 229237 & 268272 & 126126 & 195201 & 171171 & 155223 & 181181 & 119125 & 177179 & 216222 \\
\hline DU14 & 115115 & 229237 & 268268 & 000000 & 195195 & 167171 & 223223 & 215215 & 119125 & 177179 & 228256 \\
\hline
\end{tabular}


APÊNDICE 2 - Genótipos de todos os indivíduos em formato de três dígitos para cada alelo

\begin{tabular}{|c|c|c|c|c|c|c|c|c|c|c|c|}
\hline dv. & mі $\mu 8$ & Аmi $\mu 11$ & Ami $\mu 13$ & Ami $\mu 20$ & Cla 2 & Cla 5 & Cla $\mu 6$ & Cla $\mu 7$ & Сla $\mu 8$ & Cla $\mu 9$ & Cla $\mu 10$ \\
\hline DU15 & 115115 & 229237 & 268268 & 126126 & 195195 & 171171 & 219219 & 215215 & 109109 & 177179 & 28256 \\
\hline DU16 & 115115 & 229237 & 268272 & 126126 & 195201 & 171179 & 159223 & 181245 & 109109 & 177179 & 6222 \\
\hline DU17 & 115115 & 229237 & 268268 & 124126 & 195195 & 167171 & 223223 & 215215 & 109119 & 161165 & \\
\hline DU18 & 115115 & 229237 & 262268 & 124152 & 195195 & 167167 & 223223 & 181215 & 109125 & 177179 & 228256 \\
\hline DU19 & 115 & 29237 & 266270 & 126 & 195205 & 171 & 159159 & 215 & 10 & 161165 & 216 \\
\hline DU20 & 115117 & 235235 & 268270 & 152 & 195201 & 000000 & 159159 & 215243 & 109119 & 161165 & 216222 \\
\hline DU21 & 115115 & 229237 & 266268 & 152152 & 195195 & 167171 & 155223 & 215239 & 109109 & 177179 & 216256 \\
\hline U22 & 115 & 229237 & 264270 & 126 & 195201 & 171179 & 159159 & 181243 & 109109 & 177179 & 216256 \\
\hline DU23 & 115 & 237237 & 266268 & 130 & 195201 & 167179 & 159159 & 181181 & 119125 & 177179 & 216 \\
\hline CAT01 & & & & & & & & & & & $2<$ \\
\hline CA & & 23 & 204 & & & & 22 & & & & 231 \\
\hline $\mathrm{CH}$ & & & & & & & & & & & \\
\hline & & & & & & & & & & & \\
\hline & & & & & & & & & & & \\
\hline & & & & & & & & & & & \\
\hline
\end{tabular}


APÊNDICE 3. Diferenciação gênica e genotípica entre as populações estudadas

\begin{tabular}{|c|c|c|c|c|c|c|c|c|c|}
\hline \multirow[b]{2}{*}{ Locos } & \multicolumn{4}{|c|}{ Diferenciação genotípica } & \multicolumn{5}{|c|}{ Diferenciação gênica } \\
\hline & Pop1 & Pop2 & Prob & EP & Locos & Pop1 & Pop2 & Prob & EP \\
\hline Amiu8 & $\mathrm{CH}$ & $\mathrm{AL}$ & $0,00009 * *$ & 0,00006 & Amiu8 & AL & $\mathrm{CH}$ & $0,00000^{* *}$ & 0,00000 \\
\hline Amiu11 & $\mathrm{CH}$ & AL & $0,00009 * *$ & 0,00005 & Amiu11 & AL & $\mathrm{CH}$ & $0,00004^{* *}$ & 0,00004 \\
\hline Amiu13 & $\mathrm{CH}$ & $\mathrm{AL}$ & $0,00000 * *$ & 0,00000 & Amiu13 & AL & $\mathrm{CH}$ & $0,00000^{* *}$ & 0,00000 \\
\hline Amiu20 & $\mathrm{CH}$ & $\mathrm{AL}$ & $0,00000 * *$ & 0,00000 & Amiu20 & AL & $\mathrm{CH}$ & $0,00000^{* *}$ & 0,00000 \\
\hline Clau2 & $\mathrm{CH}$ & $\mathrm{AL}$ & $0,00000^{* *}$ & 0,00000 & Clau2 & AL & $\mathrm{CH}$ & $0,00000^{* *}$ & 0,00000 \\
\hline Clau5 & $\mathrm{CH}$ & $\mathrm{AL}$ & $0,00000^{* *}$ & 0,00000 & Clau5 & AL & $\mathrm{CH}$ & $0,00000^{* *}$ & 0,00000 \\
\hline Clau6 & $\mathrm{CH}$ & AL & $0,00000^{* *}$ & 0,00000 & Clau6 & AL & $\mathrm{CH}$ & $0,00000^{* *}$ & 0,00000 \\
\hline Clau7 & $\mathrm{CH}$ & AL & $0,00000 * *$ & 0,00000 & Clau7 & AL & $\mathrm{CH}$ & $0,00000^{* *}$ & 0,00000 \\
\hline Clau8 & $\mathrm{CH}$ & $\mathrm{AL}$ & $0,00000 * *$ & 0,00000 & Clau8 & AL & $\mathrm{CH}$ & $0,00000^{* *}$ & 0,00000 \\
\hline Clau9 & $\mathrm{CH}$ & AL & $0,00000^{* *}$ & 0,00000 & Clau9 & AL & $\mathrm{CH}$ & $0,00000^{* *}$ & 0,00000 \\
\hline Clau10 & $\mathrm{CH}$ & AL & $0,00000^{* *}$ & 0,00000 & Clau10 & AL & $\mathrm{CH}$ & $0,00000^{* *}$ & 0,00000 \\
\hline Amu8 & DU & $\mathrm{AL}$ & 1,00000 & 0,00000 & Amiu8 & AL & DU & 1,00000 & 0,00000 \\
\hline Amiu11 & DU & $\mathrm{AL}$ & 0,13065 & 0,00479 & Amiu11 & $\mathrm{AL}$ & DU & 0,18156 & 0,00585 \\
\hline Amiu13 & DU & AL & 0,08018 & 0,00382 & Amiu13 & AL & DU & 0,05137 & 0,00291 \\
\hline Amiu20 & DU & $\mathrm{AL}$ & $0,00000 * *$ & 0,00000 & Amiu20 & $\mathrm{AL}$ & DU & $0,00000^{* *}$ & 0,00000 \\
\hline Clau2 & DU & AL & $0,00000^{* *}$ & 0,00000 & Clau2 & AL & DU & $0,00000^{* *}$ & 0,00000 \\
\hline Clau5 & DU & AL & $0,00000 * *$ & 0,00000 & Clau5 & AL & DU & $0,00000^{* *}$ & 0,00000 \\
\hline Clau6 & DU & $\mathrm{AL}$ & $0,00000^{* *}$ & 0,00000 & Clau6 & AL & DU & $0,00000^{* *}$ & 0,00000 \\
\hline Clau7 & DU & AL & $0,00000^{* *}$ & 0,00000 & Clau7 & AL & DU & $0,00000^{* *}$ & 0,00000 \\
\hline Clau8 & DU & AL & $0,00000^{* *}$ & 0,00000 & Clau8 & AL & DU & $0,00000^{* *}$ & 0,00000 \\
\hline Clau9 & DU & $\mathrm{AL}$ & $0,00000 * *$ & 0,00000 & Clau9 & AL & DU & $0,00000^{* *}$ & 0,00000 \\
\hline Clau10 & DU & AL & $0,00000^{* *}$ & 0,00000 & Clau10 & AL & DU & $0,00000^{* *}$ & 0,00000 \\
\hline Amiu8 & IC & AL & 1,00000 & 0,00000 & Amiu8 & AL & IC & 0,45874 & 0,00221 \\
\hline Amiu11 & IC & $\mathrm{AL}$ & $0,00000 * *$ & 0,00000 & Amiu11 & $\mathrm{AL}$ & IC & $0,00000^{* *}$ & 0,00000 \\
\hline Amiu13 & IC & AL & 0,06276 & 0,00397 & Amiu13 & AL & IC & 0,02306* & 0,00324 \\
\hline Amiu20 & IC & AL & $0,00000^{* *}$ & 0,00000 & Amiu20 & AL & IC & $0,00000^{* *}$ & 0,00000 \\
\hline Clau2 & IC & $\mathrm{AL}$ & $0,00120 * *$ & 0,00035 & Clau2 & AL & IC & $0,00000^{* *}$ & 0,00000 \\
\hline Clau5 & IC & AL & $0,00000^{* *}$ & 0,00000 & Clau5 & AL & IC & $0,00000^{* *}$ & 0,00000 \\
\hline Clau6 & IC & AL & $0,00000^{* *}$ & 0,00000 & Clau6 & AL & IC & $0,00000^{* *}$ & 0,00000 \\
\hline Clau7 & IC & $\mathrm{AL}$ & $0,00972 * *$ & 0,00090 & Clau7 & AL & IC & $0,00167^{* *}$ & 0,00031 \\
\hline Clau8 & IC & AL & $0,00000^{* *}$ & 0,00000 & Clau8 & AL & IC & $0,00000^{* *}$ & 0,00000 \\
\hline Clau9 & IC & AL & 0,10497 & 0,00521 & Clau9 & AL & IC & 0,01184* & 0,00161 \\
\hline Clau10 & IC & $\mathrm{AL}$ & $0,00000 * *$ & 0,00000 & Clau10 & AL & IC & $0,00000^{* *}$ & 0,00000 \\
\hline Amiu8 & PA & AL & 0,06613 & 0,00196 & Amiu8 & AL & PA & 0,01552* & 0,00075 \\
\hline Amiu11 & PA & AL & $0,00000^{* *}$ & 0,00000 & Amiu11 & AL & PA & $0,00000^{* *}$ & 0,00000 \\
\hline Amiu13 & PA & $\mathrm{AL}$ & $0,00000 * *$ & 0,00000 & Amiu13 & AL & PA & $0,00000^{* *}$ & 0,00000 \\
\hline Amiu20 & PA & AL & $0,00000^{* *}$ & 0,00000 & Amiu20 & AL & PA & $0,00000^{* *}$ & 0,00000 \\
\hline Clau2 & PA & AL & $0,00000^{* *}$ & 0,00000 & Clau2 & AL & PA & $0,00000^{* *}$ & 0,00000 \\
\hline Clau5 & PA & $\mathrm{AL}$ & $0,00000 * *$ & 0,00000 & Clau5 & AL & PA & $0,00000^{* *}$ & 0,00000 \\
\hline Clau6 & PA & AL & 0,07866 & 0,00336 & Clau6 & AL & PA & 0,02514* & 0,00283 \\
\hline Clau7 & PA & AL & $0,00000^{* *}$ & 0,00000 & Clau7 & AL & PA & $0,00000^{* *}$ & 0,00000 \\
\hline
\end{tabular}


APÊNDICE 3. Diferenciação gênica e genotípica entre as populações estudadas

\begin{tabular}{|c|c|c|c|c|c|c|c|c|c|}
\hline \multirow[b]{2}{*}{ Locos } & \multicolumn{4}{|c|}{ Diferenciação genotípica } & \multicolumn{5}{|c|}{ Diferenciação gênica } \\
\hline & Pop1 & Pop2 & Prob & EP & Locos & Pop1 & Pop2 & Prob & EP \\
\hline Clau8 & PA & $\mathrm{AL}$ & $0,00000 * *$ & 0,00000 & Clau8 & $\mathrm{AL}$ & PA & $0,00000 * *$ & 0,00000 \\
\hline Clau9 & PA & $\mathrm{AL}$ & $0,00000^{* *}$ & 0,00000 & Clau9 & AL & PA & $0,00000^{* *}$ & 0,00000 \\
\hline Clau10 & PA & AL & $0,00000^{* *}$ & 0,00000 & Clau10 & AL & PA & $0,00000^{* *}$ & 0,00000 \\
\hline Amiu8 & PB & $\mathrm{AL}$ & $0,00037 * *$ & 0,00013 & Amiu8 & AL & PB & $0,00000^{* *}$ & 0,00000 \\
\hline Amiu11 & PB & $\mathrm{AL}$ & $0,00014^{* *}$ & 0,00009 & Amiu11 & AL & PB & $0,00012^{* *}$ & 0,00008 \\
\hline Amiu13 & PB & AL & 0,05290 & 0,00282 & Amiu13 & AL & PB & $0,00818^{* *}$ & 0,00133 \\
\hline Amiu20 & PB & $\mathrm{AL}$ & $0,00000^{* *}$ & 0,00000 & Amiu20 & AL & PB & $0,00000^{* *}$ & 0,00000 \\
\hline Clau2 & PB & $\mathrm{AL}$ & $0,00000 * *$ & 0,00000 & Clau2 & AL & PB & $0,00000^{* *}$ & 0,00000 \\
\hline Clau5 & PB & AL & $0,00000^{* *}$ & 0,00000 & Clau5 & AL & PB & $0,00000^{* *}$ & 0,00000 \\
\hline Clau6 & PB & AL & $0,00000^{* *}$ & 0,00000 & Clau6 & AL & PB & $0,00000^{* *}$ & 0,00000 \\
\hline Clau7 & PB & $\mathrm{AL}$ & $0,00000^{* *}$ & 0,00000 & Clau7 & AL & PB & $0,00000^{* *}$ & 0,00000 \\
\hline Clau8 & PB & AL & $0,00000^{* *}$ & 0,00000 & Clau8 & AL & PB & $0,00000^{* *}$ & 0,00000 \\
\hline Clau9 & PB & $\mathrm{AL}$ & $0,00001^{* *}$ & 0,00001 & Clau9 & AL & PB & $0,00000^{* *}$ & 0,00000 \\
\hline Clau10 & PB & $\mathrm{AL}$ & 0,10687 & 0,00356 & Clau10 & AL & PB & 0,12433 & 0,00501 \\
\hline Amiu8 & PT & AL & $0,00000^{* *}$ & 0,00000 & Amiu8 & AL & PT & $0,00000^{* *}$ & 0,00000 \\
\hline Amiu11 & PT & AL & $0,00005^{* *}$ & 0,00004 & Amiu11 & AL & PT & $0,00000^{* *}$ & 0,00000 \\
\hline Amiu13 & PT & $\mathrm{AL}$ & $0,00000 * *$ & 0,00000 & Amiu13 & AL & PT & $0,00000^{* *}$ & 0,00000 \\
\hline Amiu20 & PT & $\mathrm{AL}$ & $0,00000 * *$ & 0,00000 & Amiu20 & AL & $\mathrm{PT}$ & $0,00000 * *$ & 0,00000 \\
\hline Clau2 & PT & AL & $0,00000^{* *}$ & 0,00000 & Clau2 & AL & PT & $0,00000^{* *}$ & 0,00000 \\
\hline Clau5 & PT & $\mathrm{AL}$ & $0,00000^{* *}$ & 0,00000 & Clau5 & AL & PT & $0,00000^{* *}$ & 0,00000 \\
\hline Clau6 & PT & AL & $0,00000^{* *}$ & 0,00000 & Clau6 & AL & PT & $0,00000^{* *}$ & 0,00000 \\
\hline Clau7 & PT & $\mathrm{AL}$ & $0,00000^{* *}$ & 0,00000 & Clau7 & AL & PT & $0,00000^{* *}$ & 0,00000 \\
\hline Clau8 & PT & $\mathrm{AL}$ & $0,00000^{* *}$ & 0,00000 & Clau8 & AL & PT & $0,00000^{* *}$ & 0,00000 \\
\hline Clau9 & PT & $\mathrm{AL}$ & $0,00000 * *$ & 0,00000 & Clau9 & $\mathrm{AL}$ & PT & $0,00000 * *$ & 0,00000 \\
\hline Clau10 & PT & AL & $0,00000^{* *}$ & 0,00000 & Clau10 & AL & PT & $0,00000^{* *}$ & 0,00000 \\
\hline Amiu8 & RN & $\mathrm{AL}$ & $0,04300 *$ & 0,00144 & Amiu8 & AL & RN & 0,01165* & 0,00058 \\
\hline Amiu11 & RN & AL & $0,00168 * *$ & 0,00043 & Amiu11 & AL & RN & $0,00058^{* *}$ & 0,00017 \\
\hline Amiu13 & RN & $\mathrm{AL}$ & $0,00469 * *$ & 0,00083 & Amiu13 & AL & RN & $0,00018^{* *}$ & 0,00009 \\
\hline Amiu20 & RN & $\mathrm{AL}$ & $0,00005^{* *}$ & 0,00004 & Amiu20 & AL & RN & $0,00040^{* *}$ & 0,00024 \\
\hline Clau2 & $\mathrm{RN}$ & $\mathrm{AL}$ & $0,00000 * *$ & 0,00000 & Clau2 & AL & $\mathrm{RN}$ & $0,00000 * *$ & 0,00000 \\
\hline Clau5 & RN & AL & $0,00009 * *$ & 0,00005 & Clau5 & AL & RN & $0,00004^{* *}$ & 0,00004 \\
\hline Clau6 & RN & $\mathrm{AL}$ & $0,00029 * *$ & 0,00014 & Clau6 & AL & RN & $0,00000^{* *}$ & 0,00000 \\
\hline Clau7 & RN & AL & $0,00000^{* *}$ & 0,00000 & Clau7 & AL & RN & $0,00000^{* *}$ & 0,00000 \\
\hline Clau8 & RN & AL & $0,00002^{* *}$ & 0,00001 & Clau8 & AL & RN & $0,00015^{* *}$ & 0,00010 \\
\hline Clau9 & RN & $\mathrm{AL}$ & 0,00050 ** & 0,00025 & Clau9 & AL & RN & $0,00017^{* *}$ & 0,00016 \\
\hline Clau10 & RN & AL & 0,15135 & 0,00425 & Clau10 & AL & RN & 0,19975 & 0,00671 \\
\hline Amiu8 & RS & AL & 1,00000 & 0,00000 & Amiu8 & AL & RS & 1,00000 & 0,00000 \\
\hline Amiu11 & RS & $\mathrm{AL}$ & $0,00000^{* *}$ & 0,00000 & Amiu11 & AL & RS & $0,00000^{* *}$ & 0,00000 \\
\hline Amiu13 & RS & AL & $0,00000^{* *}$ & 0,00000 & Amiu13 & AL & RS & $0,00000^{* *}$ & 0,00000 \\
\hline Amiu20 & RS & AL & $0,00000^{* *}$ & 0,00000 & Amiu20 & AL & RS & $0,00000 * *$ & 0,00000 \\
\hline Clau2 & RS & $\mathrm{AL}$ & $0,00000^{* *}$ & 0,00000 & Clau2 & AL & RS & $0,00000^{* *}$ & 0,00000 \\
\hline
\end{tabular}


APÊNDICE 3. Diferenciação gênica e genotípica entre as populações estudadas

\begin{tabular}{|c|c|c|c|c|c|c|c|c|c|}
\hline \multirow[b]{2}{*}{ Locos } & \multicolumn{4}{|c|}{ Diferenciação genotípica } & \multicolumn{5}{|c|}{ Diferenciação gênica } \\
\hline & Pop1 & Pop2 & Prob & EP & Locos & Pop1 & Pop2 & Prob & EP \\
\hline Clau5 & RS & $\mathrm{AL}$ & $0,00000 * *$ & 0,00000 & Clau5 & $\mathrm{AL}$ & RS & $0,00000^{* *}$ & 0,00000 \\
\hline Clau6 & RS & AL & $0,00000 * *$ & 0,00000 & Clau6 & $\mathrm{AL}$ & RS & $0,00000^{* *}$ & 0,00000 \\
\hline Clau7 & RS & AL & $0,00000 * *$ & 0,00000 & Clau7 & $\mathrm{AL}$ & RS & $0,00000 * *$ & 0,00000 \\
\hline Clau8 & RS & AL & $0,00000 * *$ & 0,00000 & Clau8 & $\mathrm{AL}$ & RS & $0,00000 * *$ & 0,00000 \\
\hline Clau9 & RS & AL & $0,00262 * *$ & 0,00071 & Clau9 & $\mathrm{AL}$ & RS & $0,00000^{* *}$ & 0,00000 \\
\hline Clau10 & RS & AL & $0,00000 * *$ & 0,00000 & Clau10 & $\mathrm{AL}$ & RS & $0,00000 * *$ & 0,00000 \\
\hline Amiu8 & DU & $\mathrm{CH}$ & $0,00015 * *$ & 0,00009 & Amiu8 & $\mathrm{CH}$ & DU & $0,00003 * *$ & 0,00003 \\
\hline Amiu11 & DU & $\mathrm{CH}$ & $0,00623 * *$ & 0,00106 & Amiu11 & $\mathrm{CH}$ & DU & $0,00379 * *$ & 0,00071 \\
\hline Amiu13 & DU & $\mathrm{CH}$ & $0,00001^{* *}$ & 0,00001 & Amiu13 & $\mathrm{CH}$ & DU & $0,00000 * *$ & 0,00000 \\
\hline Amiu20 & DU & $\mathrm{CH}$ & $0,00209 * *$ & 0,00045 & Amiu20 & $\mathrm{CH}$ & DU & $0,00103 * *$ & 0,00065 \\
\hline Clau2 & DU & $\mathrm{CH}$ & $0,00000 * *$ & 0,00000 & Clau2 & $\mathrm{CH}$ & DU & $0,00000 * *$ & 0,00000 \\
\hline Clau5 & DU & $\mathrm{CH}$ & $0,00000^{* *}$ & 0,00000 & Clau5 & $\mathrm{CH}$ & DU & $0,00000 * *$ & 0,00000 \\
\hline Clau6 & DU & $\mathrm{CH}$ & 0,06698 & 0,00266 & Clau6 & $\mathrm{CH}$ & DU & $0,03270 *$ & 0,00241 \\
\hline Clau7 & DU & $\mathrm{CH}$ & $0,01344 *$ & 0,00142 & Clau7 & $\mathrm{CH}$ & DU & $0,00296 * *$ & 0,00073 \\
\hline Clau8 & DU & $\mathrm{CH}$ & $0,00000 * *$ & 0,00000 & Clau8 & $\mathrm{CH}$ & DU & $0,00000^{* *}$ & 0,00000 \\
\hline Clau9 & DU & $\mathrm{CH}$ & $0,00702 * *$ & 0,00111 & Clau9 & $\mathrm{CH}$ & DU & $0,00973 * *$ & 0,00101 \\
\hline Clau10 & DU & $\mathrm{CH}$ & $0,00000 * *$ & 0,00000 & Clau10 & $\mathrm{CH}$ & DU & $0,00000 * *$ & 0,00000 \\
\hline Amiu8 & PT & $\mathrm{CH}$ & 0,23124 & 0,00326 & Amiu8 & $\mathrm{CH}$ & PT & 0,12040 & 0,00284 \\
\hline Amiu11 & PT & $\mathrm{CH}$ & $0,00003 * *$ & 0,00003 & Amiu11 & $\mathrm{CH}$ & PT & $0,00000^{* *}$ & 0,00000 \\
\hline Amiu13 & PT & $\mathrm{CH}$ & $0,00000 * *$ & 0,00000 & Amiu13 & $\mathrm{CH}$ & PT & $0,00000 * *$ & 0,00000 \\
\hline Amiu20 & PT & $\mathrm{CH}$ & 0,15861 & 0,00578 & Amiu20 & $\mathrm{CH}$ & PT & 0,06698 & 0,00485 \\
\hline Clau2 & PT & $\mathrm{CH}$ & $0,00275^{* *}$ & 0,00062 & Clau2 & $\mathrm{CH}$ & PT & $0,00000 * *$ & 0,00000 \\
\hline Clau5 & PT & $\mathrm{CH}$ & 0,08049 & 0,00379 & Clau5 & $\mathrm{CH}$ & PT & 0,04965 & 0,00369 \\
\hline Clau6 & PT & $\mathrm{CH}$ & 0,05663 & 0,00299 & Clau6 & $\mathrm{CH}$ & PT & $0,01515^{*}$ & 0,00199 \\
\hline Clau7 & PT & $\mathrm{CH}$ & $0,00000 * *$ & 0,00000 & Clau7 & $\mathrm{CH}$ & PT & $0,00000 * *$ & 0,00000 \\
\hline Clau8 & PT & $\mathrm{CH}$ & 0,15695 & 0,00451 & Clau8 & $\mathrm{CH}$ & PT & 0,10267 & 0,00565 \\
\hline Clau9 & PT & $\mathrm{CH}$ & 0,25085 & 0,00377 & Clau9 & $\mathrm{CH}$ & PT & 0,42349 & 0,00553 \\
\hline Clau10 & PT & $\mathrm{CH}$ & $0,00000 * *$ & 0,00000 & Clau10 & $\mathrm{CH}$ & PT & $0,00000 * *$ & 0,00000 \\
\hline Amiu8 & PT & DU & $0,00000 * *$ & 0,00000 & Amiu8 & DU & PT & $0,00000 * *$ & 0,00000 \\
\hline Amiu11 & PT & DU & $0,00140 * *$ & 0,00036 & Amiu11 & DU & PT & $0,00075^{* *}$ & 0,00031 \\
\hline Amiu13 & PT & DU & $0,00000 * *$ & 0,00000 & Amiu13 & DU & PT & $0,00000 * *$ & 0,00000 \\
\hline Amiu20 & PT & DU & $0,00000 * *$ & 0,00000 & Amiu20 & DU & PT & $0,00000 * *$ & 0,00000 \\
\hline Clau2 & PT & DU & $0,00000 * *$ & 0,00000 & Clau2 & DU & PT & $0,00000 * *$ & 0,00000 \\
\hline Clau5 & PT & DU & $0,00000 * *$ & 0,00000 & Clau5 & DU & PT & $0,00000^{* *}$ & 0,00000 \\
\hline Clau6 & PT & DU & $0,00002 * *$ & 0,00002 & Clau6 & DU & PT & $0,00000 * *$ & 0,00000 \\
\hline Clau7 & PT & DU & $0,00000 * *$ & 0,00000 & Clau7 & DU & PT & $0,00000 * *$ & 0,00000 \\
\hline Clau8 & PT & DU & $0,00000 * *$ & 0,00000 & Clau8 & DU & PT & $0,00000 * *$ & 0,00000 \\
\hline Clau9 & PT & DU & $0,00009 * *$ & 0,00005 & Clau9 & DU & PT & $0,00004 * *$ & 0,00004 \\
\hline Clau10 & PT & DU & $0,00000 * *$ & 0,00000 & Clau10 & DU & PT & $0,00000 * *$ & 0,00000 \\
\hline Amiu8 & $\mathrm{CH}$ & IC & $0,01100^{*}$ & 0,00058 & Amiu8 & IC & $\mathrm{CH}$ & $0,00219 * *$ & 0,00028 \\
\hline Amiu11 & $\mathrm{CH}$ & IC & $0,00082 * *$ & 0,00023 & Amiu11 & IC & $\mathrm{CH}$ & $0,00054 * *$ & 0,00030 \\
\hline
\end{tabular}


APÊNDICE 3. Diferenciação gênica e genotípica entre as populações estudadas

\begin{tabular}{|c|c|c|c|c|c|c|c|c|c|}
\hline \multirow[b]{2}{*}{ Locos } & \multicolumn{4}{|c|}{ Diferenciação genotípica } & \multicolumn{5}{|c|}{ Diferenciação gênica } \\
\hline & Pop1 & Pop2 & Prob & EP & Locos & Pop1 & Pop2 & Prob & EP \\
\hline Amiu13 & $\mathrm{CH}$ & IC & $0,00060^{* *}$ & 0,00032 & Amiu13 & IC & $\mathrm{CH}$ & $0,00000 * *$ & 0,00000 \\
\hline Amiu20 & $\mathrm{CH}$ & IC & $0,00001^{* *}$ & 0,00001 & Amiu20 & IC & $\mathrm{CH}$ & $0,00000 * *$ & 0,00000 \\
\hline Clau2 & $\mathrm{CH}$ & IC & $0,00000 * *$ & 0,00000 & Clau2 & IC & $\mathrm{CH}$ & $0,00000 * *$ & 0,00000 \\
\hline Clau5 & $\mathrm{CH}$ & IC & $0,00000 * *$ & 0,00000 & Clau5 & IC & $\mathrm{CH}$ & $0,00000 * *$ & 0,00000 \\
\hline Clau6 & $\mathrm{CH}$ & IC & $0,00000 * *$ & 0,00000 & Clau6 & IC & $\mathrm{CH}$ & $0,00000 * *$ & 0,00000 \\
\hline Clau7 & $\mathrm{CH}$ & IC & $0,00000^{* *}$ & 0,00000 & Clau7 & IC & $\mathrm{CH}$ & $0,00000 * *$ & 0,00000 \\
\hline Clau8 & $\mathrm{CH}$ & IC & $0,00003 * *$ & 0,00003 & Clau8 & IC & $\mathrm{CH}$ & $0,00047 * *$ & 0,00030 \\
\hline Clau9 & $\mathrm{CH}$ & IC & $0,00000 * *$ & 0,00000 & Clau9 & IC & $\mathrm{CH}$ & $0,00000 * *$ & 0,00000 \\
\hline Clau10 & $\mathrm{CH}$ & IC & $0,00000 * *$ & 0,00000 & Clau10 & IC & $\mathrm{CH}$ & $0,00000 * *$ & 0,00000 \\
\hline Amiu8 & DU & IC & 1,00000 & 0,00000 & Amiu8 & IC & DU & 0,48350 & 0,00224 \\
\hline Amiu11 & DU & IC & $0,00000 * *$ & 0,00000 & Amiu11 & IC & DU & $0,00000 * *$ & 0,00000 \\
\hline Amiu13 & DU & IC & $0,00974 * *$ & 0,00121 & Amiu13 & IC & DU & $0,00258 * *$ & 0,00082 \\
\hline Amiu20 & DU & IC & $0,00000 * *$ & 0,00000 & Amiu20 & IC & DU & $0,00000 * *$ & 0,00000 \\
\hline Clau2 & DU & IC & $0,00000^{* *}$ & 0,00000 & Clau2 & IC & DU & $0,00000 * *$ & 0,00000 \\
\hline Clau5 & DU & IC & $0,00000 * *$ & 0,00000 & Clau5 & IC & DU & $0,00000 * *$ & 0,00000 \\
\hline Clau6 & DU & IC & $0,00000^{* *}$ & 0,00000 & Clau6 & IC & DU & $0,00000 * *$ & 0,00000 \\
\hline Clau7 & DU & IC & $0,00000 * *$ & 0,00000 & Clau7 & IC & DU & $0,00000 * *$ & 0,00000 \\
\hline Clau8 & DU & IC & $0,00000 * *$ & 0,00000 & Clau8 & IC & DU & $0,00000 * *$ & 0,00000 \\
\hline Clau9 & DU & IC & $0,00000^{* *}$ & 0,00000 & Clau9 & IC & DU & $0,00000 * *$ & 0,00000 \\
\hline Clau10 & DU & IC & $0,00000 * *$ & 0,00000 & Clau10 & IC & DU & $0,00000 * *$ & 0,00000 \\
\hline Amiu8 & PA & IC & 0,47205 & 0,00296 & Amiu8 & IC & PA & 0,34037 & 0,00248 \\
\hline Amiu11 & PA & IC & $0,00001^{* *}$ & 0,00001 & Amiu11 & IC & PA & $0,00000 * *$ & 0,00000 \\
\hline Amiu13 & PA & IC & $0,00000^{* *}$ & 0,00000 & Amiu13 & IC & PA & $0,00000 * *$ & 0,00000 \\
\hline Amiu20 & PA & IC & $0,00003 * *$ & 0,00003 & Amiu20 & IC & $\mathrm{PA}$ & $0,00000 * *$ & 0,00000 \\
\hline Clau2 & PA & IC & $0,00002 * *$ & 0,00002 & Clau2 & IC & PA & $0,00000 * *$ & 0,00000 \\
\hline Clau5 & PA & IC & $0,00004^{* *}$ & 0,00004 & Clau5 & IC & PA & $0,00000 * *$ & 0,00000 \\
\hline Clau6 & PA & IC & $0,00004^{* *}$ & 0,00004 & Clau6 & IC & PA & $0,00000 * *$ & 0,00000 \\
\hline Clau7 & PA & IC & $0,00012^{* *}$ & 0,00008 & Clau7 & IC & PA & $0,00000 * *$ & 0,00000 \\
\hline Clau8 & PA & IC & $0,00010^{* *}$ & 0,00006 & Clau8 & IC & PA & $0,00041 * *$ & 0,00018 \\
\hline Clau9 & PA & IC & $0,00007 * *$ & 0,00007 & Clau9 & IC & PA & $0,00000 * *$ & 0,00000 \\
\hline Clau10 & PA & IC & $0,00009 * *$ & 0,00009 & Clau10 & IC & PA & $0,00000 * *$ & 0,00000 \\
\hline Amiu8 & PB & IC & $0,02689 * *$ & 0,00105 & Amiu8 & IC & PB & $0,00514 * *$ & 0,00043 \\
\hline Amiu11 & PB & IC & $0,00096 * *$ & 0,00025 & Amiu11 & IC & PB & $0,00007 * *$ & 0,00006 \\
\hline Amiu13 & $\mathrm{PB}$ & IC & 0,85489 & 0,00389 & Amiu13 & IC & PB & 0,73088 & 0,00598 \\
\hline Amiu20 & PB & IC & 0,01533* & 0,00104 & Amiu20 & IC & PB & $0,00402 * *$ & 0,00061 \\
\hline Clau2 & PB & IC & $0,00000 * *$ & 0,00000 & Clau2 & IC & PB & $0,00000 * *$ & 0,00000 \\
\hline Clau5 & $\mathrm{PB}$ & IC & $0,00000 * *$ & 0,00000 & Clau5 & IC & PB & $0,00000 * *$ & 0,00000 \\
\hline Clau6 & PB & IC & $0,00173 * *$ & 0,00039 & Clau6 & IC & PB & $0,00030 * *$ & 0,00017 \\
\hline Clau7 & $\mathrm{PB}$ & IC & $0,00003 * *$ & 0,00003 & Clau7 & IC & PB & $0,00000 * *$ & 0,00000 \\
\hline Clau8 & $\mathrm{PB}$ & IC & $0,00000 * *$ & 0,00000 & Clau8 & IC & PB & $0,00000 * *$ & 0,00000 \\
\hline Clau9 & PB & IC & $0,00020 * *$ & 0,00013 & Clau9 & IC & PB & $0,00000 * *$ & 0,00000 \\
\hline
\end{tabular}


APÊNDICE 3. Diferenciação gênica e genotípica entre as populações estudadas

\begin{tabular}{|c|c|c|c|c|c|c|c|c|c|}
\hline \multirow[b]{2}{*}{ Locos } & \multicolumn{4}{|c|}{ Diferenciação genotípica } & \multicolumn{5}{|c|}{ Diferenciação gênica } \\
\hline & Pop1 & Pop2 & Prob & EP & Locos & Pop1 & Pop2 & Prob & EP \\
\hline Clau10 & PB & IC & $0,00000 * *$ & 0,00000 & Clau10 & IC & PB & $0,00000 * *$ & 0,00000 \\
\hline Amiu8 & PT & IC & $0,00012 * *$ & 0,00005 & Amiu8 & IC & PT & $0,00000^{* *}$ & 0,00000 \\
\hline Amiu11 & PT & IC & $0,00000 * *$ & 0,00000 & Amiu11 & IC & PT & $0,00000 * *$ & 0,00000 \\
\hline Amiu13 & PT & IC & $0,00000 * *$ & 0,00000 & Amiu13 & IC & PT & $0,00000^{* *}$ & 0,00000 \\
\hline Amiu20 & PT & IC & $0,00000 * *$ & 0,00000 & Amiu20 & IC & PT & $0,00000^{* *}$ & 0,00000 \\
\hline Clau2 & PT & IC & $0,00000 * *$ & 0,00000 & Clau2 & IC & PT & $0,00000 * *$ & 0,00000 \\
\hline Clau5 & PT & IC & $0,00000 * *$ & 0,00000 & Clau5 & IC & PT & $0,00000 * *$ & 0,00000 \\
\hline Clau6 & PT & IC & $0,00000 * *$ & 0,00000 & Clau6 & IC & PT & $0,00000^{* *}$ & 0,00000 \\
\hline Clau7 & PT & IC & $0,00000^{* *}$ & 0,00000 & Clau7 & IC & PT & $0,00000^{* *}$ & 0,00000 \\
\hline Clau8 & PT & IC & $0,00000 * *$ & 0,00000 & Clau8 & IC & PT & $0,00000^{* *}$ & 0,00000 \\
\hline Clau9 & PT & IC & $0,00000 * *$ & 0,00000 & Clau9 & IC & PT & $0,00000 * *$ & 0,00000 \\
\hline Clau10 & PT & IC & $0,00000 * *$ & 0,00000 & Clau10 & IC & PT & $0,00000 * *$ & 0,00000 \\
\hline Amiu8 & $\mathrm{RN}$ & IC & 0,42480 & 0,00259 & Amiu8 & IC & $\mathrm{RN}$ & $0,11479 * *$ & 0,00207 \\
\hline Amiu11 & $\mathrm{RN}$ & IC & 0,07067 & 0,00274 & Amiu11 & IC & $\mathrm{RN}$ & $0,06507 * *$ & 0,00239 \\
\hline Amiu13 & RN & IC & 0,25966 & 0,00465 & Amiu13 & IC & RN & $0,03690 * *$ & 0,00313 \\
\hline Amiu20 & $\mathrm{RN}$ & IC & $0,00029 * *$ & 0,00012 & Amiu20 & IC & $\mathrm{RN}$ & $0,00000 * *$ & 0,00000 \\
\hline Clau2 & $\mathrm{RN}$ & IC & $0,00056^{* *}$ & 0,00021 & Clau2 & IC & $\mathrm{RN}$ & $0,00000 * *$ & 0,00000 \\
\hline Clau5 & $\mathrm{RN}$ & IC & $0,00026^{* *}$ & 0,00013 & Clau5 & IC & $\mathrm{RN}$ & $0,00000^{* *}$ & 0,00000 \\
\hline Clau6 & $\mathrm{RN}$ & IC & $0,01511^{*}$ & 0,00089 & Clau6 & IC & $\mathrm{RN}$ & $0,00807 * *$ & 0,00074 \\
\hline Clau7 & $\mathrm{RN}$ & IC & $0,00251 * *$ & 0,00039 & Clau7 & IC & $\mathrm{RN}$ & $0,00000 * *$ & 0,00000 \\
\hline Clau8 & $\mathrm{RN}$ & IC & $0,00244 * *$ & 0,00046 & Clau8 & IC & $\mathrm{RN}$ & $0,00004 * *$ & 0,00004 \\
\hline Clau9 & $\mathrm{RN}$ & IC & $0,00067 * *$ & 0,00019 & Clau9 & IC & $\mathrm{RN}$ & $0,00104^{* *}$ & 0,00050 \\
\hline Clau10 & $\mathrm{RN}$ & IC & $0,00048^{* *}$ & 0,00018 & Clau10 & IC & $\mathrm{RN}$ & $0,00001^{* *}$ & 0,00001 \\
\hline Amiu8 & $\mathrm{CH}$ & PA & 0,21093 & 0,00289 & Amiu8 & PA & $\mathrm{CH}$ & 0,10480 & 0,00237 \\
\hline Amiu11 & $\mathrm{CH}$ & PA & $0,00247 * *$ & 0,00039 & Amiu11 & PA & $\mathrm{CH}$ & $0,00034^{* *}$ & 0,00014 \\
\hline Amiu13 & $\mathrm{CH}$ & PA & $0,01677^{*}$ & 0,00130 & Amiu13 & PA & $\mathrm{CH}$ & 0,01199* & 0,00140 \\
\hline Amiu20 & $\mathrm{CH}$ & PA & $0,00143^{* *}$ & 0,00044 & Amiu20 & PA & $\mathrm{CH}$ & $0,00038 * *$ & 0,00019 \\
\hline Clau2 & $\mathrm{CH}$ & PA & $0,00227 * *$ & 0,00045 & Clau2 & PA & $\mathrm{CH}$ & $0,00000 * *$ & 0,00000 \\
\hline Clau5 & $\mathrm{CH}$ & PA & $0,00030 * *$ & 0,00023 & Clau5 & PA & $\mathrm{CH}$ & $0,00000 * *$ & 0,00000 \\
\hline Clau6 & $\mathrm{CH}$ & PA & $0,01182 *$ & 0,00099 & Clau6 & PA & $\mathrm{CH}$ & $0,01016^{*}$ & 0,00140 \\
\hline Clau7 & $\mathrm{CH}$ & PA & $0,00304 * *$ & 0,00059 & Clau7 & PA & $\mathrm{CH}$ & $0,00444 * *$ & 0,00082 \\
\hline Clau8 & $\mathrm{CH}$ & PA & $0,00000 * *$ & 0,00000 & Clau8 & PA & $\mathrm{CH}$ & $0,00013^{* *}$ & 0,00009 \\
\hline Clau9 & $\mathrm{CH}$ & PA & $0,01259 *$ & 0,00105 & Clau9 & PA & $\mathrm{CH}$ & $0,02908 *$ & 0,00134 \\
\hline Clau10 & $\mathrm{CH}$ & PA & $0,00010 * *$ & 0,00006 & Clau10 & PA & $\mathrm{CH}$ & $0,00097 * *$ & 0,00041 \\
\hline Amiu8 & DU & PA & 0,07449 & 0,00233 & Amiu8 & PA & DU & 0,01882* & 0,00080 \\
\hline Amiu11 & DU & PA & $0,00346 * *$ & 0,00053 & Amiu11 & PA & DU & $0,00165 * *$ & 0,00038 \\
\hline Amiu13 & DU & PA & $0,00000 * *$ & 0,00000 & Amiu13 & PA & DU & $0,00000 * *$ & 0,00000 \\
\hline Amiu20 & DU & PA & $0,00344 * *$ & 0,00096 & Amiu20 & PA & DU & $0,00055^{* *}$ & 0,00025 \\
\hline Clau2 & DU & PA & $0,00000 * *$ & 0,00000 & Clau2 & PA & DU & $0,00000^{* *}$ & 0,00000 \\
\hline Clau5 & DU & PA & $0,00000 * *$ & 0,00000 & Clau5 & PA & DU & $0,00000 * *$ & 0,00000 \\
\hline Clau6 & DU & PA & $0,00517 * *$ & 0,00079 & Clau6 & PA & DU & $0,00170 * *$ & 0,00037 \\
\hline
\end{tabular}


APÊNDICE 3. Diferenciação gênica e genotípica entre as populações estudadas

\begin{tabular}{|c|c|c|c|c|c|c|c|c|c|}
\hline \multirow[b]{2}{*}{ Locos } & \multicolumn{4}{|c|}{ Diferenciação genotípica } & \multicolumn{5}{|c|}{ Diferenciação gênica } \\
\hline & Pop1 & Pop2 & Prob & EP & Locos & Pop1 & Pop2 & Prob & EP \\
\hline Clau7 & DU & PA & $0,00598 * *$ & 0,00089 & Clau7 & PA & DU & $0,00094 * *$ & 0,00043 \\
\hline Clau8 & DU & PA & $0,00466^{* *}$ & 0,00066 & Clau8 & PA & DU & $0,00748 * *$ & 0,00091 \\
\hline Clau9 & DU & PA & $0,00723 * *$ & 0,00088 & Clau9 & PA & DU & $0,00164 * *$ & 0,00039 \\
\hline Clau10 & DU & PA & $0,00000 * *$ & 0,00000 & Clau10 & PA & DU & $0,00012 * *$ & 0,00009 \\
\hline Amiu8 & PT & PA & $0,00800 * *$ & 0,00064 & Amiu8 & PA & PT & $0,00130 * *$ & 0,00028 \\
\hline Amiu11 & PT & PA & $0,00419 * *$ & 0,00066 & Amiu11 & PA & PT & $0,00758 * *$ & 0,00086 \\
\hline Amiu13 & PT & PA & $0,00000 * *$ & $=0,00000$ & Amiu13 & PA & PT & $0,00000 * *$ & 0,00000 \\
\hline Amiu20 & PT & PA & $0,00349 * *$ & 0,00078 & Amiu20 & PA & PT & $0,00011 * *$ & 0,00006 \\
\hline Clau2 & $\mathrm{PT}$ & PA & $0,01542 *$ & 0,00127 & Clau2 & PA & PT & $0,00193 * *$ & 0,00044 \\
\hline Clau5 & PT & PA & $0,00000 * *$ & $=0,00000$ & Clau5 & PA & PT & $0,00000 * *$ & 0,00000 \\
\hline Clau6 & $\mathrm{PT}$ & PA & $0,00168 * *$ & $=0,00033$ & Clau6 & PA & PT & $0,00000 * *$ & 0,00000 \\
\hline Clau7 & PT & PA & $0,00000 * *$ & 0,00000 & Clau7 & PA & PT & $0,00000 * *$ & 0,00000 \\
\hline Clau8 & PT & PA & $0,00009 * *$ & : 0,00009 & Clau8 & PA & PT & $0,00003 * *$ & 0,00003 \\
\hline Clau9 & PT & PA & $0,02589 *$ & 0,00149 & Clau9 & PA & PT & 0,11008 & 0,00310 \\
\hline Clau10 & PT & PA & $0,00000 * *$ & $=0,00000$ & Clau10 & PA & PT & $0,00010^{* *}$ & 0,00006 \\
\hline Amiu8 & $\mathrm{CH}$ & PB & 1,00000 & 0,00000 & Amiu8 & PB & $\mathrm{CH}$ & 1,00000 & 0,00000 \\
\hline Amiu11 & $\mathrm{CH}$ & PB & 0,01958* & 0,00167 & Amiu11 & PB & $\mathrm{CH}$ & $0,00367 * *$ & 0,00078 \\
\hline Amiu13 & $\mathrm{CH}$ & PB & $0,00203 * *$ & 0,00048 & Amiu13 & PB & $\mathrm{CH}$ & $0,00006^{* *}$ & 0,00005 \\
\hline Amiu20 & $\mathrm{CH}$ & PB & $0,00000 * *$ & 0,00000 & Amiu20 & PB & $\mathrm{CH}$ & $0,00000 * *$ & 0,00000 \\
\hline Clau2 & $\mathrm{CH}$ & PB & $0,00013 * *$ & 0,00013 & Clau2 & PB & $\mathrm{CH}$ & $0,00000 * *$ & 0,00000 \\
\hline Clau5 & $\mathrm{CH}$ & PB & $0,00000 * *$ & $=0,00000$ & Clau5 & PB & $\mathrm{CH}$ & $0,00000 * *$ & 0,00000 \\
\hline Clau6 & $\mathrm{CH}$ & PB & $0,00000 * *$ & $=0,00000$ & Clau6 & PB & $\mathrm{CH}$ & $0,00000 * *$ & 0,00000 \\
\hline Clau7 & $\mathrm{CH}$ & PB & $0,00010 * *$ & 0,00005 & Clau7 & PB & $\mathrm{CH}$ & $0,00193 * *$ & 0,00064 \\
\hline Clau8 & $\mathrm{CH}$ & PB & $0,00000 * *$ & 0,00000 & Clau8 & PB & $\mathrm{CH}$ & $0,00000 * *$ & 0,00000 \\
\hline Clau9 & $\mathrm{CH}$ & PB & $0,00000 * *$ & $=0,00000$ & Clau9 & PB & $\mathrm{CH}$ & $0,00000 * *$ & 0,00000 \\
\hline Clau10 & $\mathrm{CH}$ & PB & $0,00000 * *$ & 0,00000 & Clau10 & PB & $\mathrm{CH}$ & $0,00000 * *$ & 0,00000 \\
\hline Amiu8 & DU & PB & $0,00041 * *$ & 0,00012 & Amiu8 & PB & DU & $0,00000 * *$ & 0,00000 \\
\hline Amiu11 & DU & PB & $0,00027 * *$ & 0,00014 & Amiu11 & PB & DU & $0,00000 * *$ & 0,00000 \\
\hline Amiu13 & DU & PB & $0,01545 *$ & 0,00140 & Amiu13 & PB & DU & $0,00411^{* *}$ & 0,00087 \\
\hline Amiu20 & DU & PB & $0,00000 * *$ & 0,00000 & Amiu20 & PB & DU & $0,00000 * *$ & 0,00000 \\
\hline Clau2 & DU & PB & $0,00000 * *$ & 0,00000 & Clau2 & PB & DU & $0,00000 * *$ & 0,00000 \\
\hline Clau5 & DU & PB & $0,00000^{* *}$ & $=0,00000$ & Clau5 & PB & DU & $0,00000 * *$ & 0,00000 \\
\hline Clau6 & DU & PB & $0,00000 * *$ & 0,00000 & Clau6 & PB & DU & $0,00000 * *$ & 0,00000 \\
\hline Clau7 & DU & PB & $0,00000 * *$ & 0,00000 & Clau7 & PB & DU & $0,00000 * *$ & 0,00000 \\
\hline Clau8 & DU & PB & $0,00000^{* *}$ & 0,00000 & Clau8 & PB & DU & $0,00000 * *$ & 0,00000 \\
\hline Clau9 & DU & PB & $0,00000^{* *}$ & $=0,00000$ & Clau9 & PB & DU & $0,00000 * *$ & 0,00000 \\
\hline Clau10 & DU & PB & $0,00000 * *$ & $=0,00000$ & Clau10 & PB & DU & $0,00000 * *$ & 0,00000 \\
\hline Amiu8 & PA & PB & 0,33076 & 0,00322 & Amiu8 & PB & PA & 0,19176 & 0,00257 \\
\hline Amiu11 & PA & PB & $0,00000^{* *}$ & 0,00000 & Amiu11 & PB & PA & $0,00000 * *$ & 0,00000 \\
\hline Amiu13 & PA & PB & $0,00004^{* *}$ & 0,00004 & Amiu13 & PB & PA & $0,00000 * *$ & 0,00000 \\
\hline Amiu20 & PA & PB & $0,00000 * *$ & $=0,00000$ & Amiu20 & PB & PA & $0,00000 * *$ & 0,00000 \\
\hline
\end{tabular}


APÊNDICE 3. Diferenciação gênica e genotípica entre as populaçõesestudadas

\begin{tabular}{|c|c|c|c|c|c|c|c|c|c|}
\hline \multirow[b]{2}{*}{ Locos } & \multicolumn{4}{|c|}{ Diferenciação genotípica } & \multicolumn{5}{|c|}{ Diferenciação gênica } \\
\hline & Pop1 & Pop2 & Prob & EP & Locos & Pop1 & Pop2 & Prob & EP \\
\hline Clau2 & PA & PB & $0,00008 * *$ & 0,00008 & Clau2 & PB & PA & $0,00000 * *$ & 0,00000 \\
\hline Clau5 & PA & PB & $0,00000 * *$ & 0,00000 & Clau5 & PB & PA & $0,00000 * *$ & 0,00000 \\
\hline Clau6 & PA & PB & $0,00005^{* *}$ & 0,00005 & Clau6 & PB & PA & $0,00000 * *$ & 0,00000 \\
\hline Clau7 & PA & PB & $0,00000 * *$ & 0,00000 & Clau7 & PB & PA & $0,00000 * *$ & 0,00000 \\
\hline Clau8 & PA & PB & $0,00000 * *$ & 0,00000 & Clau8 & PB & PA & $0,00000 * *$ & 0,00000 \\
\hline Clau9 & PA & PB & $0,00000 * *$ & 0,00000 & Clau9 & PB & PA & $0,00000 * *$ & 0,00000 \\
\hline Clau10 & PA & PB & $0,00000 * *$ & 0,00000 & Clau10 & PB & PA & $0,00000 * *$ & 0,00000 \\
\hline Amiu8 & PT & PB & 0,11273 & 0,00233 & Amiu8 & PB & PT & 0,06626 & 0,00215 \\
\hline Amiu11 & PT & PB & $0,00000 * *$ & 0,00000 & Amiu11 & PB & PT & $0,00000 * *$ & 0,00000 \\
\hline Amiu13 & PT & PB & $0,00000 * *$ & 0,00000 & Amiu13 & PB & PT & $0,00000 * *$ & 0,00000 \\
\hline Amiu20 & PT & PB & $0,00000 * *$ & 0,00000 & Amiu20 & PB & PT & $0,00000 * *$ & 0,00000 \\
\hline Clau2 & PT & PB & $0,00000 * *$ & 0,00000 & Clau2 & PB & PT & $0,00000 * *$ & 0,00000 \\
\hline Clau5 & PT & PB & $0,00000 * *$ & 0,00000 & Clau5 & PB & PT & $0,00000 * *$ & 0,00000 \\
\hline Clau6 & PT & PB & $0,00000 * *$ & 0,00000 & Clau6 & PB & PT & $0,00000 * *$ & 0,00000 \\
\hline Clau7 & PT & PB & $0,00000 * *$ & 0,00000 & Clau7 & PB & PT & $0,00000 * *$ & 0,00000 \\
\hline Clau8 & PT & PB & $0,00000 * *$ & 0,00000 & Clau8 & PB & PT & $0,00000 * *$ & 0,00000 \\
\hline Clau9 & PT & PB & $0,00000 * *$ & 0,00000 & Clau9 & PB & PT & $0,00000 * *$ & 0,00000 \\
\hline Clau10 & PT & PB & $0,00000 * *$ & 0,00000 & Clau10 & PB & PT & $0,00000 * *$ & 0,00000 \\
\hline Amiu8 & $\mathrm{RN}$ & PB & 0,56379 & 0,00282 & Amiu8 & PB & $\mathrm{RN}$ & 0,46657 & 0,00264 \\
\hline Amiu11 & $\mathrm{RN}$ & PB & $0,00249 *$ & 0,00041 & Amiu11 & PB & $\mathrm{RN}$ & $0,00010 * *$ & 0,00010 \\
\hline Amiu13 & $\mathrm{RN}$ & PB & 0,33502 & 0,00631 & Amiu13 & PB & $\mathrm{RN}$ & 0,08352 & 0,00557 \\
\hline Amiu20 & $\mathrm{RN}$ & PB & 0,22478 & 0,00466 & Amiu20 & PB & $\mathrm{RN}$ & 0,11177 & 0,00319 \\
\hline Clau2 & $\mathrm{RN}$ & PB & $0,04831^{*}$ & 0,00246 & Clau2 & PB & $\mathrm{RN}$ & $0,01800 *$ & 0,00174 \\
\hline Clau5 & $\mathrm{RN}$ & PB & 0,10498 & 0,00359 & Clau5 & PB & $\mathrm{RN}$ & 0,13480 & 0,00448 \\
\hline Clau6 & $\mathrm{RN}$ & PB & 0,51647 & 0,00162 & Clau6 & PB & $\mathrm{RN}$ & 0,20036 & 0,00228 \\
\hline Clau7 & $\mathrm{RN}$ & PB & 1,00000 & 0,00000 & Clau7 & PB & $\mathrm{RN}$ & 1,00000 & 0,00000 \\
\hline Clau8 & $\mathrm{RN}$ & PB & 0,21930 & 0,00443 & Clau8 & PB & $\mathrm{RN}$ & 0,17888 & 0,00467 \\
\hline Clau9 & $\mathrm{RN}$ & PB & 0,04218* & 0,00230 & Clau9 & PB & $\mathrm{RN}$ & 0,03590* & 0,00222 \\
\hline Clau10 & $\mathrm{RN}$ & PB & 0,27836 & 0,00384 & Clau10 & PB & $\mathrm{RN}$ & 0,38455 & 0,00501 \\
\hline Amiu8 & $\mathrm{CH}$ & $\mathrm{RN}$ & 0,53952 & 0,00243 & Amiu8 & $\mathrm{RN}$ & $\mathrm{CH}$ & 0,45613 & 0,00269 \\
\hline Amiu11 & $\mathrm{CH}$ & $\mathrm{RN}$ & $0,03405^{*}$ & 0,00200 & Amiu11 & $\mathrm{RN}$ & $\mathrm{CH}$ & 0,01885* & 0,00183 \\
\hline Amiu13 & $\mathrm{CH}$ & $\mathrm{RN}$ & 0,61180 & 0,00605 & Amiu13 & $\mathrm{RN}$ & $\mathrm{CH}$ & 0,33580 & 0,00683 \\
\hline Amiu20 & $\mathrm{CH}$ & $\mathrm{RN}$ & 0,03353* & 0,00182 & Amiu20 & $\mathrm{RN}$ & $\mathrm{CH}$ & 0,05689 & 0,00318 \\
\hline Clau2 & $\mathrm{CH}$ & $\mathrm{RN}$ & $0,00109 * *$ & 0,00024 & Clau2 & $\mathrm{RN}$ & $\mathrm{CH}$ & $0,00000 * *$ & 0,00000 \\
\hline Clau5 & $\mathrm{CH}$ & $\mathrm{RN}$ & $0,00071^{* *}$ & 0,00027 & Clau5 & $\mathrm{RN}$ & $\mathrm{CH}$ & $0,00000 * *$ & 0,00000 \\
\hline Clau6 & $\mathrm{CH}$ & $\mathrm{RN}$ & $0,00011^{* *}$ & 0,00006 & Clau6 & RN & $\mathrm{CH}$ & $0,00000 * *$ & 0,00000 \\
\hline Clau7 & $\mathrm{CH}$ & $\mathrm{RN}$ & $0,04332 *$ & 0,00190 & Clau7 & $\mathrm{RN}$ & $\mathrm{CH}$ & 0,05117 & 0,00304 \\
\hline Clau8 & $\mathrm{CH}$ & $\mathrm{RN}$ & 0,05550 & 0,00246 & Clau8 & $\mathrm{RN}$ & $\mathrm{CH}$ & 0,05127 & 0,00272 \\
\hline Clau9 & $\mathrm{CH}$ & $\mathrm{RN}$ & $0,00090 * *$ & 0,00034 & Clau9 & $\mathrm{RN}$ & $\mathrm{CH}$ & $0,00011 * *$ & 0,00008 \\
\hline Clau10 & $\mathrm{CH}$ & $\mathrm{RN}$ & $0,00078 * *$ & 0,00025 & Clau10 & $\mathrm{RN}$ & $\mathrm{CH}$ & $0,00035^{* *}$ & 0,00013 \\
\hline Amiu8 & DU & $\mathrm{RN}$ & 0,04981* & 0,00153 & Amiu8 & $\mathrm{RN}$ & DU & 0,01653* & 0,00088 \\
\hline
\end{tabular}


APÊNDICE 3. Diferenciação gênica e genotípica entre as populaçõesestudadas

\begin{tabular}{|c|c|c|c|c|c|c|c|c|c|}
\hline \multirow[b]{2}{*}{ Locos } & \multicolumn{4}{|c|}{ Diferenciação genotípica } & \multicolumn{5}{|c|}{ Diferenciação gênica } \\
\hline & Pop1 & Pop2 & Prob & EP & Locos & Pop1 & Pop2 & Prob & EP \\
\hline Amiu11 & $\mathrm{DU}$ & $\mathrm{RN}$ & $0,00801 * *$ & 0,00132 & Amiu11 & $\mathrm{RN}$ & $\mathrm{DU}$ & $0,00246^{* *}$ & 0,00042 \\
\hline Amiu13 & DU & $\mathrm{RN}$ & 0,05405 & 0,00321 & Amiu13 & $\mathrm{RN}$ & DU & $0,00571^{* *}$ & 0,00116 \\
\hline Amiu20 & DU & $\mathrm{RN}$ & $0,00869 * *$ & 0,00132 & Amiu20 & RN & DU & $0,00406 * *$ & 0,00101 \\
\hline Clau2 & DU & $\mathrm{RN}$ & $0,00000 * *$ & 0,00000 & Clau2 & $\mathrm{RN}$ & DU & $0,00000 * *$ & 0,00000 \\
\hline Clau5 & DU & $\mathrm{RN}$ & $0,00000 * *$ & 0,00000 & Clau5 & $\mathrm{RN}$ & DU & $0,00000^{* *}$ & 0,00000 \\
\hline Clau6 & DU & $\mathrm{RN}$ & $0,00000 * *$ & 0,00000 & Clau6 & $\mathrm{RN}$ & DU & $0,00000^{* *}$ & 0,00000 \\
\hline Clau7 & DU & $\mathrm{RN}$ & $0,00000 * *$ & 0,00000 & Clau7 & $\mathrm{RN}$ & DU & $0,00000^{* *}$ & 0,00000 \\
\hline Clau8 & DU & $\mathrm{RN}$ & $0,00000 * *$ & 0,00000 & Clau8 & $\mathrm{RN}$ & DU & $0,00000 * *$ & 0,00000 \\
\hline Clau9 & DU & $\mathrm{RN}$ & $0,00022 * *$ & 0,00013 & Clau9 & $\mathrm{RN}$ & DU & $0,00000 * *$ & 0,00000 \\
\hline Clau10 & DU & $\mathrm{RN}$ & $0,00000 * *$ & 0,00000 & Clau10 & $\mathrm{RN}$ & DU & $0,00000 * *$ & 0,00000 \\
\hline Amiu8 & PA & $\mathrm{RN}$ & 1,00000 & 0,00000 & Amiu8 & $\mathrm{RN}$ & PA & 0,67431 & 0,00194 \\
\hline Amiu11 & PA & $\mathrm{RN}$ & $0,02147 *$ & 0,00125 & Amiu11 & $\mathrm{RN}$ & PA & $0,04760 *$ & 0,00257 \\
\hline Amiu13 & PA & $\mathrm{RN}$ & $0,00054^{* *}$ & 0,00018 & Amiu13 & RN & PA & $0,00012 * *$ & 0,00012 \\
\hline Amiu20 & PA & $\mathrm{RN}$ & $0,00621 * *$ & 0,00072 & Amiu20 & $\mathrm{RN}$ & PA & $0,00587 * *$ & 0,00100 \\
\hline Clau2 & PA & $\mathrm{RN}$ & $0,00286 * *$ & 0,00049 & Clau2 & $\mathrm{RN}$ & PA & $0,00010 * *$ & 0,00009 \\
\hline Clau5 & PA & $\mathrm{RN}$ & $0,00052 * *$ & 0,00015 & Clau5 & $\mathrm{RN}$ & PA & $0,00000 * *$ & 0,00000 \\
\hline Clau6 & PA & $\mathrm{RN}$ & $0,00077 * *$ & 0,00024 & Clau6 & $\mathrm{RN}$ & PA & $0,00000 * *$ & 0,00000 \\
\hline Clau7 & PA & $\mathrm{RN}$ & $0,00126 * *$ & 0,00029 & Clau7 & RN & PA & $0,00131 * *$ & 0,00033 \\
\hline Clau8 & PA & $\mathrm{RN}$ & $0,00053 * *$ & 0,00014 & Clau8 & RN & PA & $0,00000^{* *}$ & 0,00000 \\
\hline Clau9 & PA & $\mathrm{RN}$ & $0,00431 * *$ & 0,00064 & Clau9 & $\mathrm{RN}$ & PA & $0,00109 * *$ & 0,00027 \\
\hline Clau10 & PA & $\mathrm{RN}$ & $0,00064 * *$ & 0,00021 & Clau10 & $\mathrm{RN}$ & PA & $0,00089 * *$ & 0,00031 \\
\hline Amiu8 & $\mathrm{PT}$ & $\mathrm{RN}$ & 0,05216 & 0,00155 & Amiu8 & $\mathrm{RN}$ & PT & $0,02950 *$ & 0,00111 \\
\hline Amiu11 & PT & $\mathrm{RN}$ & $0,03400 *$ & 0,00198 & Amiu11 & $\mathrm{RN}$ & PT & $0,01540 *$ & 0,00143 \\
\hline Amiu13 & PT & $\mathrm{RN}$ & $0,00039 * *$ & 0,00022 & Amiu13 & $\mathrm{RN}$ & PT & $0,00000 * *$ & 0,00000 \\
\hline Amiu20 & PT & $\mathrm{RN}$ & $0,00019 * *$ & 0,00009 & Amiu20 & $\mathrm{RN}$ & PT & $0,00000 * *$ & 0,00000 \\
\hline Clau2 & PT & $\mathrm{RN}$ & $0,00000 * *$ & 0,00000 & Clau2 & $\mathrm{RN}$ & PT & $0,00000^{* *}$ & 0,00000 \\
\hline Clau5 & PT & $\mathrm{RN}$ & $0,00005^{* *}$ & 0,00004 & Clau5 & $\mathrm{RN}$ & PT & $0,00000^{* *}$ & 0,00000 \\
\hline Clau6 & PT & $\mathrm{RN}$ & $0,00002 * *$ & 0,00002 & Clau6 & RN & PT & $0,00000^{* *}$ & 0,00000 \\
\hline Clau7 & PT & $\mathrm{RN}$ & $0,01061^{*}$ & 0,00086 & Clau7 & $\mathrm{RN}$ & PT & $0,00549 * *$ & 0,00062 \\
\hline Clau8 & PT & $\mathrm{RN}$ & $0,02082 *$ & 0,00223 & Clau8 & $\mathrm{RN}$ & PT & $0,01163 *$ & 0,00132 \\
\hline Clau9 & PT & $\mathrm{RN}$ & $0,00076^{* *}$ & 0,00027 & Clau9 & $\mathrm{RN}$ & PT & $0,00023 * *$ & 0,00012 \\
\hline Clau10 & PT & $\mathrm{RN}$ & $0,00005^{* *}$ & 0,00005 & Clau10 & $\mathrm{RN}$ & PT & $0,00000 * *$ & 0,00000 \\
\hline Amiu8 & $\mathrm{CH}$ & RS & $0,00014 * *$ & 0,00008 & Amiu8 & RS & $\mathrm{CH}$ & $0,00000 * *$ & 0,00000 \\
\hline Amiu11 & $\mathrm{CH}$ & $\mathrm{RS}$ & $0,00000 * *$ & 0,00000 & Amiu11 & $\mathrm{RS}$ & $\mathrm{CH}$ & $0,00000^{* *}$ & 0,00000 \\
\hline Amiu13 & $\mathrm{CH}$ & RS & $0,00000 * *$ & 0,00000 & Amiu13 & RS & $\mathrm{CH}$ & $0,00000 * *$ & 0,00000 \\
\hline Amiu20 & $\mathrm{CH}$ & RS & $0,00954 * *$ & 0,00101 & Amiu20 & $\mathrm{RS}$ & $\mathrm{CH}$ & $0,00618 * *$ & 0,00108 \\
\hline Clau2 & $\mathrm{CH}$ & RS & $0,00000 * *$ & 0,00000 & Clau2 & RS & $\mathrm{CH}$ & $0,00000^{* *}$ & 0,00000 \\
\hline Clau5 & $\mathrm{CH}$ & RS & $0,00000 * *$ & 0,00000 & Clau5 & RS & $\mathrm{CH}$ & $0,00000 * *$ & 0,00000 \\
\hline Clau6 & $\mathrm{CH}$ & RS & $0,00000 * *$ & 0,00000 & Clau6 & RS & $\mathrm{CH}$ & $0,00000 * *$ & 0,00000 \\
\hline Clau7 & $\mathrm{CH}$ & RS & $0,00000 * *$ & 0,00000 & Clau7 & RS & $\mathrm{CH}$ & $0,00000^{* *}$ & 0,00000 \\
\hline Clau8 & $\mathrm{CH}$ & RS & $0,00003 * *$ & 0,00003 & Clau8 & RS & $\mathrm{CH}$ & $0,00000 * *$ & 0,00000 \\
\hline
\end{tabular}


APÊNDICE 3. Diferenciação gênica e genotípica entre as populaçõesestudadas

\begin{tabular}{|c|c|c|c|c|c|c|c|c|c|}
\hline \multirow[b]{2}{*}{ Locos } & \multicolumn{4}{|c|}{ Diferenciação genotípica } & \multicolumn{5}{|c|}{ Diferenciação gênica } \\
\hline & Pop1 & Pop2 & Prob & EP & Locos & Pop1 & Pop2 & Prob & EP \\
\hline Clau9 & $\mathrm{CH}$ & RS & $0,00000 * *$ & 0,00000 & Clau9 & RS & $\mathrm{CH}$ & $0,00000 * *$ & 0,00000 \\
\hline Clau10 & $\mathrm{CH}$ & RS & $0,00000 * *$ & 0,00000 & Clau10 & RS & $\mathrm{CH}$ & $0,00000 * *$ & 0,00000 \\
\hline Amiu8 & DU & RS & 1,00000 & 0,00000 & Amiu8 & RS & DU & 1,00000 & 0,00000 \\
\hline Amiu11 & DU & RS & $0,00000 * *$ & 0,00000 & Amiu11 & RS & DU & $0,00000 * *$ & 0,00000 \\
\hline Amiu13 & DU & RS & $0,00000 * *$ & 0,00000 & Amiu13 & RS & DU & $0,00000 * *$ & 0,00000 \\
\hline Amiu20 & DU & RS & $0,00000 * *$ & 0,00000 & Amiu20 & RS & DU & $0,00000 * *$ & 0,00000 \\
\hline Clau2 & DU & RS & $0,00000 * *$ & 0,00000 & Clau2 & RS & DU & $0,00000 * *$ & 0,00000 \\
\hline Clau5 & DU & $\mathrm{RS}$ & $0,00000 * *$ & 0,00000 & Clau5 & $\mathrm{RS}$ & DU & $0,00000 * *$ & 0,00000 \\
\hline Clau6 & DU & RS & $0,00000 * *$ & 0,00000 & Clau6 & RS & DU & $0,00000 * *$ & 0,00000 \\
\hline Clau7 & DU & RS & $0,00000 * *$ & 0,00000 & Clau7 & RS & DU & $0,00000 * *$ & 0,00000 \\
\hline Clau8 & DU & RS & $0,00000 * *$ & 0,00000 & Clau8 & RS & DU & $0,00000 * *$ & 0,00000 \\
\hline Clau9 & DU & RS & $0,00000 * *$ & 0,00000 & Clau9 & RS & DU & $0,00000 * *$ & 0,00000 \\
\hline Clau10 & DU & RS & $0,00000 * *$ & 0,00000 & Clau10 & RS & DU & $0,00000 * *$ & 0,00000 \\
\hline Amiu8 & IC & RS & 0,34268 & 0,00166 & Amiu8 & RS & IC & 0,34438 & 0,00199 \\
\hline Amiu11 & IC & RS & $0,00000 * *$ & 0,00000 & Amiu11 & RS & IC & $0,00000 * *$ & 0,00000 \\
\hline Amiu13 & IC & $\mathrm{RS}$ & $0,00000 * *$ & 0,00000 & Amiu13 & $\mathrm{RS}$ & IC & $0,00000 * *$ & 0,00000 \\
\hline Amiu20 & IC & RS & $0,00000 * *$ & 0,00000 & Amiu20 & $\mathrm{RS}$ & IC & $0,00000 * *$ & 0,00000 \\
\hline Clau2 & IC & RS & $0,00000 * *$ & 0,00000 & Clau2 & RS & IC & $0,00000 * *$ & 0,00000 \\
\hline Clau5 & IC & RS & $0,00000 * *$ & 0,00000 & Clau5 & RS & IC & $0,00000 * *$ & 0,00000 \\
\hline Clau6 & IC & RS & $0,00039 * *$ & 0,00015 & Clau6 & RS & IC & $0,00000 * *$ & 0,00000 \\
\hline Clau7 & IC & RS & $0,01357^{*}$ & 0,00102 & Clau7 & $\mathrm{RS}$ & IC & $0,00182 * *$ & 0,00033 \\
\hline Clau8 & IC & RS & $0,00000 * *$ & 0,00000 & Clau8 & $\mathrm{RS}$ & IC & $0,00000 * *$ & 0,00000 \\
\hline Clau9 & IC & RS & $0,00525 * *$ & 0,00086 & Clau9 & RS & IC & $0,00088 * *$ & 0,00031 \\
\hline Clau10 & IC & RS & $0,00000 * *$ & 0,00000 & Clau10 & RS & IC & $0,00000 * *$ & 0,00000 \\
\hline Amiu8 & PA & RS & 0,11004 & 0,00170 & Amiu8 & RS & PA & 0,01039* & 0,00063 \\
\hline Amiu11 & PA & RS & $0,00141 * *$ & 0,00022 & Amiu11 & $\mathrm{RS}$ & PA & $0,00381 * *$ & 0,00056 \\
\hline Amiu13 & PA & RS & $0,00000 * *$ & 0,00000 & Amiu13 & RS & PA & $0,00000 * *$ & 0,00000 \\
\hline Amiu20 & PA & RS & $0,00000 * *$ & 0,00000 & Amiu20 & $\mathrm{RS}$ & PA & $0,00000 * *$ & 0,00000 \\
\hline Clau2 & PA & RS & $0,00000 * *$ & 0,00000 & Clau2 & RS & PA & $0,00000 * *$ & 0,00000 \\
\hline Clau5 & PA & RS & $0,00000 * *$ & 0,00000 & Clau5 & $\mathrm{RS}$ & PA & $0,00000 * *$ & 0,00000 \\
\hline Clau6 & PA & RS & $0,00000 * *$ & 0,00000 & Clau6 & RS & PA & $0,00000 * *$ & 0,00000 \\
\hline Clau7 & PA & RS & $0,00005^{* *}$ & 0,00004 & Clau7 & $\mathrm{RS}$ & PA & $0,00000 * *$ & 0,00000 \\
\hline Clau8 & PA & RS & $0,00000 * *$ & 0,00000 & Clau8 & $\mathrm{RS}$ & PA & $0,00000 * *$ & 0,00000 \\
\hline Clau9 & PA & RS & $0,00000 * *$ & 0,00000 & Clau9 & RS & PA & $0,00000 * *$ & 0,00000 \\
\hline Clau10 & PA & RS & $0,00000 * *$ & 0,00000 & Clau10 & RS & PA & $0,00000 * *$ & 0,00000 \\
\hline Amiu8 & PB & RS & $0,00048 * *$ & 0,00013 & Amiu8 & RS & PB & $0,00000 * *$ & 0,00000 \\
\hline Amiu11 & PB & RS & $0,00000 * *$ & 0,00000 & Amiu11 & RS & PB & $0,00000 * *$ & 0,00000 \\
\hline Amiu13 & PB & RS & $0,00006 * *$ & 0,00006 & Amiu13 & RS & PB & $0,00000 * *$ & 0,00000 \\
\hline Amiu20 & PB & RS & $0,00000 * *$ & 0,00000 & Amiu20 & $\mathrm{RS}$ & PB & $0,00000 * *$ & 0,00000 \\
\hline Clau2 & PB & RS & $0,00000 * *$ & 0,00000 & Clau2 & $\mathrm{RS}$ & PB & $0,00000 * *$ & 0,00000 \\
\hline Clau5 & PB & RS & $0,00000 * *$ & 0,00000 & Clau5 & RS & PB & $0,00000 * *$ & 0,00000 \\
\hline
\end{tabular}


APÊNDICE 3. Diferenciação gênica e genotípica entre as populaçõesestudadas

\begin{tabular}{|c|c|c|c|c|c|c|c|c|c|}
\hline \multirow[b]{2}{*}{ Locos } & \multicolumn{4}{|c|}{ Diferenciação genotípica } & \multicolumn{5}{|c|}{ Diferenciação gênica } \\
\hline & Pop1 & Pop2 & Prob & EP & Locos & Pop1 & Pop2 & Prob & EP \\
\hline Clau6 & PB & $\mathrm{RS}$ & 0,17815 & 0,00406 & Clau6 & RS & PB & 0,07460 & 0,00235 \\
\hline Clau7 & PB & RS & $0,00000^{* *}$ & 0,00000 & Clau7 & RS & PB & $0,00000 * *$ & 0,00000 \\
\hline Clau8 & PB & RS & $0,03838 *$ & 0,00221 & Clau8 & RS & PB & $0,00449 * *$ & 0,00079 \\
\hline Clau9 & PB & RS & 0,15031 & 0,00566 & Clau9 & RS & PB & 0,09741 & 0,00499 \\
\hline Clau10 & PB & RS & $0,00003 * *$ & 0,00002 & Clau10 & RS & PB & $0,00000 * *$ & 0,00000 \\
\hline Amiu8 & PT & RS & $0,00000 * *$ & 0,00000 & Amiu8 & RS & PT & $0,00000 * *$ & 0,00000 \\
\hline Amiu11 & PT & RS & $0,00000 * *$ & 0,00000 & Amiu11 & RS & PT & $0,00000 * *$ & 0,00000 \\
\hline Amiu13 & PT & RS & $0,00000 * *$ & 0,00000 & Amiu13 & RS & PT & $0,00000 * *$ & 0,00000 \\
\hline Amiu20 & PT & RS & $0,00000 * *$ & 0,00000 & Amiu20 & RS & PT & $0,00000 * *$ & 0,00000 \\
\hline Clau2 & PT & RS & $0,00000^{* *}$ & 0,00000 & Clau2 & $\mathrm{RS}$ & PT & $0,00000 * *$ & 0,00000 \\
\hline Clau5 & PT & RS & $0,00000^{* *}$ & 0,00000 & Clau5 & $\mathrm{RS}$ & PT & $0,00000 * *$ & 0,00000 \\
\hline Clau6 & PT & $\mathrm{RS}$ & $0,00000 * *$ & 0,00000 & Clau6 & RS & PT & $0,00000 * *$ & 0,00000 \\
\hline Clau7 & PT & RS & $0,00000 * *$ & 0,00000 & Clau7 & RS & PT & $0,00000 * *$ & 0,00000 \\
\hline Clau8 & PT & RS & $0,00000 * *$ & 0,00000 & Clau8 & RS & PT & $0,00000 * *$ & 0,00000 \\
\hline Clau9 & PT & RS & $0,00000 * *$ & 0,00000 & Clau9 & RS & PT & $0,00000 * *$ & 0,00000 \\
\hline Clau10 & PT & RS & $0,00000 * *$ & 0,00000 & Clau10 & RS & PT & $0,00000 * *$ & 0,00000 \\
\hline Amiu8 & RN & $\mathrm{RS}$ & $0,04514^{*}$ & 0,00136 & Amiu8 & RS & $\mathrm{RN}$ & $0,00873 * *$ & 0,00055 \\
\hline Amiu11 & $\mathrm{RN}$ & RS & $0,00000 * *$ & 0,00000 & Amiu11 & RS & $\mathrm{RN}$ & $0,00000 * *$ & 0,00000 \\
\hline Amiu13 & $\mathrm{RN}$ & RS & $0,00392 * *$ & 0,00065 & Amiu13 & RS & $\mathrm{RN}$ & $0,00060 * *$ & 0,00035 \\
\hline Amiu20 & RN & RS & $0,00003 * *$ & 0,00003 & Amiu20 & $\mathrm{RS}$ & $\mathrm{RN}$ & $0,00064 * *$ & 0,00025 \\
\hline Clau2 & $\mathrm{RN}$ & RS & $0,00001^{* *}$ & 0,00001 & Clau2 & RS & $\mathrm{RN}$ & $0,00000 * *$ & 0,00000 \\
\hline Clau5 & $\mathrm{RN}$ & RS & $0,00002^{* *}$ & 0,00002 & Clau5 & RS & $\mathrm{RN}$ & $0,00000 * *$ & 0,00000 \\
\hline Clau6 & $\mathrm{RN}$ & RS & 0,84367 & 0,00300 & Clau6 & RS & $\mathrm{RN}$ & 1,00000 & 0,00000 \\
\hline Clau7 & $\mathrm{RN}$ & RS & $0,00025^{* *}$ & 0,00008 & Clau7 & RS & $\mathrm{RN}$ & $0,00000 * *$ & 0,00000 \\
\hline Clau8 & $\mathrm{RN}$ & RS & 0,66992 & 0,00465 & Clau8 & RS & $\mathrm{RN}$ & 0,44656 & 0,00501 \\
\hline Clau9 & $\mathrm{RN}$ & RS & 0,21443 & 0,00589 & Clau9 & RS & $\mathrm{RN}$ & 0,17136 & 0,00685 \\
\hline Clau10 & RN & RS & $0,00000 * *$ & 0,00000 & Clau10 & RS & $\mathrm{RN}$ & $0,00004^{* *}$ & 0,00004 \\
\hline
\end{tabular}

